\title{
THE EFFECTS OF WELD THERMAL CYCLES ON ADDITIVELY MANUFACTURED 316L STAINLESS STEEL
}

\author{
A Thesis \\ presented to \\ the Faculty of California Polytechnic State University, \\ San Luis Obispo
}

\author{
In Partial Fulfillment \\ of the Requirements for the Degree of \\ Master of Science in Industrial Engineering
}

by

Hajime Yamanaka

June 2019 
(C) 2019

Hajime Yamanaka

ALL RIGHTS RESERVED 
COMMITTEE MEMBERSHIP

TITLE: The Effects of Weld Thermal Cycles on

Additively Manufactured 316L Stainless Steel

AUTHOR: Hajime Yamanaka

DATE SUBMITTED: June 2019

COMMITTEE MEMBER: Xuan Wang, Ph.D.

Professor of Industrial and Manufacturing

Engineering

COMMITTEE MEMBER: Dan Walsh, Ph.D.

Professor Emeritus of Materials Engineering

COMMITTEE MEMBER: Ryan T. Smith, Ph.D.

Professor of Materials Engineering 


\section{ACKNOWLEDGMENTS}

First of all, I would like to thank my family for providing my journey to the United States, emotional support, and trust of me in my entire life. All the hardships and challenges could be overcome thanks to you.

I would like to thank Dr. Xuan Wang for giving me the opportunity to work on my master's thesis and work as an operator of the additive manufacturing machines on campus. Your endless support grew me up and could make me who I wanted to be.

I would like to thank Dr. Dan Walsh and Professor David Gibbs for giving me the opportunity to use Gleeble machine to get a large number of data and helped me interpreting the metallography well. I appreciate your encouragement in the metallographic works and opinions in the test results. Your knowledge and comments always grew me up as a good engineer.

I would like to thank Dr. Ryan T. Smith for helping me understanding the failure analysis of the test results and having discussions with me to analyze the result data. Also, I appreciate all of your comments and encouragement over my work. I could get going because of those encouragements from you.

I would like to thank Brooke Marvin, Ashley Masuda, Kyle Kurashima Maddie Reed, Mihai Gherghina and Julio Escamilla for your best friendship, companionship, and endless words of affirmation. Each of you helped me in different way and I could not have been at this stage without each of your unique friendship.

I would like to thank Dr. Jimmy Doi, Mrs. Midori Doi, and Dr. Goro Kato for providing me emotional supports as Cal Poly "Host Family". Your companionship with Japanese culture always made me feel like I am at home in Japan.

I would like to thank the IME and MATE department for allowing me to use your facilities and giving me opportunities to work with other students. 


\begin{abstract}
The Effects of Weld Thermal Cycles on Additively Manufactured 316L Stainless Steel Hajime Yamanaka
\end{abstract}

To address the size limitation of the powder bed fusion system in additive manufacturing, the welding properties of $316 \mathrm{~L}$ stainless steel manufactured by SLM $125 \mathrm{HL}$ are investigated by conducting hot ductility test and nil strength temperature (NST) test with a physical thermal mechanical simulator, Gleeble. In this study, the print orientations (Z-direction and XY-direction) and the laser patterns (stripe and checker board) are studied. In NST test, the orientation showed a statistical significance in NST: Zdirection was $1384^{\circ} \mathrm{C}$ and $\mathrm{XY}$-direction was $1400^{\circ} \mathrm{C}$. In hot ductility test, all of ductility curves show similar behaviors: hardening region, recrystallization region, and liquation region. The additively manufactured 316L shows poor ductility compared to wrought $316 \mathrm{~L}$ stainless steel. Also, there is a noticeable difference in ductility between laser pattern. Finally, ductility after the thermal cycle shows higher than that before the thermal cycle. For the future recommendation, investigation on the interelayer temperatures and sigma phase determination should be conducted to confirm the hypotheses to explain the phenomena observed in this study.

Key words: Additive manufacturing, 316L stainless steel, Hot ductility test, Nil strength temperature test, Sigma $(\sigma)$ phase 


\section{TABLE OF CONTENTS}

Page

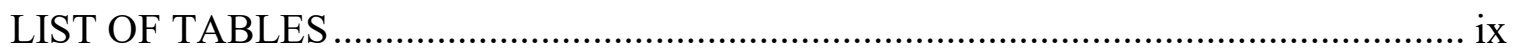

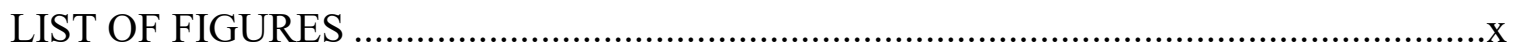

CHAPTER

1. INTRODUCTION AND BACKGROUND …......................................................

2. LITERATURE REVIEW …................................................................................

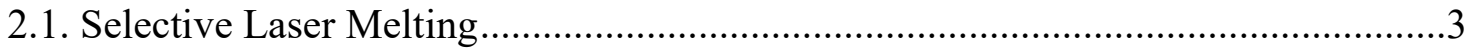

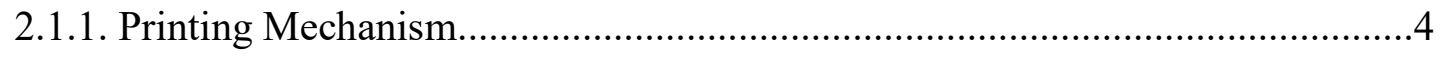

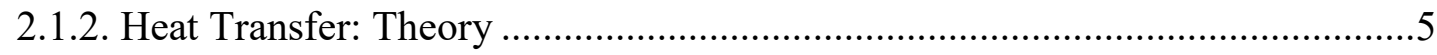

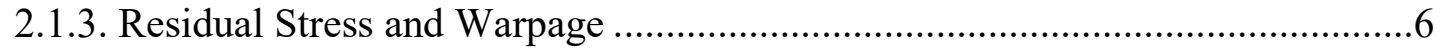

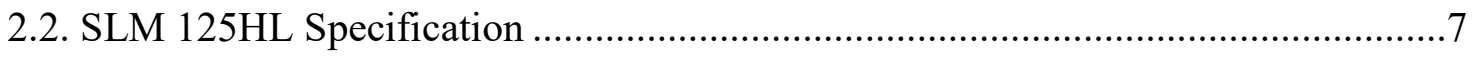

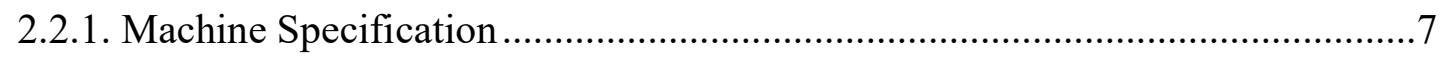

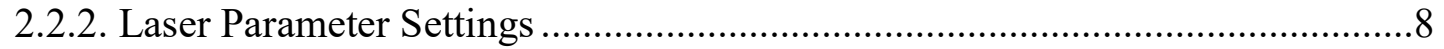

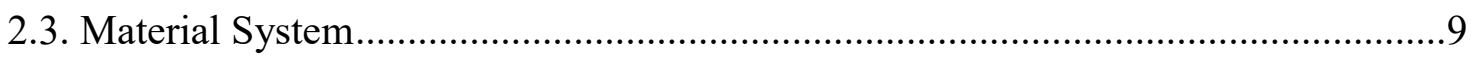

2.3.1. Overview of Austenitic Stainless Steel .....................................................

2.3.2. Solidification of Austenitic Stainless Steel ......................................................10

2.3.3. 316L Stainless Steel Powder ........................................................................ 15

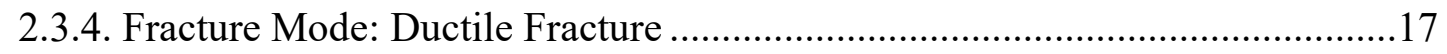

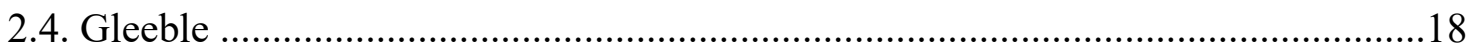

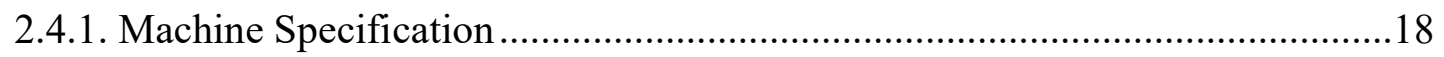

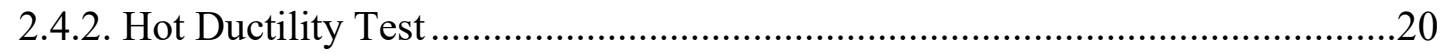

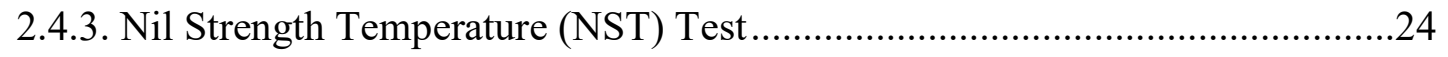

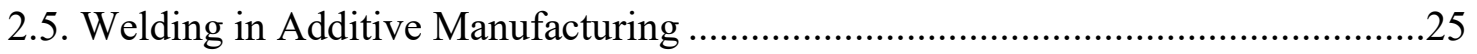




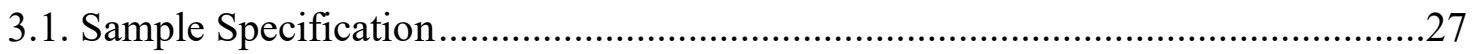

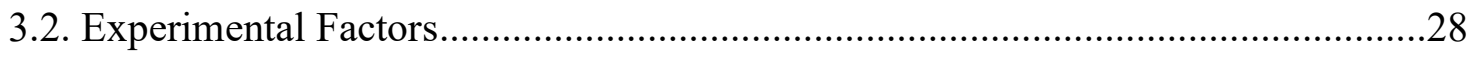

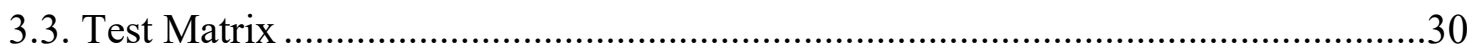

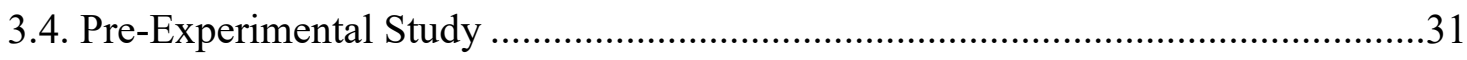

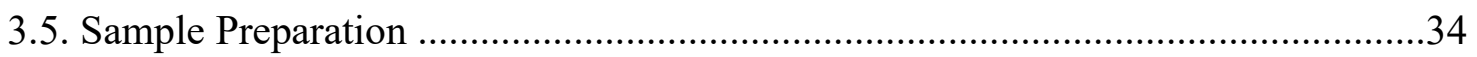

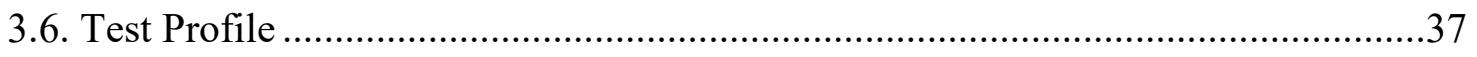

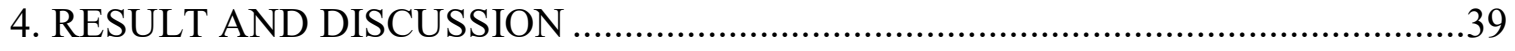

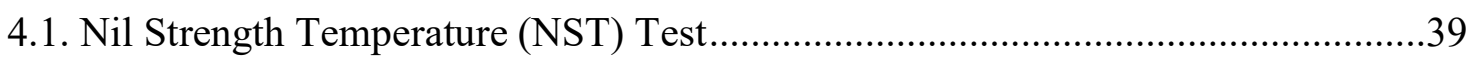

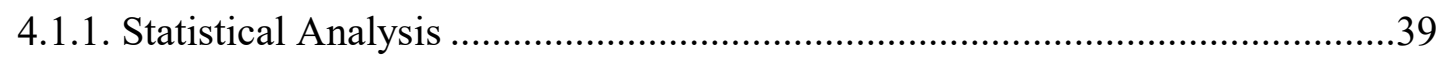

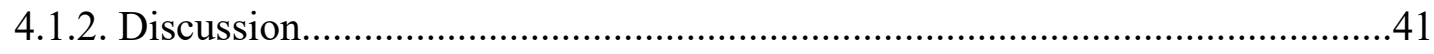

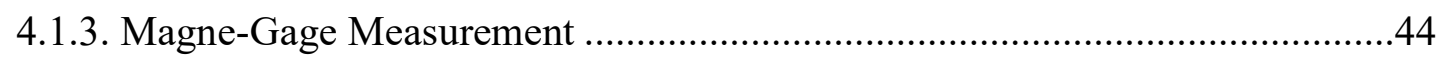

4.1.4. Scanning Electron Microscopy (SEM) Characterization ...............................47

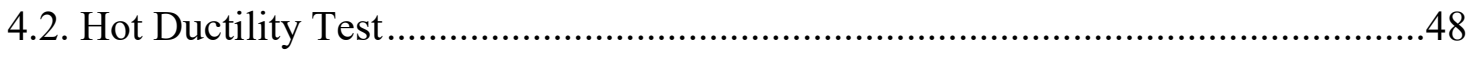

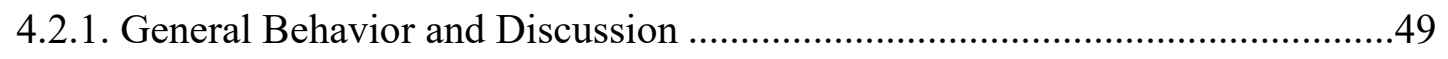

4.2.2. Comparison with Wrought 316L Stainless Steel.........................................54

4.2.3. Comparison Between Laser Patterns ..........................................................58

4.2.4. Comparison Between On-Heating and On-Cooling Curves ...........................60

4.2.5. Precipitation Density Changes Over Distance ...........................................62

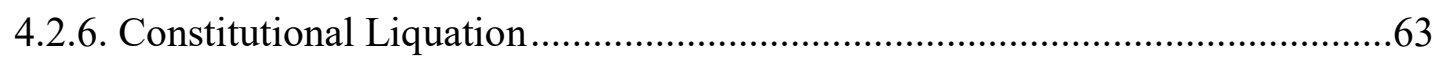

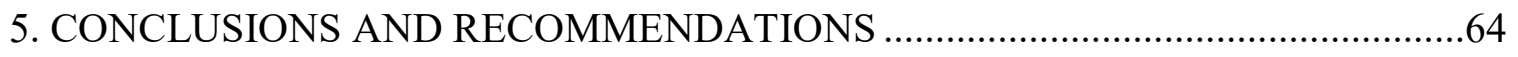

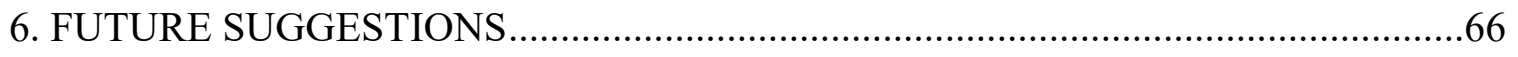

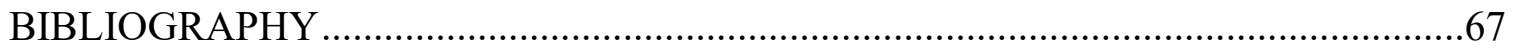




\section{APPENDICES}

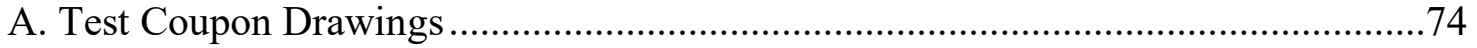

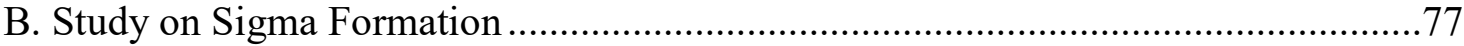




\section{LIST OF TABLES}

Table

Page

1. Chemical Composition (wt. \%) of 316L Stainless Steel Powder ........................ 16

2. Test Matrix of Hot Ductility Testing at One Temperature ............................... 31

3. Test Matrix of Nil Strength Temperature Testing ................................................... 31

4. Dial Reading on Magne-Gage and the Corresponding Ferrite Number ............... 47 


\section{LIST OF FIGURES}

Figure

Page

1. 3D Printer with Powder Bed Fusion System of 125HL From SLM Solutions Group AG. ("SLM Solutions Group AG: Home”)...........................................................

2. Overview of the Repeated Process in Powder Bed Fusion System. ("SLM Solutions

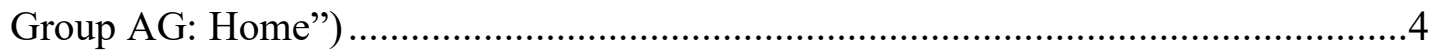

3. Thermal Model of SLM Process in the Chamber ....................................................5

4. Residual Stress State at Different Position in Weld Path ........................................

5. Pseudo Binary Phase Diagram of Fe-Cr-Ni System When Fe Is at 70 wt.\%.

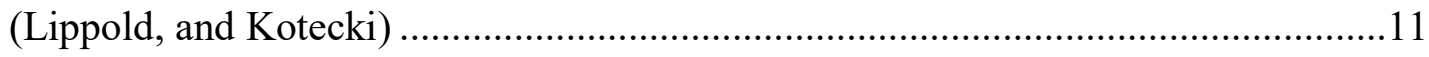

6. Primary Austenitic Solidification and Primary Ferrite Solidification .......................12

7. Initial Stage of Case III Solidification of Austenitic Stainless Steel ........................14

8. Ni and Cr Compositional Distribution Across a Subgrain as Solidification

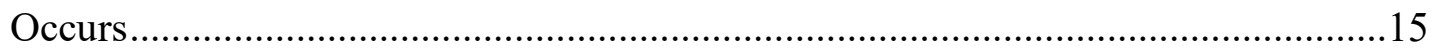

9. An Example of Powder Shape Used in Additive Manufacturing ............................16

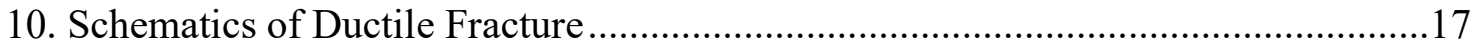

11. An Example of Ductile of 316L Stainless Steel with Scanning Election

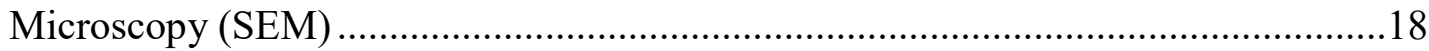

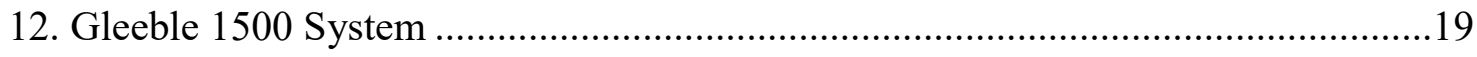

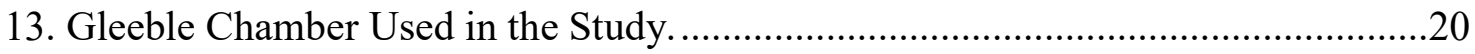

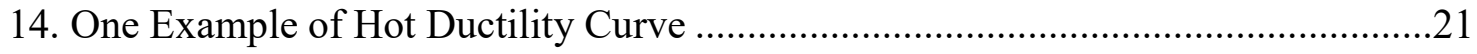

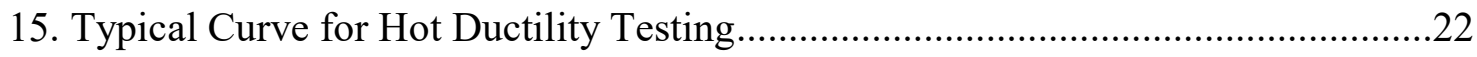

16. The Contributing Factors in Hot Ductility Testing ...........................................24 
17. The 3D Model of Gleeble Sample for Hot Ductility Test .27

18. The 3D Model of Gleeble Sample for NST Test ...................................................28

19. (a) Z-Direction Samples and (b) XY-Direction Samples .........................................30

20. First Iteration of Density Cube Experiment............................................................32

21. The Second Iteration of Density Cube Print .............................................................33

22. Relative Density vs Linear Energy Density Applied on the Powder Bed .................34

23. The Image Shows the Amount of Warpage from Different Orientation of Print .....35

24.The Measurement Window for the Warpage Analysis ..............................................36

25. The Assumption in the Warpage Analysis..............................................................

26. The Comparison of the Amount of Warpage in the Rod ..........................................37

27. The Temperature Profile Used in (a) On-Heating Test at $1000^{\circ} \mathrm{C}$ and (b) On-

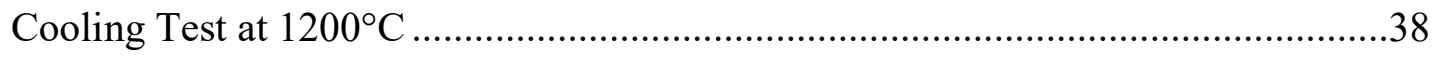

28. The ANOVA Table from the NST Test..................................................................

29. The One-Way ANOVA Table from the NST Test .................................................40

30. (a) The Interval Plot and (b) Residual Plots to Show the Validity of the Statistical

Study

31. Cracks in NST Sample Captured by Light Microscopy at (a) 200x and (b) 500x Magnification .42

32. Comparison of Cross Section Between Z-Direction Sample and XY-Direction Sample. .43

33. Time-Temperature Transition (TTT) Diagram for Sigma Phase in Austenitic

Stainless Steel. 44

34. Magne-Gage Used to Find the Ferrite Number of the Test Samples. 45 
35. Ferrite Number Chart for the Magne-Gage System Used in This Study 46

36. SEM Image of (a) Z-Direction at 1343x and (b) XY-Direction at $1992 \mathrm{x}$ .47

37. Result Graphs of Ductility from Hot Ductility Test with Different Treatment .49

38. Result Graphs of Strength from Hot Ductility Test with Different Treatment..... 49

39. Micrograph of On-Heating Z-Direction and Stripe Laser Pattern Sample Tested at $1000^{\circ} \mathrm{C}$ with (a) 200x Magnification and (b) 500x Magnification .52

40. Micrographs of On-Heating XY-Direction and Stripe Laser Pattern Sample Tested at $1200^{\circ} \mathrm{C}$ with (a) $100 \mathrm{x}$ Magnification and (b) 500x Magnification .53

41. Micrograph of NST Z-Direction and Stripe Laser Pattern Sample with (a) 200x Magnification and (b) 500x Magnification .54

42. The Test Result of Reduction of Area of Wrought 316L Stainless Steel Conducted by Walsh .55

43. Microstructure of As-Printed Z-Direction Stripe Sample at 500x Magnification ....57

44. A Large Oxide Crack Seen on Z-Direction Stripe Sample at 500x .58

45. The Carbide Formation on the Edge of the Laser Weld Path Due to the Austenitic Solidification .59

46. The Number of Laser Pattern of (a) Stripe and (b) Checker Board .........................60

47. Metallography of (a) $\mathrm{OH}$ and (b) $\mathrm{OC}$ Sample at $1300^{\circ} \mathrm{C}$ at $500 \mathrm{x}$ Magnification.....61

48. The Microstructure of NST Sample at Different Locations from the Crack Tip (a) $1 \mathrm{~mm}$ Away, (b) 3mm Away, and (c) 6mm Away .62

49. Constitutional Liquation Captured from NST Samples .63

50. (a) The Recommended Orientation of the Build and Laser Setting for the Box and (b) the Direction of the Box That Will Be Welded to Other Parts .65 


\section{INTRODUCTION AND BACKGROUND}

Selective laser melting (SLM) is one of the fastest growing additive manufacturing fields in both industries and academia. Among the additive manufacturing methods, selective laser melting is called powder bed fusion method which is a repetitive process of coating a thin layer of metal powder on a build plate and applying laser selectively on the powder bed to melt and form a thin layer. This layer-by-layer process can produce a higher dimensional accuracy and better mechanical properties compared to the same materials manufactured by traditional methods such as reductive manufacturing and casting.

Even though SLM is one of the powerful tools in manufacturing, there are several issues associated with this method, one of which is the residual stress stored in the printed parts, and thus, the warpage as the result of the stress. The warpage of the printed pieces is a common problem in almost any $3 \mathrm{D}$ printing technology because most of additive manufacturing techniques involve uneven cooling of each layer. SLM is not the exception. In SLM, this warpage problem is one of the critical issues because it can ruin the quality of the print. Since the laser applies and melts the powder from one end to the other end of the printed layer, the solidification occurs unevenly, creating a complex stress state of compression and tension in the layer. This problem is unavoidable because it is the very mechanism of SLM, however this makes the SLM printed samples stronger. One of the solutions to minimize it is to modify the laser parameter and scanning speed of the laser.

Because of the warpage, it can lead to another problem, which is the dimensional limit of the print. The warpage problem in SLM gets more severe as the size of the parts gets bigger because the heat gradient in the parts get bigger as the size increases. The SLM Solution Inc., which is the company of the machine used in this study, has the largest SLM 
machine called SLM 800. This machine has the build envelope of the dimension of 500 mm length $\times 280 \mathrm{~mm}$ width $\times 800 \mathrm{~mm}$ height. Even though SLM can produce high accurate parts and better mechanical properties, it is impossible to print a large dimensional object such as car frames. Therefore, if SLM parts are used to manufacture a large part, the welding technology should be utilized to merge the parts into one piece because welding is so common to be used in the industries and it is the most effective method to merge multiple metal parts into one piece.

The use of welding on SLM samples is necessary, however, there is no published scientific work that describes the effect from welding such as heat affected zone (HAZ) on the SLM samples and associated microstructural changes. In this study, the physical thermal mechanical simulator called Gleeble is utilized to collect the data of the behavior of SLM samples by hot ductility test. Data is collected based on the design of experiment, and it is statistically analyzed, and finally, changes in microstructure are shown to support the hypotheses of the phenomena. 


\section{LITERATURE REVIEW}

In this section, literature review about the structure, process, properties and performance of $316 \mathrm{~L}$ stainless steel in additive manufacturing is studied.

\subsection{Selective Laser Melting}

Additive manufacturing (AM) has a variety of merits compared with the conventional manufacturing such as subtractive manufacturing. AM can be fast and efficient in production such as casting because there is no need to make molds or take several steps in CNC machine to produce the complex geometry. Another merits for AM is that it can produce high geometrically accurate parts. The iconic structure AM can produce compared with subtractive manufacturing is the lattice structure. The powder used in AM is always recycled in the process and this can lead to lower the cost effectively in manufacturing. Even though there are a number of AM methods growing in the industries such as direct melt deposition, stereolithography, and selective laser sintering (SLS), SLM has a strength in geometric accuracy.

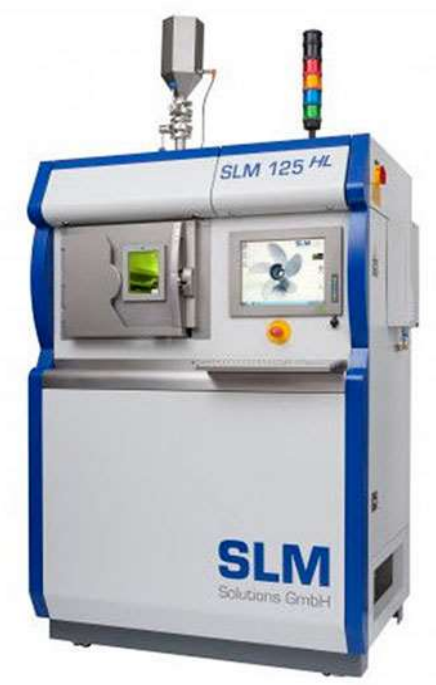

Figure 1. 3D Printer with Powder Bed Fusion System of 125HL from SLM Solutions Group AG. ("SLM Solutions Group AG: Home") 


\subsubsection{Printing Mechanism}

The mechanism used in SLM is called powder bed fusion. In this mechanism, a cycle of powder coating and laser application is repeated until the part is done. The powder is initially loaded from powder loader to a coating unit called recoator. Recoator has slots for front coating and back coating so that it can distribute powder on the build plate for both ways of movement. The recoator moves with a certain rate in the chamber and the rubber recoator blade which is attached at the bottom of the recoator evenly smooth out the powder on the build plate. The layer thickness of powder coating can be set up with the machine. It can range from $30 \mu \mathrm{m}$ to $1 \mathrm{~mm}$, depending on the dimensional accuracy requirement and the speed of production. Once the powder is distributed evenly, the fiber laser is applied from the top of the chamber. The printer chamber is filled up with inert atmosphere (Argon) for the operation to avoid any reactions of oxygen with metallic powder. The Figure 2 shows the schematics of the mechanism.
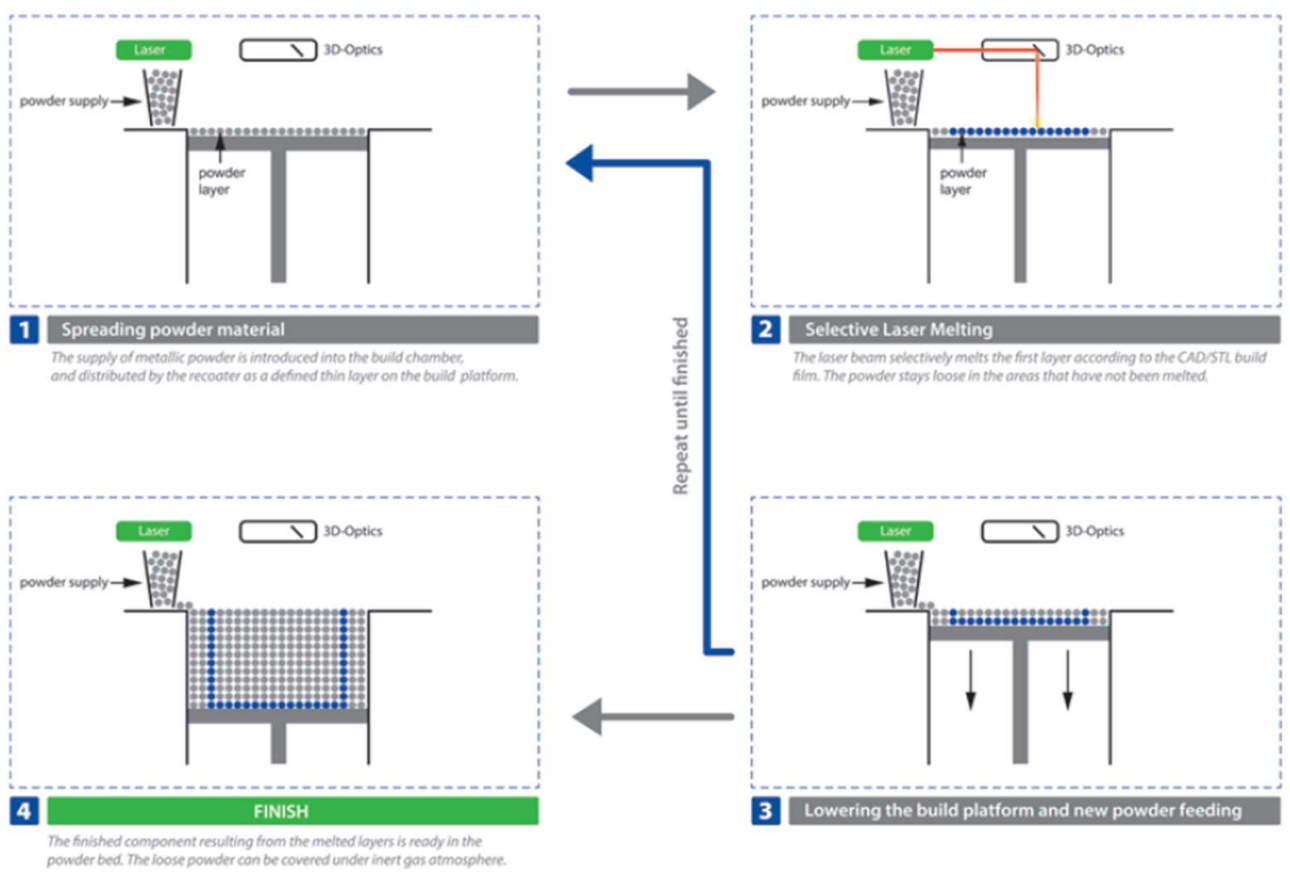

Figure 2. Overview of the Repeated Process in Powder Bed Fusion System. ("SLM Solutions Group AG: Home") 


\subsubsection{Heat Transfer: Theory}

The mechanism of SLM involves heat transfer. The theoretical thermal model can be constructed with the powder bed fusion system process. Figure 3 shows the thermal model during the SLM process. In thermodynamics standpoint, all the energy input to the system should be dissipated away from the system. The input heat during the SLM process is from laser which melts the powder to form a thin layer and the heat from solidification. There are three mechanisms in heat transfer: conduction, convection, and radiation. The conduction, which is the major way of heat transfer, happens not only through the parts or build plate but also through the powder. However, the heat conduction through powder should be much less than the heat conduction through solid part because the air pockets in the powder can hinder the heat transfer. Right above the build plate, an inert gas is blown theoretically at laminar flow. This gas flow can work as convection cooling process which is one of the three heat transfer methods. Finally, radiation is one of the mechanisms to dissipate the heat. However, the radiation is much smaller compared with other two heat transfer methods.

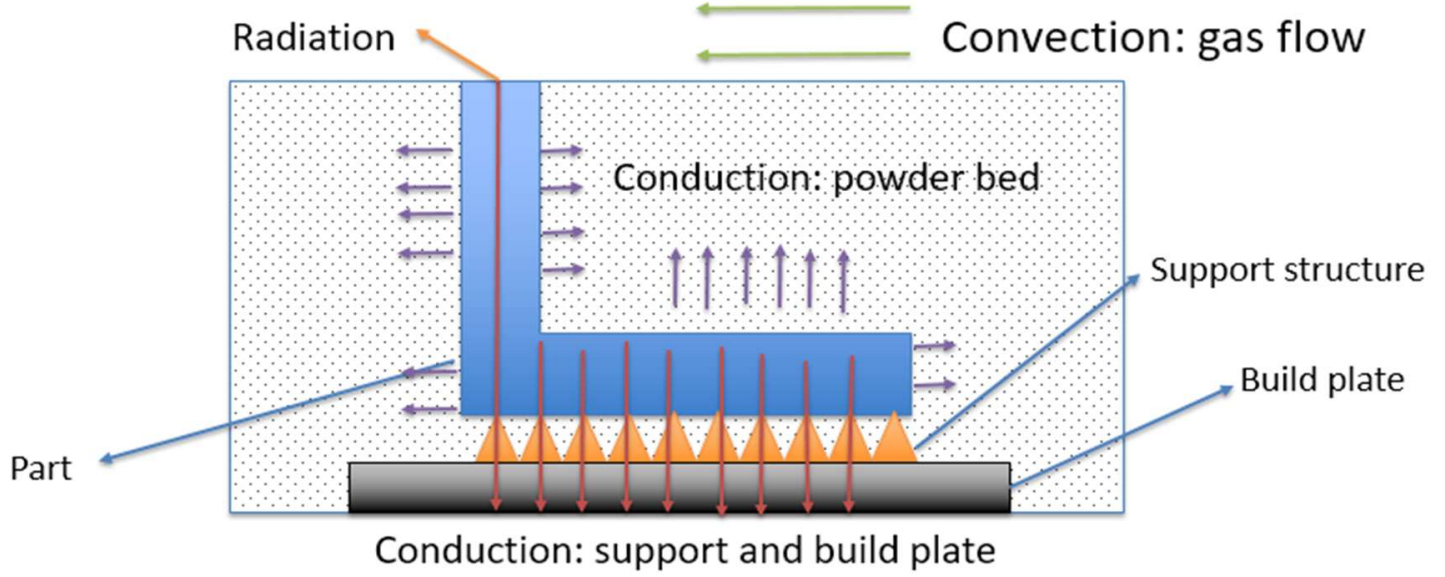

Figure 3. Thermal Model of SLM Process in the Chamber. Not only conduction, but convection is also a major contributor of heat transfer. (Wang) 


\subsubsection{Residual Stress and Warpage}

Residual stress is caused by the thermal stress in additive manufacturing processes and SLM parts can have the warpage problem because of it. Residual stress is occurred by the temperature differences in the material, and in SLM, this difference in temperature can be caused by the laser path. When a laser scans the layer of powder from one end to the other end, thermal expansion by melting and shrinkage by solidification happens for each path of laser. When the laser melts the powder, forming the melt pool, weld metal should experience compression because thermal expansion is restrained by the surroundings. When the laser passed and the melt pool starts to solidify, the shrinkage will pull the surroundings to cause some tensile stress on the material (Kou). The mechanism of forming this residual stress is similar with the one in welding. The Figure 4 shows the residual stress state in the welding at each point of weld path. In SLM, this stress state should form because the laser path in SLM process is the same as the welding process. 


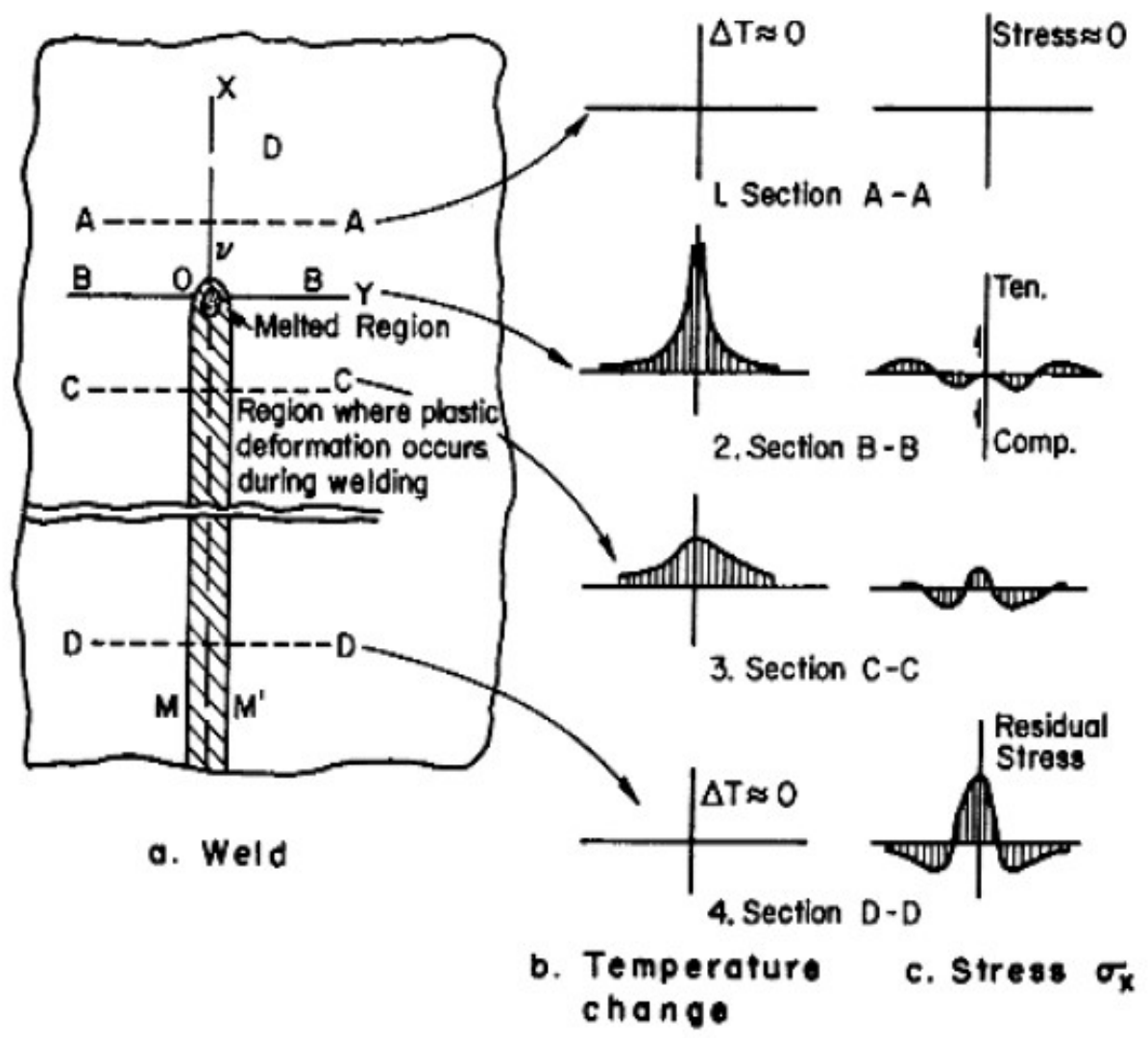

Figure 4. Residual Stress State at Different Position in Weld Path. Since the laser scanning in SLM is the same process as welding, the similar stress state should be expected on the layer of powder bed fusion system. (Kou)

\subsection{SLM 125HL Specification}

The SLM 125HL is an additive manufacturing machine used in this study. This machine is manufactured by SLM Solutions Inc., in Germany. The SLM 125 HL was donated by Lawrence Livermore national laboratory and installed in California Polytechnic University San Luis Obispo (Cal Poly) in 2017. The following sections describe the specification of the machine and settings to operate the machine.

\subsubsection{Machine Specification}

The SLM $125 \mathrm{HL}$ has the print volume of $125 \mathrm{~mm} \times 125 \mathrm{~mm} \times 125 \mathrm{~mm}$. Since the machine is the smallest scale among other series of machines manufactured by the company, the number of laser the machine contains is only one with the maximum power 
of $400 \mathrm{~W}$. The laser is generated by the fiber laser with wavelength of $1070 \mathrm{~nm}$. The layer thickness can range from $20 \mu \mathrm{m}$ to $75 \mu \mathrm{m}$, and this study uses $30 \mu \mathrm{m}$ of layer thickness. The minimum feature size of print is $140 \mu \mathrm{m}$. The beam diameter is $70 \mu \mathrm{m}$ measured by caustic measurement. Laser scanning speed can maximize to $10 \mathrm{~m} / \mathrm{s}$ but, on average, $400 \mathrm{~mm} / \mathrm{s}$ to $1000 \mathrm{~mm} / \mathrm{s}$ is used to print parts. The building chamber is filled up with ultra-high purity grade argon gas. The gas consumption purging into the chamber is $70 \mathrm{~L} / \mathrm{min}$ and the consumption during the printing process is $2 \mathrm{~L} / \mathrm{min}$. The gas is circulated in the chamber during the print from one side to the other side to function as clearing out the laser path in the air because flowed powder can interact with laser from the ceiling of chamber. ("SLM Solutions Group AG: SLM $\left.{ }^{\circledR} 125^{\prime \prime}\right)$

\subsubsection{Laser Parameter Settings}

The source of laser in SLM 125HL is a doped optic fiber laser which has the wavelength of about $1070 \mathrm{~nm}$ and the maximum power of $400 \mathrm{~W}$. Even though the power can produce up to $400 \mathrm{~W}$, the laser setting used in this study is different from the maximum power settings. The pre-experiment about optimization of laser setting should be described later in chapter. The laser is one of the crucial settings that can heavily affect the print quality because the laser power and scan speed can determine the amount of layers the melts pool can melt. Therefore, there are a number of studies that show the optimized setting for laser in SLM. However, optimal setting is almost dependent on the individual machine and material system used in the machine. Therefore, it is necessary to conduct this study prior to this study to make sure the print quality is good. 


\subsection{Material System}

Even though there are a wide range of material powder used in AM field, the material used in this study is 316L stainless steel. As one of commonly used alloys, studying 316L stainless steel is effective. The following sections shows the general overview of stainless steel and the solidification mechanism of the steel. These components are important to understand to tackle the problem with microstructural analyses conducted in this study.

\subsubsection{Overview of Austenitic Stainless Steel}

Stainless steel is defined as high-alloy steels containing more than $10.5 \mathrm{wt} . \%$ of chromium. The stainless steel is based on iron-chromium, iron-chromium-carbon, or ironchromium-nickel phase diagram system, depending on alloying elements in the stainless steel. There are three types of stainless steel: ferrite austenitic, martensitic, and mixture (duplex). These categories are determined by the phase dominating in the microstructure. Stainless steel is commonly known as corrosion resistive steel. This is because a thin layer of chromium oxide forms on the surface of steel to protect from oxidation reaction (corrosion). Austenitic stainless steel which is studied in this work usually has identification number series of $2 \mathrm{xx}$ and $3 \mathrm{xx}$. Austenitic stainless steel is generally nonmagnetic, low thermal conductivity, high thermal expansion, higher distortion by welding. The austenitic stainless steel is also resistive to intergranular stress corrosion cracking in heat affected zone and transgranular stress corrosion cracking. (Folkhard, and Rabensteiner) 


\subsubsection{Solidification of Austenitic Stainless Steel}

In the solidification of austenitic stainless steel, there are two types of solidification modes: primary austenite and primary ferrite. The solidification mode is dependent on the composition of the nickel and chromium in the stainless steel. The nickel is known to be as austenite promoter, and therefore, the more nickel the steel contains the more austenite phase could be expected from the solidification according to the phase diagram. On the other hand, chromium is known to be as a ferrite promoter, and it is expected to see primary ferrite solidification with higher amount of ferrite. For 316L stainless steel, a unique phase diagram called pseudo binary phase diagram is used to characterize the phase in the steel at certain temperatures. Pseudo binary phase diagram is a phase diagram where one of the component is held at constant compositional value. The pseudo phase diagram for iron at $70 \mathrm{wt} . \%$ is shown in Figure 5. This diagram could be the best representative for the material in this study because the composition of $316 \mathrm{~L}$ stainless steel powder in this work is similar. (Kou) 


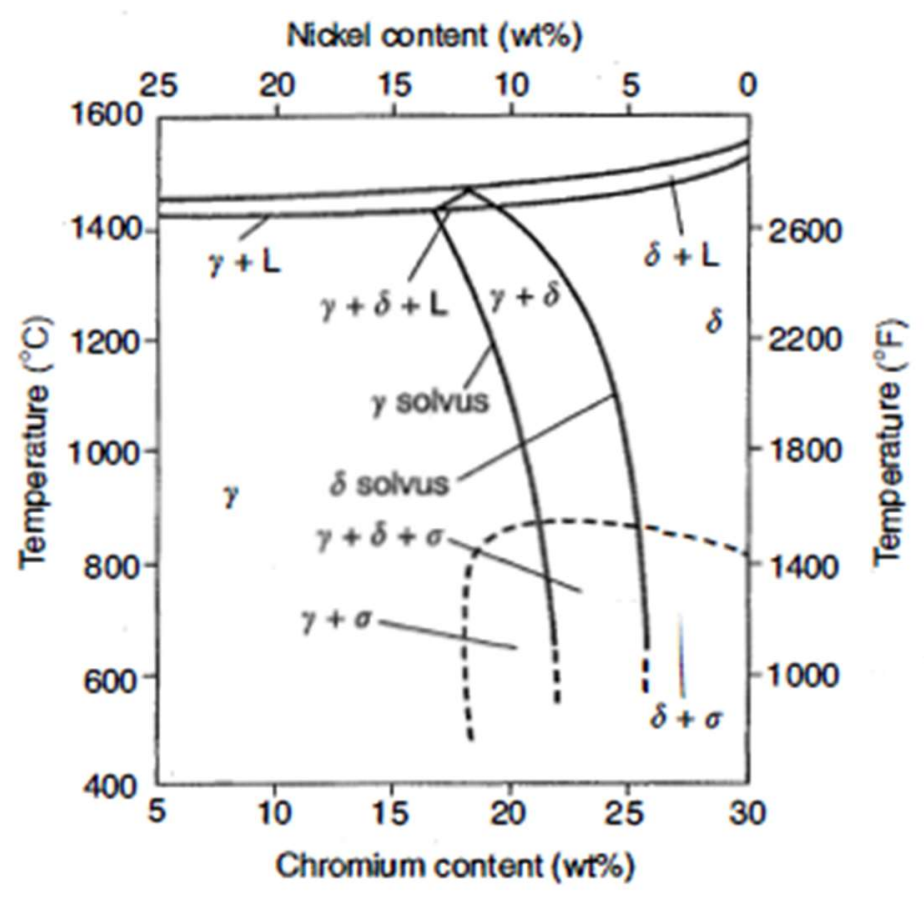

Figure 5. Pseudo Binary Phase Diagram of Fe-Cr-Ni System When Fe Is at 70 wt.\%. (Lippold, and Kotecki)

In the primary austenitic solidification, austenite is the first solid forms from the liquid. As the core dendrites of austenite grows, a small amount of ferrite forms on the edge of the dendrite due to the phase segregation as solidification by solute gradients. This makes the ferrite to be formed on the edge of the austenite grains. On the other hand, in the primary ferrite solidification, the ferrite initially forms from liquid. However, as the metal cools, the ferrite goes through solid-state transformation to austenite. This transformation from ferrite to austenite continues until the composition of steel approaches to nominal composition. (Lippold, and Savage). In the end, the microstructure looks like a "skeleton" of ferrite running through the microstructure. The differences in these solidification are described in Figure 6. 


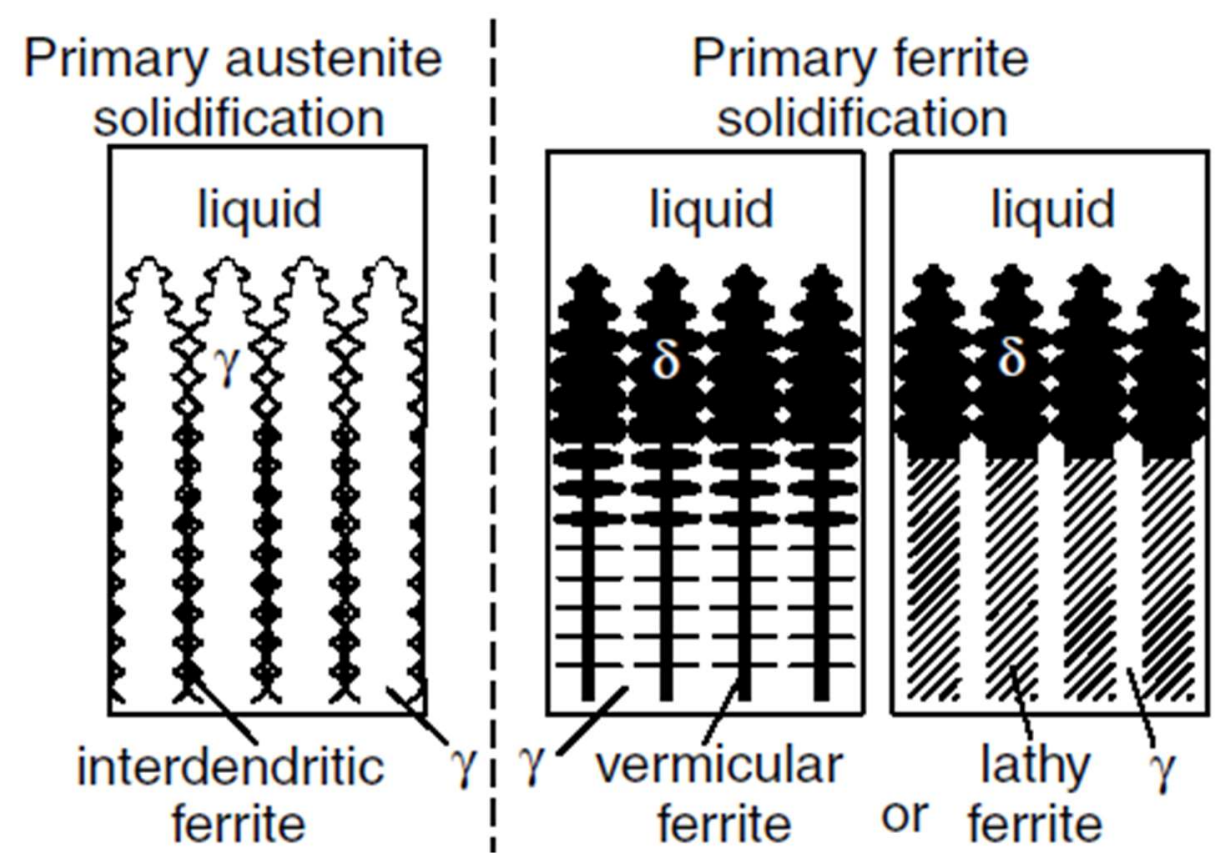

Figure 6. Primary Austenitic Solidification and Primary Ferrite Solidification. The primary ferrite solidification goes through transformation of ferrite phase to austenite phase. (Kou)

The difference in solidification can be explained by phase diagram. However, the phase diagram is the best to predict the existing phases in the microstructure in the equilibrium solidification. The solidification with fast cooling (quenching) is not equilibrium solidification because diffusion is hard to occur in the fast cooling. Thus, the solidification should be explained based on the kinetics rather than thermodynamics. The SLM process and dendrite growth in SLM is not in equilibrium solidification because solidification process in SLM is close to the one in welding. For the non-equilibrium solidification, there are four assumptions made to analyze the solidification profile. First, diffusion does not have time and therefore it is assumed not to happen in the metal weld pool. Second, mechanical mixing in the weld pool should not occur at the interface of solid and liquid. Third, the adjustment of composition in the liquid is solely by diffusion since diffusion in liquid is much faster the one in solid. Finally, microscopic equilibrium exists between the solid and liquid phase at the moving solidification boundary. The solidification 
theory based on these four assumptions are Case III solidification. The characteristics of Case III solidification are: initial transient stage, steady-state stage, and terminal transient stage of solute composition. In the initial transient stage, the solidification occurs with the composition at $\mathrm{kC}_{0}$, where $\mathrm{k}$ is the effective distribution coefficient for the solid $(0<\mathrm{k}<$ 1) and $\mathrm{C}_{0}$ is the nominal composition of a certain element in the metal. The composition starts from lower than the nominal composition and it gradually increases to the nominal composition. In the next stage, the nominal composition is held and steady-state solidification is seen. In the last stage, the composition of a component exponentially increases as the distance from the moving solidification boundary gets further away and approaches to the other solidification dendrites (Lippold, and Savage). The Figure 7 shows the schematic of the case III solidification. 

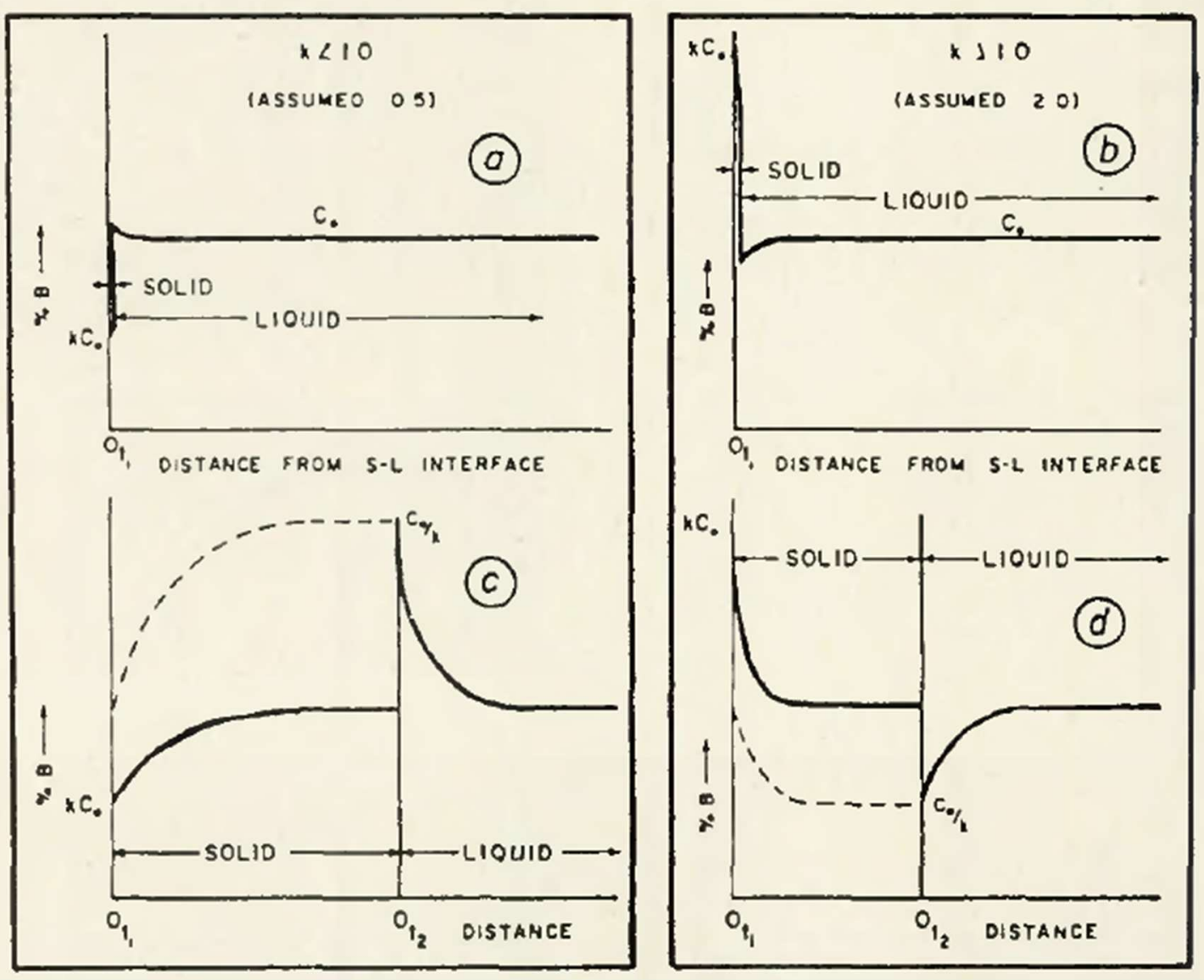

Figure 7. Initial Stage of Case III Solidification of Austenitic Stainless Steel. (a) and (c) shows the compositional changes when $\mathrm{k}=0.5$. (b) and (d) shows the compositional changes when $\mathrm{k}=2.0$. (Lippold, and Savage)

This compositional difference upon solidification happens in nickel and chromium in stainless steel. Figure 8 describes the amount of nickel and chromium in dendrite for both primary ferrite solidification and primary austenite solidification. As is described above, in primary ferrite solidification, nickel is not rich as the center of dendrite and chromium is, on the other hands, rich. This relationship gets reverse as the distance from the core of dendrite gets further. In the primary austenite solidification, this entire relationship is opposite; nickel is rich in the core of the dendrite, but chromium is not. However, chromium is rich on the edge of dendrite and nickel is not. 


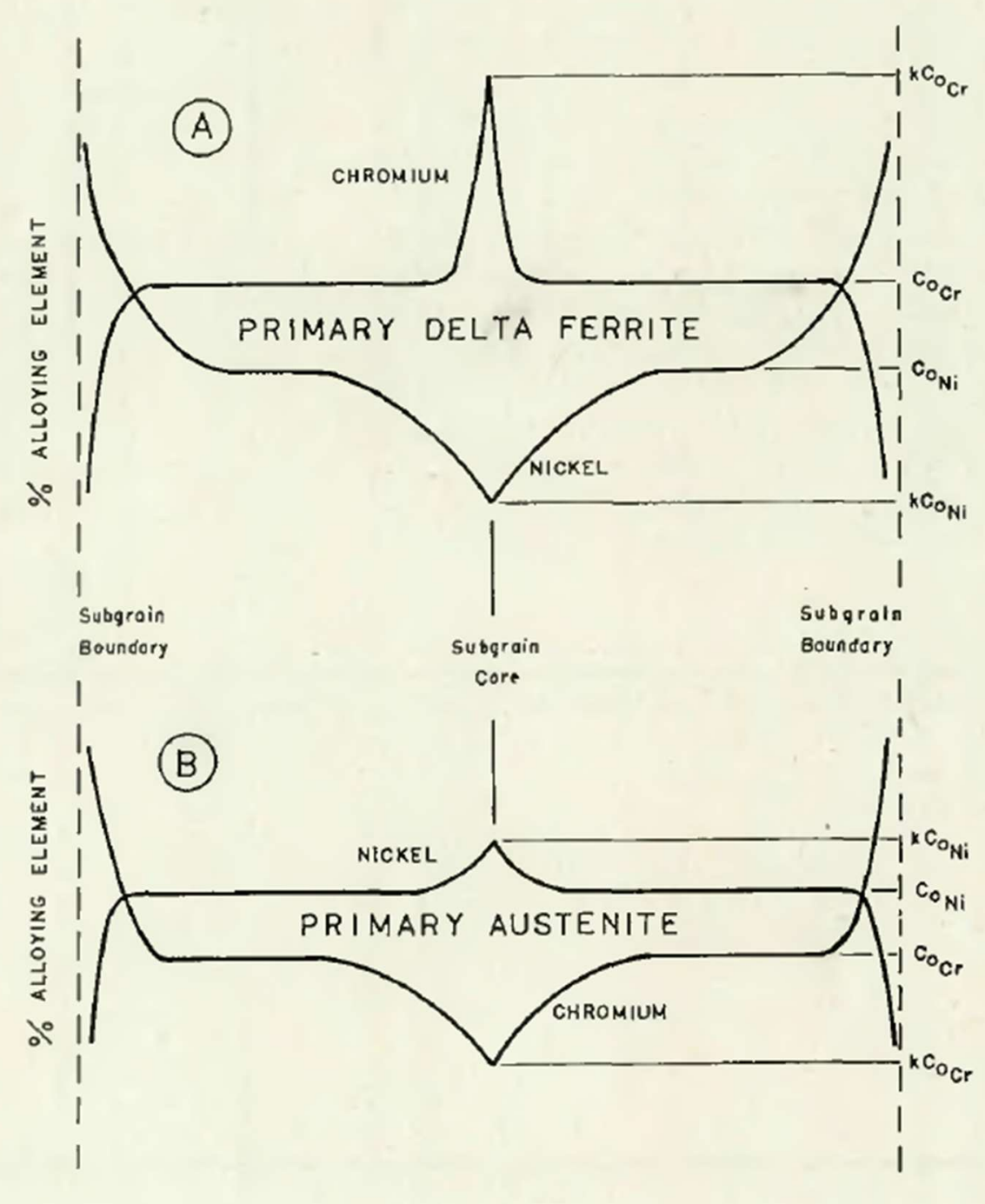

Figure 8. Ni and Cr Compositional Distribution Across a Subgrain as Solidification Occurs. (A) describes primary ferrite solidification and (B) describes primary austenite solidification. (Lippold, and Savage)

\subsubsection{L Stainless Steel Powder}

The 316L stainless steel powder used in this study has the dimension of $10-45 \mu \mathrm{m}$ in powder diameter. The composition of the material is listed in the following table I. From the table above and the pseudo binary phase diagram, it can be expected that the solidification of SLM parts could be primary austenitic. 
Table 1. Chemical Composition (wt. \%) of 316L Stainless Steel Powder

\begin{tabular}{|c|c|c|c|c|c|c|c|c|c|c|}
\hline $\mathrm{Fe}$ & $\mathrm{Cr}$ & $\mathbf{N i}$ & Mo & Si & Mn & $\mathbf{C}$ & $\mathbf{N}$ & $\mathbf{P}$ & $\mathbf{S}$ & 0 \\
\hline Bal. & $\begin{array}{c}16.00- \\
18.00\end{array}$ & $\begin{array}{c}10.00- \\
14.00\end{array}$ & $\begin{array}{c}2.00- \\
3.00\end{array}$ & 1.00 & 2.00 & 0.030 & 0.10 & 0.045 & 0.030 & 0.10 \\
\hline
\end{tabular}

The powder quality in terms of the shape is important because it can affect the flowability of recoating process in SLM (Wang). Therefore, the spherical shape is considered to be the most desirable shape of the powder. An example SEM image of the powder is shown in Figure 9. As is seen from the SEM image, the shapes of powder are mostly sphere.

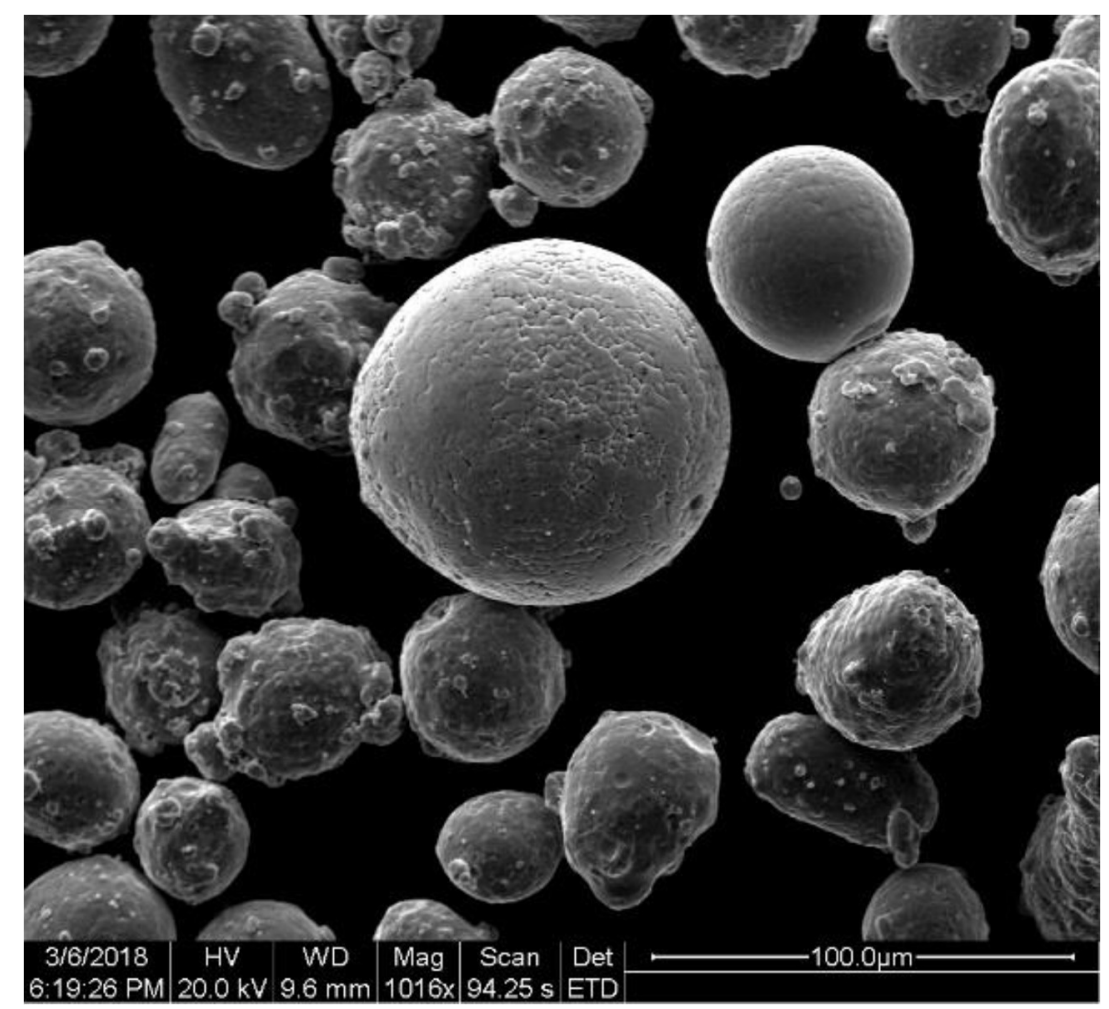

Figure 9. An Example of Powder Shape Used in Additive Manufacturing. Spherical shape is important for the flowability of powder and powder recoating during the printing process. (Wang) 


\subsubsection{Fracture Mode: Ductile Fracture}

A number of studies show the failure mode of $316 \mathrm{~L}$ stainless steel is ductile fracture. Ductile fracture is one of the failure modes which have mainly three steps: microvoids formation, microvoids growth and linkage (coalescence), and fracture by the shear stress. Figure 10 shows the schematics of this process. Initially, when the material is under load, the microvoids nucleates at inclusions or secondary phase precipitation. The microvoids, then, grows with continuous loads and start to link with other growing microvoids. The linkage of the microvoids forms the continuous fractures. This fracture progresses more as the load is applied on the material.

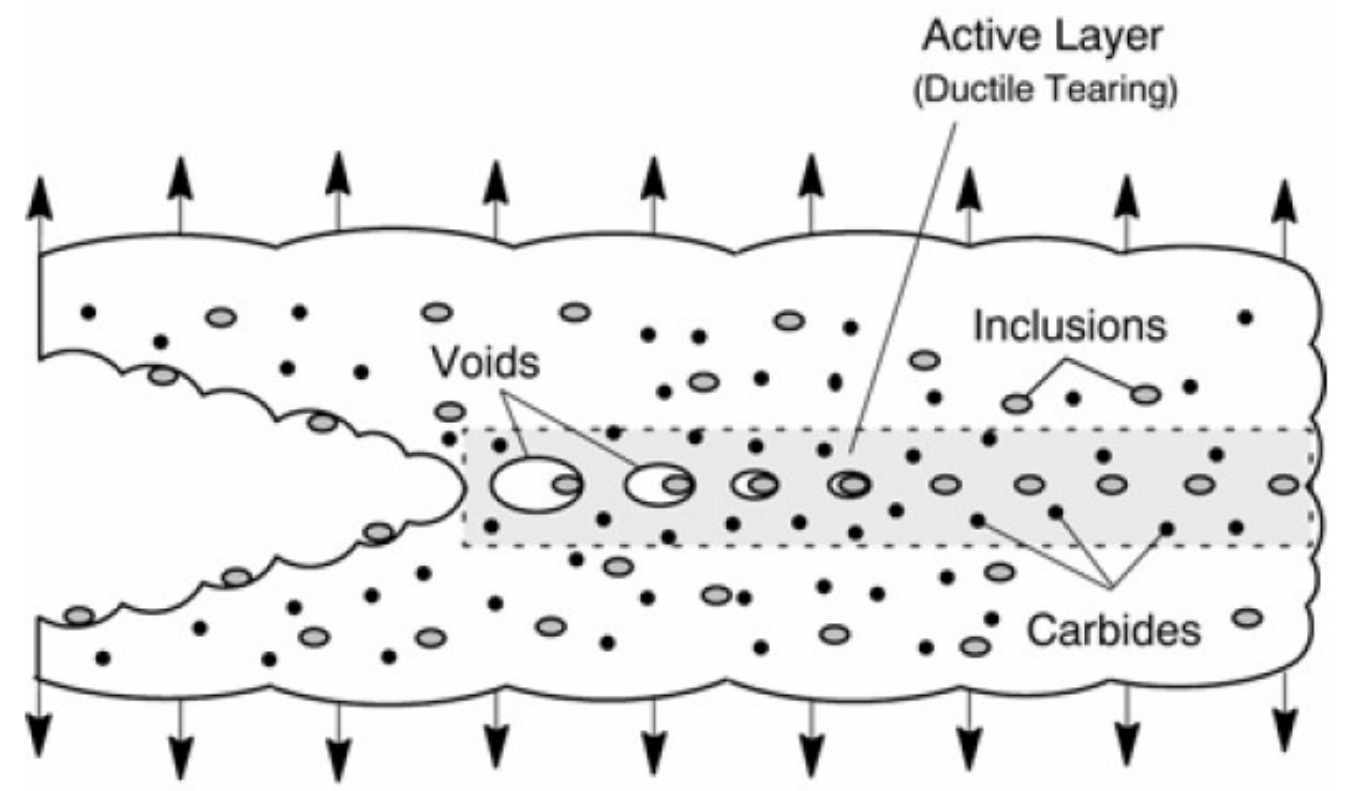

Figure 10. Schematics of Ductile Fracture. The nucleation of microvoids start around the inclusion sites. The microvoids grow and link with other microvoids together as the fracture propagates. (Ruggieri)

Therefore, the fracture surface of the ductile fracture shows a lot of dimples which indicate the coalescence of microvoids. 


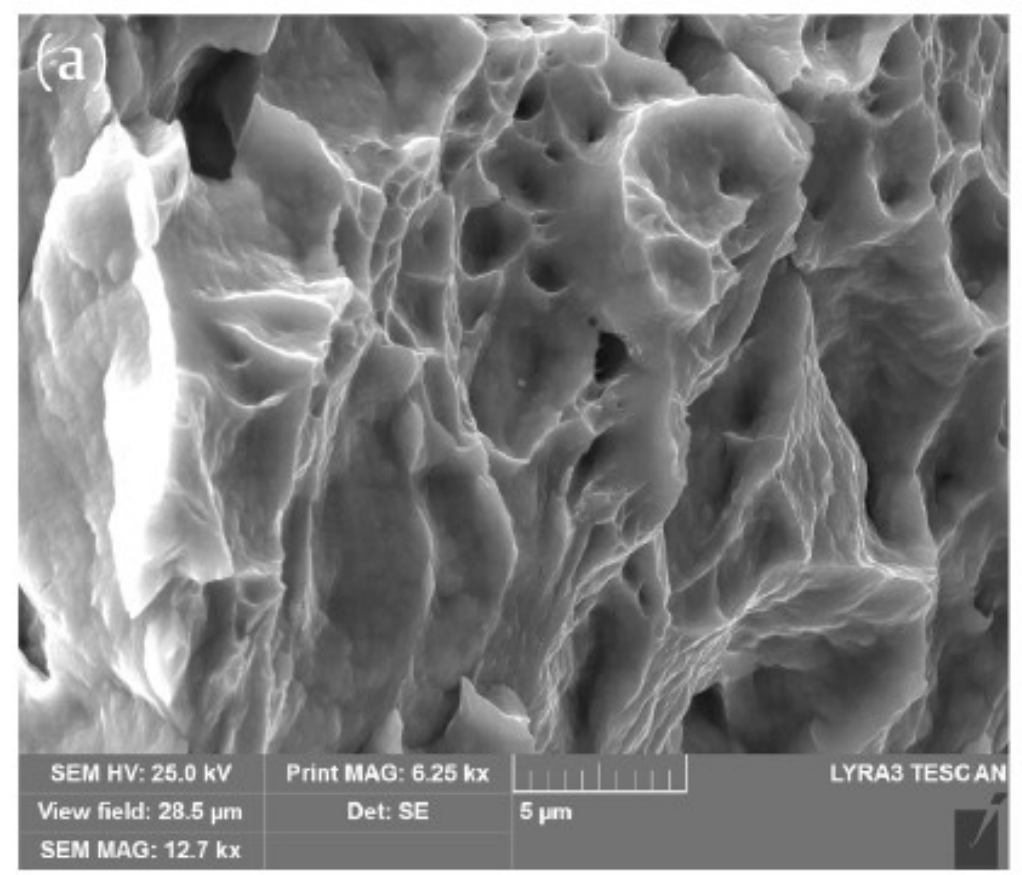

Figure 11. An Example of Ductile of 316L Stainless Steel with Scanning Election Microscopy (SEM). The dimples indicate the fracture mode is dominant by ductile fracture. (Kubík et al.)

\subsection{Gleeble}

Gleeble is one of the most powerful physical thermal mechanical simulation machines manufactured by Dynamic Systems Inc. in NY, the U.S. This machine is essentially a combination of heating unit and mechanical testing equipment in both tensile and compression. The heating unit uses Joule heating that can rise up to $10,000 \mathrm{C} / \mathrm{s}$ on the sample and precisely recreates microstructural gradients and residual stresses affected by HAZ. Because of this feature it can allow users to conduct a number of testing such as hot ductility test, dynamic recrystallization test, strain induced crack opening test, and nil strength temperature testing.

\subsubsection{Machine Specification}

Gleeble used in this study is Gleeble 1500 with system 3.0 upgrade. This machine is much older than other products from DSI Inc,. Before the system is upgraded to version 3.0, all the input and test profiles were controlled by the physical knobs. However, the 
upgrade allows to use the computer to construct the temperature and mechanical test profile and collected data can be processed and exported to csv file. The heating mechanism is joule heating and it allows to heat the test sample at maximum rate of $10,000{ }^{\circ} \mathrm{C} / \mathrm{s}$, which can easily simulate the same heating rate as welding arcs. The sample must have cylindrical shape with a diameter of $6 \mathrm{~mm}$ with some threads on. Before the sample is loaded on the machine, the type-K thermocouples (Chromel/Alumel) are welded into the sample by a capacitance discharger welding machine. Since the type-K thermocouple resists until about $1250{ }^{\circ} \mathrm{C}$, the testing above the temperature requires other type of thermocouple; type-S. The type-S thermocouples (Platinum/Platinum-Rhodium) are used in high temperature applications and they can read the temperature until around $1480^{\circ} \mathrm{C}$. The high temperature testing in hot ductility testing and NST testing described below uses those thermocouples to collect the signal from the material correctly. ("Thermocouple-Thermocouples-What Is A Thermocouple-Types Of Thermocouples")

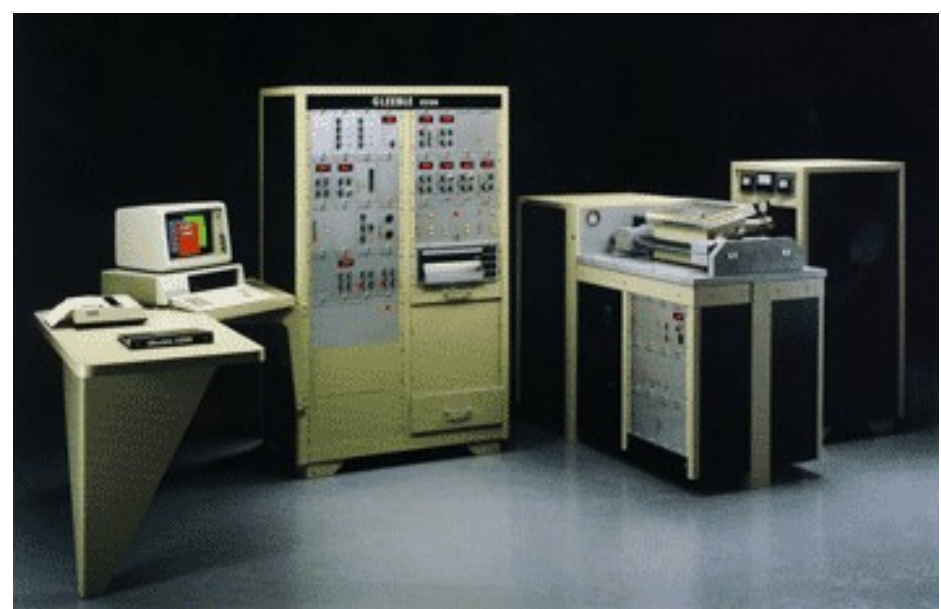

Figure 12. Gleeble 1500 System. The software used in this study is upgraded to 3.0 which allows users to control the machine from computer. ("Gleeble - Home")

Once correct thermal couples are welded into the sample, it is loaded in the chamber of Gleeble. The sample rod is locked with four copper block and tightened by the spacers shown in Figure 13. 


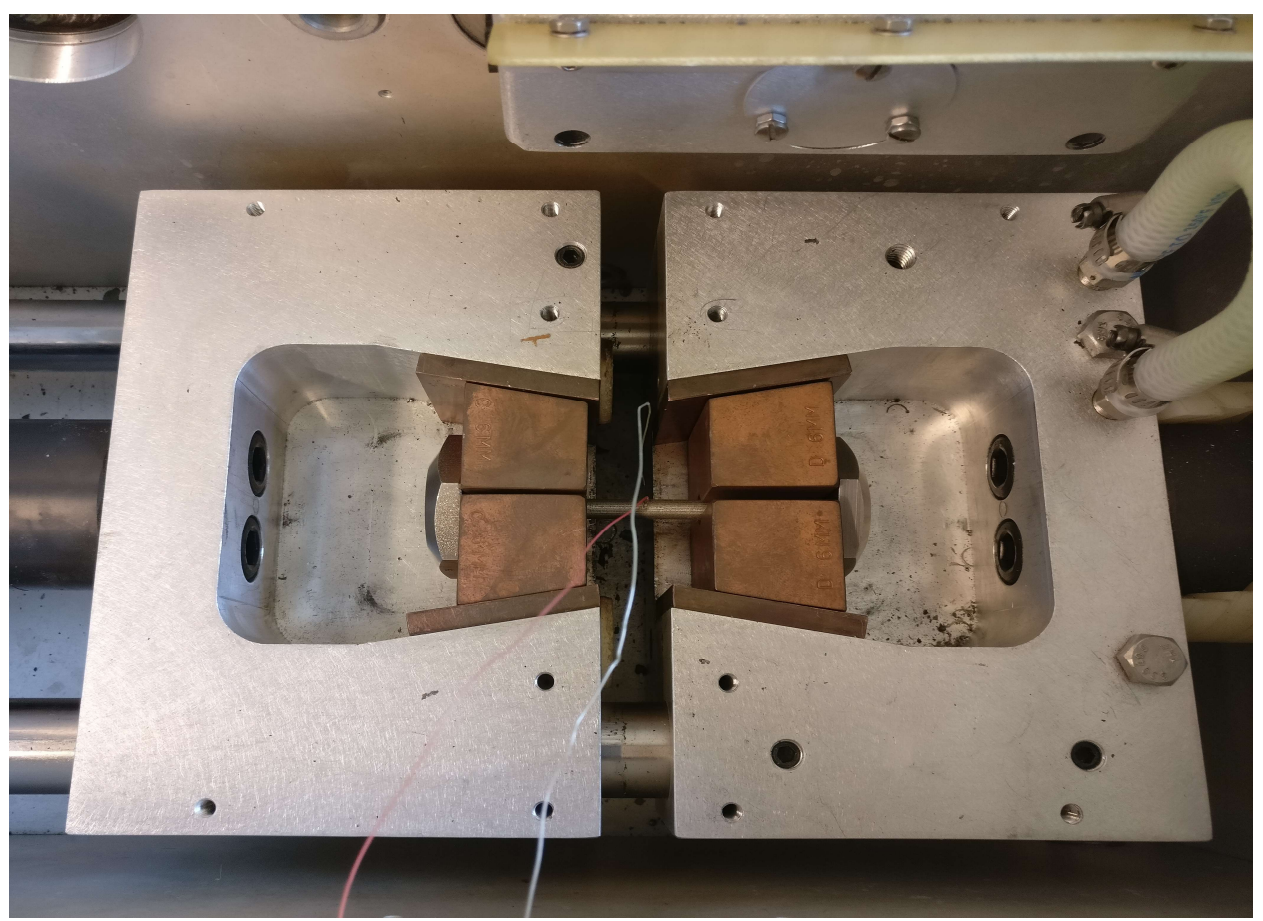

Figure 13. Gleeble Chamber Used in the Study. The sample is locked with four copper blocks and spacers which is not shown in the image.

\subsubsection{Hot Ductility Test}

Hot ductility test is one of the tests Gleeble can conduct to see the mechanical properties of metal at high (or almost melting) temperature. This test came from the idea to measure the weldability of metal alloys because cracking caused by welding is due to the lack of ductility in the material at elevated temperature. Unfortunately, there is no established testing standard for this test, but a number of studies have been conducted to establish the general behavior of stainless steel. There are two parts in this test: on-heating and on-cooling. In the on-heating testing, the sample gets heated up by the resistive heating unit in the chamber and force the material can carry is measured during the heating. Ductility is measured by taking the reduction of are of the sample before and after the test. When the ductility is measured as zero at a certain temperature, it is called nil ductility temperature (NDT) and additional test is run to see the zero strength called nil strength temperature (NST). The general behavior describes some increase in ductility as 
temperature increases and drops at NDT. In the on-cooling test, the process adds a thermal cycle before the mechanical testing; the sample initially gets heated up to NST and will be cooled from NST to a target temperature, and then the mechanical testing measures the force before the material fails by the testing. Depending on the material, the on-heating curve and on-cooling curve could be similar or completely different. For the similar curves, the material is known to be weldable and for the different curves, the material is not weldable because the behavior of ductility through thermal cycle should be similar for the material to be welded.

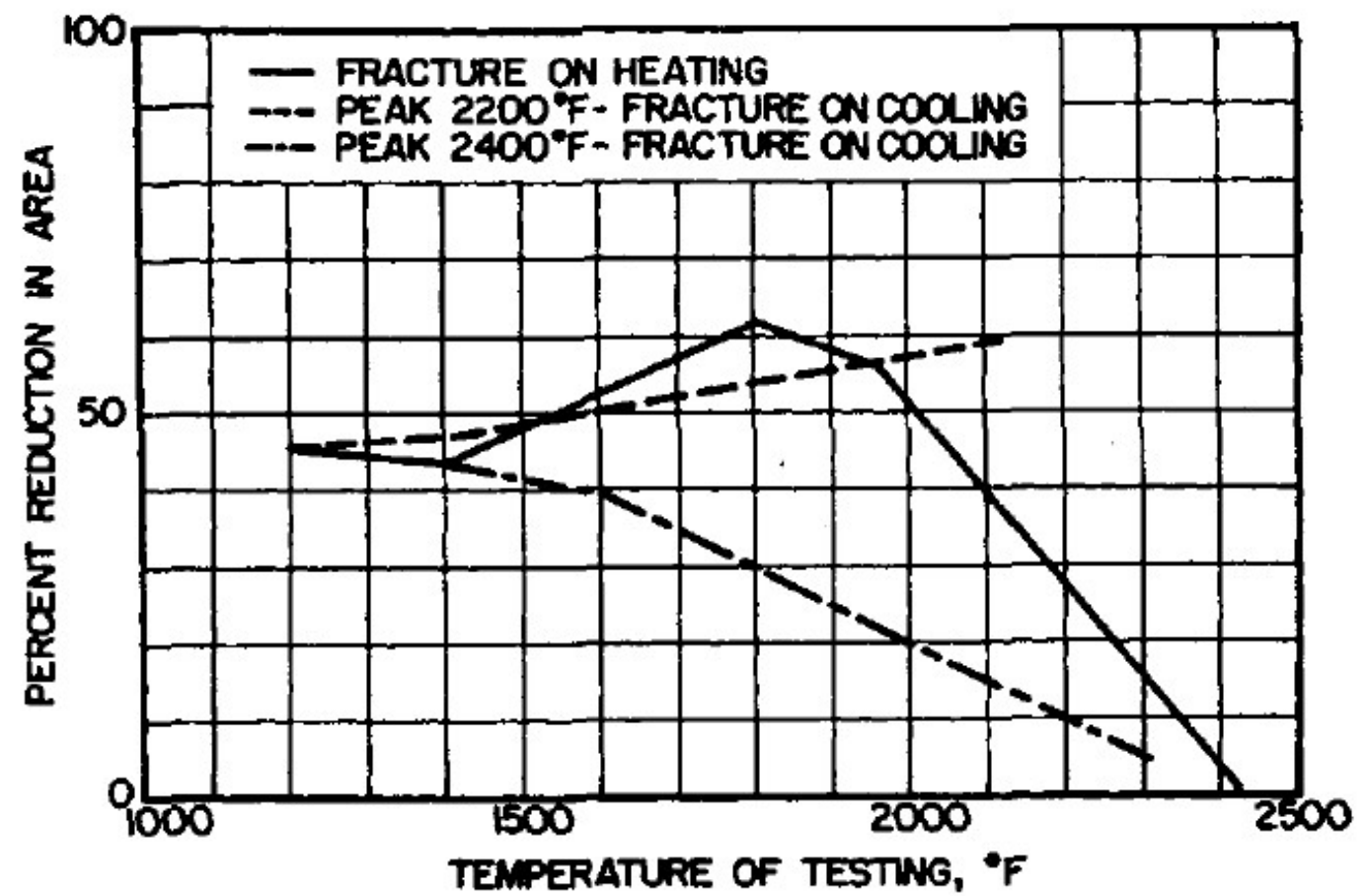

Figure 14. One Example of Hot Ductility Curve. The curves show reduction of area for on-heating and oncooling for $316 \mathrm{Cb}$ stainless steel. (Savage)

Nippes, Savege, and Gordon were the first researchers to conduct this weldability test on a number of different kinds of materials including 316L. They find in the experiment there are two general trends on-heating and three trends on-cooling. 
One type of on-heating trend shown on Figure 15 (a) indicates some increase in ductility (reduction in area) upon heating and a drastic drop in ductility at temperature right below the liquidus temperature. This type of ductility profile is categorized as $\mathrm{H} 1$ in the article and the same identification would be used in this paper. The other type of on-heating trend shown on Figure 15 (b) indicates the gradual decrease in ductility as temperature goes higher and eventually gets to zero ductility. This trend is identified as H2. One of the three trend types on-cooling is the same as H1 (shown on Figure 15 (c)) and this is called C1. C2, shown on Figure 15 (d), has a trend where the initial ductility is not high but it gets higher as the temperature increases. In the end, the ductility drops drastically right below the melting point. Finally, C3 shown on the Figure 15 (e) follows the same as H2. (Nippes et. al)
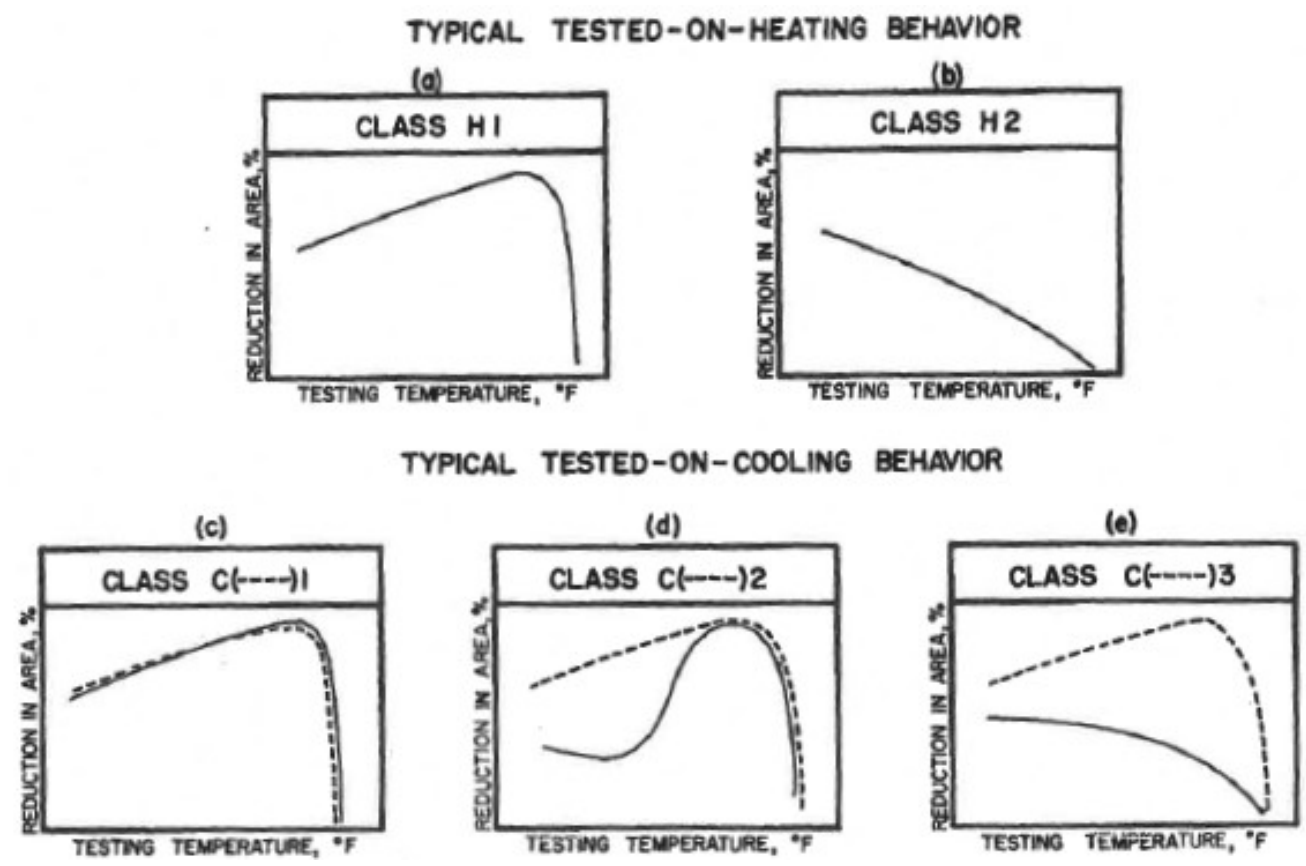

Figure 15. Typical Curve for Hot Ductility Testing. (a) and (b) describes for on-heating. (c), (d), and (e) describes the curve trends for on-cooling. For 316L stainless steel, H1 and $\mathrm{C} 1$ or $\mathrm{C} 2$ should be expected. (Nippes et al.) 
What they find out in the article for $316 \mathrm{~L}$ is that the on-heating shows $\mathrm{H} 1$ behavior but on-cooling behavior is either $\mathrm{C} 1$ or $\mathrm{C} 2$, dependent on the testing temperature. The researchers try to explain these differences in behaviors due to the melting behavior at the grain boundaries by the precipitation and incipient. What they conclude in the paper is that $\mathrm{H} 1$ and $\mathrm{C} 1$ or $\mathrm{C} 2$ behavior should not be susceptible to cracking, but they strongly recommend to conduct more experiment to make certain for this conclusion.

Weiss, Grotke, and Stickle test Inconel 600 on Gleeble with hot ductility test and give an explanation of some behavior of the metal at high temperatures. Figure 16 shows the contributing factors to the behavior in hot ductility testing. The behavior of strength and ductility is simply based on the hardening and softening process in the microstructure. Hardening process includes precipitation, strain, and solid-solution hardening mechanism. In Region I, the ductility decreases as the temperature increases. This could be explained the relationship between recovery in annealing process and hardening mechanism. In this region, the hardening process is more dominate than the softening process. The material fails with lower ductility. In the Region II, the recrystallization starts to occurs at the grain, which is dislocation free and soften the material. The competition of dislocation introduced in the testing and relaxation by the recrystallization can explain the increase in the Region II. In Region III, a sudden drop of ductility is seen. This is due to the liquation at the grain boundary. The liquation is caused by the secondary phase in the microstructure and they occur at the grain boundary. This liquation effect will not let the material deform, but it fractures since local liquid at the grain boundary cannot hold any loads. This mechanism can explain the sudden drop in the Region III. (Weiss et al.) 


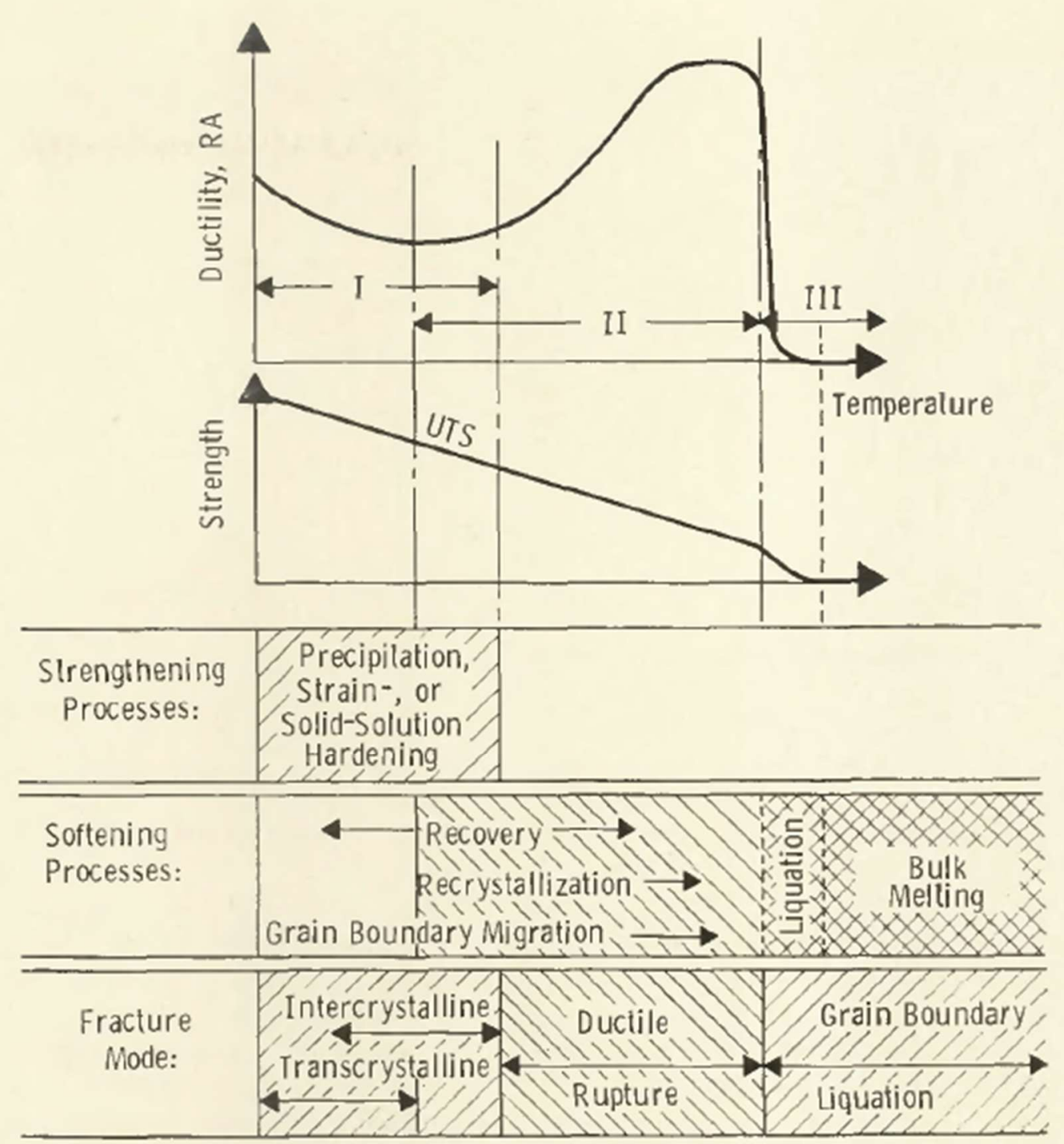

Figure 16. The Contributing Factors in Hot Ductility Testing. The simple competition of hardening process and softening process can control the behavior of the metal at high temperatures. (Weiss et al.)

\subsubsection{Nil Strength Temperature (NST) Test}

In order to complete hot ductility testing, additional testing must be done. Nil strength temperature testing can describe the material's solidus temperature. In this study, a small load $(\sim 20 \mathrm{lb})$ is applied on the material by spring before heating up, and the temperature is heated up with constant rate until the material factures due to liquation at the grain boundaries. Since the material fails at a certain temperature with small loads, this temperature is called nil strength temperature (NST). NST is used in hot ductility testing 
because test samples will melt in the chamber and contaminate it if NST is not known. Also, mechanical properties cannot be measured if the material has zero strength. Therefore, NST testing is mandatory on top of the hot ductility testing especially with the unknown samples.

\subsection{Welding in Additive Manufacturing}

Currently, there is not a number of literature about the welding properties of additively manufactured parts to address the size limitation of the powder bed fusion (PBF) system. Ville-Pekka, Joonas, and Antti investigated on the comparison in weldability of cold rolled 316L stainless steel and additively manufactured 316L stainless steel. In their study, thin sheets of stainless steel with the two manufacturing methods are welded with a fiber laser welding method with different parameters in linear energy inputs. They investigated on the macro-size quality of the weld and the failure analysis such as cracks on the weldments. One of the differences they find in the literature is that the cracks are recognized only in the weldment on the sheet with powder bed fusion (PBF) method. The penetration of the weld is better in the metal sheets with PBF when the energy input is low on the material. They attribute this phenomenon to the surface roughness on the PBF samples due to the residual powder fused on the surface during the printing process. They associate this roughness and the absorption of the energy to explain the penetration of the weld. Finally, they find that the existence of porosity in the weldment when the weldment has a lack of penetration. (Matilainen et al.) Overall, they conclude that the weldability of PBF stainless steel has a "good quality". In their study, any microstructural analyses are not investigated at all to look into the phases present in the material. Also, they do not investigate on the physical behavior of the material at higher temperature to describe the 
material properties at higher temperatures. The qualitative investigation is well done in their study, but the quantitative investigation about the weldability is necessary to generalize the high temperature behavior of the material. 


\section{DESIGN OF EXPERIMENT}

In this study, there are two experiments: nil strength temperature (NST) test and hot ductility test. The NST test is a complementary test to conduct hot ductility test since for hot ductility test requires the peak temperature and NST can tell the peak temperature of the tested materials. The following sections describe the sample preparation and experimental factors based on design of experiment.

\subsection{Sample Specification}

The sample for hot ductility test is a rod that has diameter of $6 \mathrm{~mm}$ and $111.50 \mathrm{~mm}$ length. On both sides of rods has 10mm of M6x1.00 thread. The Figure 17 shows the 3D image of the sample on solidworks. The threads on rods were printed on SLM, and then, they were manually tapped to clear up the threads. The engineering drawing is attached at the appendix. The samples do not go through any of post processing such as sand blasting because the as-printed samples are intended in this study.

Figure 17. The 3D Model of Gleeble Sample for Hot Ductility Test. The M6x1.00 threads are printed without adding any support structure. 
The sample geometry for nil strength temperature (NST) testing is similar with the ones in hot ductility testing without threads. The rod has $6 \mathrm{~mm}$ diameter and $63.5 \mathrm{~mm}$ length. Since NST testing focuses on the temperature where the sample fails, the length of sample is not important. Thus, the length of the sample is much shorter than the one in hot ductility test. The threads are not needed for this sample because only small load is applied on the sample during the test. The engineering drawing is attached in the appendix as well. As is the case with the hot ductility testing, the post processing on NST samples are not performed.

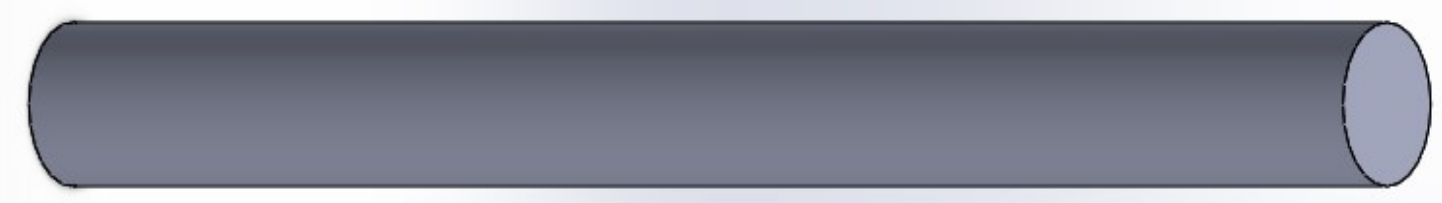

Figure 18. The 3D Model of Gleeble Sample for NST Test. Since the length in the sample is not important, it is shorter than the one for hot ductility testing.

\subsection{Experimental factors}

The factors in this experiment can be categorized as Gleeble factors or SLM factors. Even though Gleeble has an ability to change the total strain and strain rate of tensile test, they are held at a constant value in this study because the tensile test is conducted until the material factures. The only factor Gleeble controls in this study is the temperature of testing. This factor is considered to be blocks because the temperature should change the mechanical properties but this study does not intend to prove the effect on mechanical properties due to the temperature. This blocking factor has 6 levels: $900^{\circ} \mathrm{C}, 1000^{\circ} \mathrm{C}$, $1100^{\circ} \mathrm{C}, 1200^{\circ} \mathrm{C}, 1300^{\circ} \mathrm{C}$, and $1350^{\circ} \mathrm{C}$. The last two temperatures will be selected based 
on the result of NST testing because NST can determine the maximum temperature before the materials melts. This temperature range is selected to cover the thermal mechanical behavior for wide temperature range.

There are two experimental factors on SLM process parameters. One of the factors is the print laser pattern: stripe and checker board. The stripe laser pattern is a way for the laser to scan the layer from one end to the other end. This laser pattern can create a uniform laser weld bead pattern in each layer. However, the heat dissipation is not considered to be good since the heat gradient is severe on this laser pattern. The checker board pattern is a way for the laser to scan small square sections on the layer. The laser is applied every other section to scan small squares, so the heat dissipation is considered to be better in this laser pattern. This pattern takes slightly longer time to fabricate compared with stripe laser pattern. This difference in heat transfer based on the laser pattern is the reason why the laser pattern is one of the factors in this study. It is expected that the stripe pattern should have much higher residual stress. This could lead to different mechanical properties in higher temperature environment. The size of checker board was defined to be $1 \mathrm{~mm}$ on Magics software. For stripe, the laser was overlapped by 1.0050. These settings are the default settings for the machine. The other factor controlled in this study is the direction of the print. For the naming scheme, Z-direction represents the print where the rods are printed vertically against the buildplate shown in Figure 19 (a). XY-direction represents the print where the rods are built horizontally on the buildplate shown Figure 19 (b). In general, Zdirection rod samples do no experience part warpage since the cross sectional area of part is much smaller in fabrication. XY-direction samples tend to see some warpage and it is difficult to fabricate a straight rod. The XY-direction samples are also considered to be a 
little bit stronger in mechanical properties because the weld beads are continuous in the longitudinal direction, which makes like a collection of weld beads in the rod. This difference in mechanical properties due to the structure difference is the reason why it is the factor in this study.

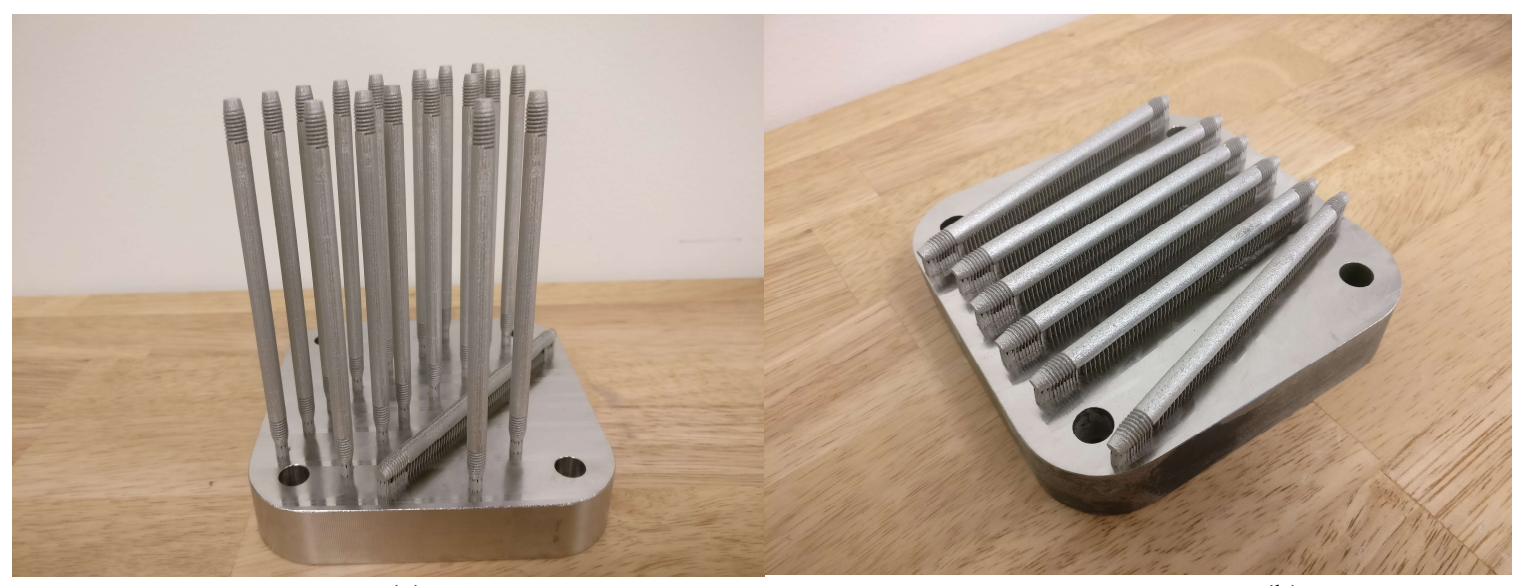

(a)

(b)

Figure 19. (a) Z-Direction Samples and (b) XY-Direction Samples. Z-direction samples are built vertically on the build plate, whereas XY-direction samples are built horizontally on the build plate.

With all the blocking factors and experimental factors, the replicates in this study is determined to be two samples because having replicates allows to conduct the analysis of variance (ANOVA) with error terms and due to the time conflict. This design of experiment is a multi-factor $2^{2}$ full factorial experiment with blocking factors.

\subsection{Test Matrix}

The entire number of samples for each type of hot ductility test are simply calculated by the multiplication of experimental factors, block factors, and sample size. Since there are four treatments and the sample size is two in order to increase the reliability in the test result, the total number of observation is 96 . The test matrix for hot ductility test is shown in the Table II. A similar calculation is applied to Nil Strength Temperature test. However, in NST test, different temperature is not examined, so the total number of observation is 8 . The test matrix for NST test is shown in Table III. 
Table 2: Test Matrix of Hot Ductility Testing at One Temperature Direction

\begin{tabular}{|c|c|c|c|c|c|c|c|}
\hline \multirow{2}{*}{\multicolumn{2}{|c|}{ On-Heating }} & \multicolumn{2}{|c|}{ Direction } & \multirow{2}{*}{\multicolumn{2}{|c|}{ On-Cooling }} & \multicolumn{2}{|c|}{ Direction } \\
\hline & & XY & Z & & & XY & Z \\
\hline Laser & Checker & 2 & 2 & Laser & Checker & 2 & 2 \\
\hline Pattern & Stripe & 2 & 2 & Pattern & Stripe & 2 & 2 \\
\hline
\end{tabular}

Table 3: Test Matrix of Nil Strength Temperature Testing

\begin{tabular}{|c|c|c|c|}
\cline { 3 - 4 } \multicolumn{1}{c|}{} & \multicolumn{2}{c|}{ Direction } \\
\hline Laser & Checker & 4 & Z \\
\hline Pattern & Stripe & 4 & 4 \\
\hline
\end{tabular}

\subsection{Pre-Experimental Study}

Before printing the samples, an optimization study was conducted to find the best setting for laser setting and dimensional accuracy. In this optimization study, several matrices of simple cubes with different linear energy density were built to determine the density. The linear energy density equation is shown in the following (Pohl):

$$
\mathrm{E}_{A}=\frac{P}{S * D} \quad \cdots E q(1)
$$

$\mathrm{P}$ stands for laser power in $\mathrm{J} / \mathrm{s}$. S stands for the laser scan speed in $\mathrm{mm} / \mathrm{s}$, and $\mathrm{D}$ stands for the distance between the laser path called hatch distance. Since the linear energy density input is the interest to optimize the laser setting of the system, the unit for the energy density input is $\mathrm{J} / \mathrm{mm}$.

This equation describes that the linear energy density input is dependent on laser power, laser scan speed, and the hatching distance. This equation can associate the energy input to the powder bed to the density because the higher energy input to powder bed should melt the powder certainly and the higher density should be achieved. In this study, the hatch distance was held to be constant to make this experiment simple. The first build was a matrix of cubes with the laser power ranging from $100 \mathrm{~W}$ to $300 \mathrm{~W}$ with $50 \mathrm{~W}$ increment 
and the scanning speed ranging from $400 \mathrm{~mm} / \mathrm{s}$ to $1200 \mathrm{~mm} / \mathrm{s}$ with $200 \mathrm{~mm} / \mathrm{s}$ increment. The center of the matrix was the original setting the machine was assigned when the machine was installed. The following image (Figure 20) shows the result of the print. It is seen that the visual part quality gets worse as the laser power increases by showing discoloration on the surface and deformation of the cubes.

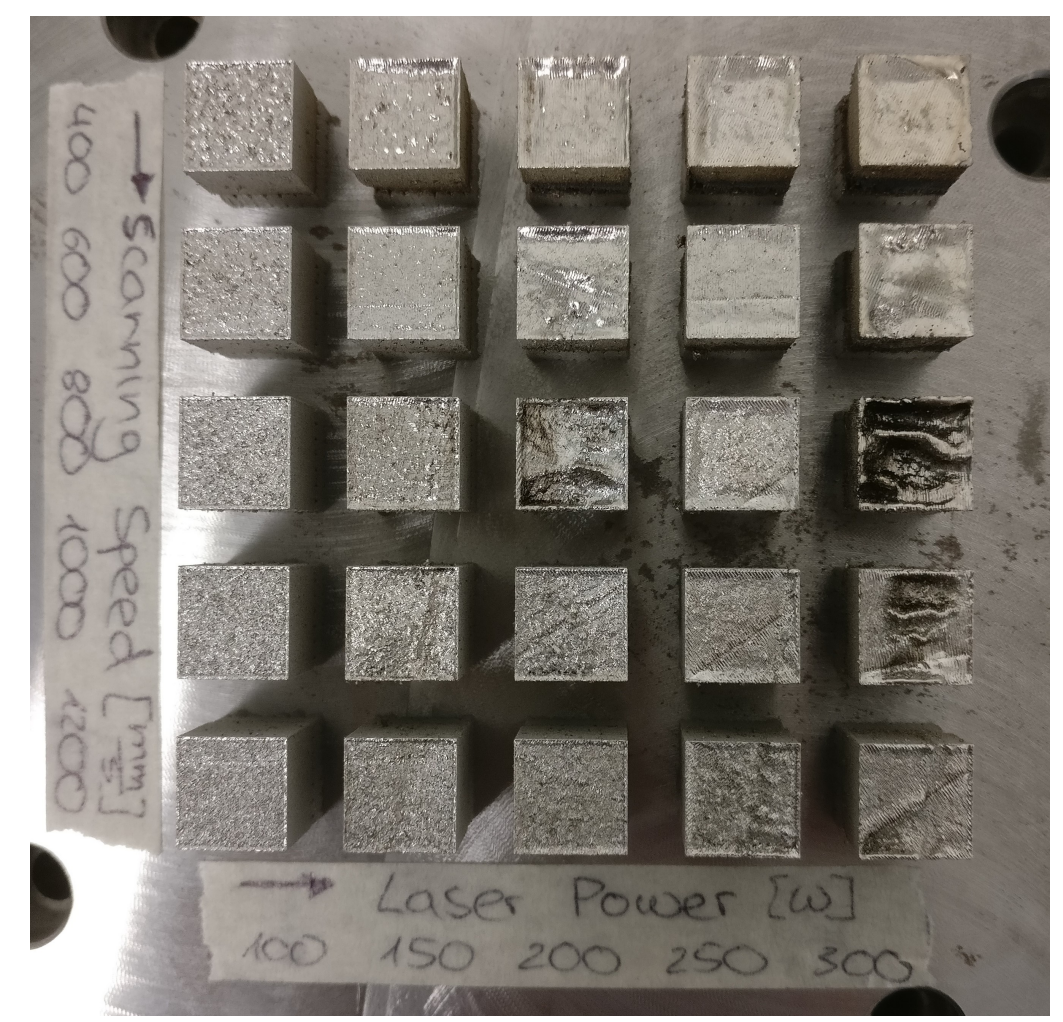

Figure 20. First Iteration of Density Cube Experiment. The quality of cube gets worse as the power of cube increases. (Pohl)

For the second iteration, a matrix of cubes with the laser power ranging from $50 \mathrm{~W}$ to $200 \mathrm{~W}$ with $50 \mathrm{~W}$ increment and the scanning speed ranging from $600 \mathrm{~mm} / \mathrm{s}$ to $1200 \mathrm{~mm} / \mathrm{s}$ with $200 \mathrm{~mm} / \mathrm{s}$ increment was built. The Figure 21 shows the result from the second iteration. 


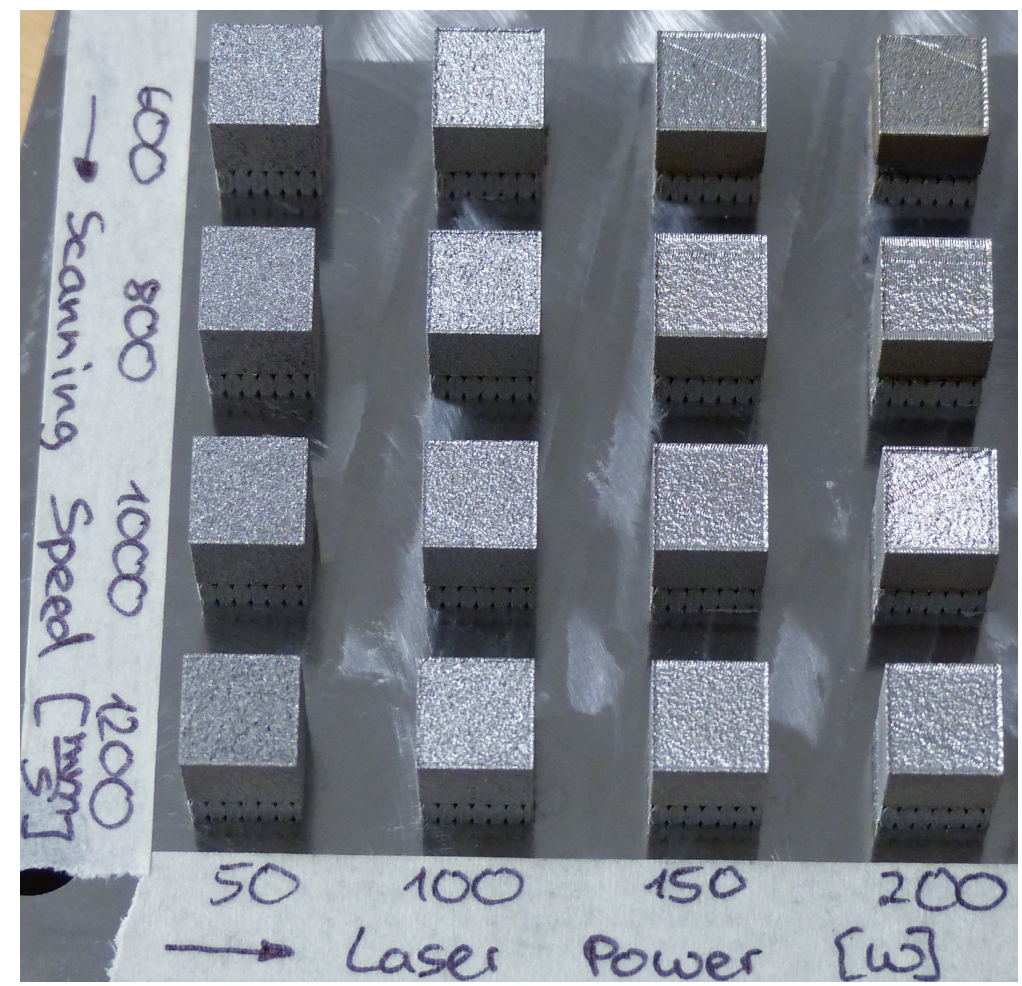

Figure 21. The Second Iteration of Density Cube Print. The visual print quality improved greatly by choosing the appropriate process windows. (Pohl)

The volumes of cubes were measured by Archimedes' method and the mass was measured with a scale. The result of relation between density and linear energy density is shown in Figure 22. The first portion of graph shows linearity of density and linear energy density input, which was expected from the equation (1). However, at some point, the density decreases as the energy density input increases. This is due to the defects such as warpage and burning in cubes from the high energy input. From this preliminary experiment to optimize the laser setting, the best energy density input was determined to be $0.13 \mathrm{~J} / \mathrm{mm}$ and the corresponding laser power and laser scan speed were determined to be $150 \mathrm{~W}$ and $1000 \mathrm{~mm} / \mathrm{s}$. 


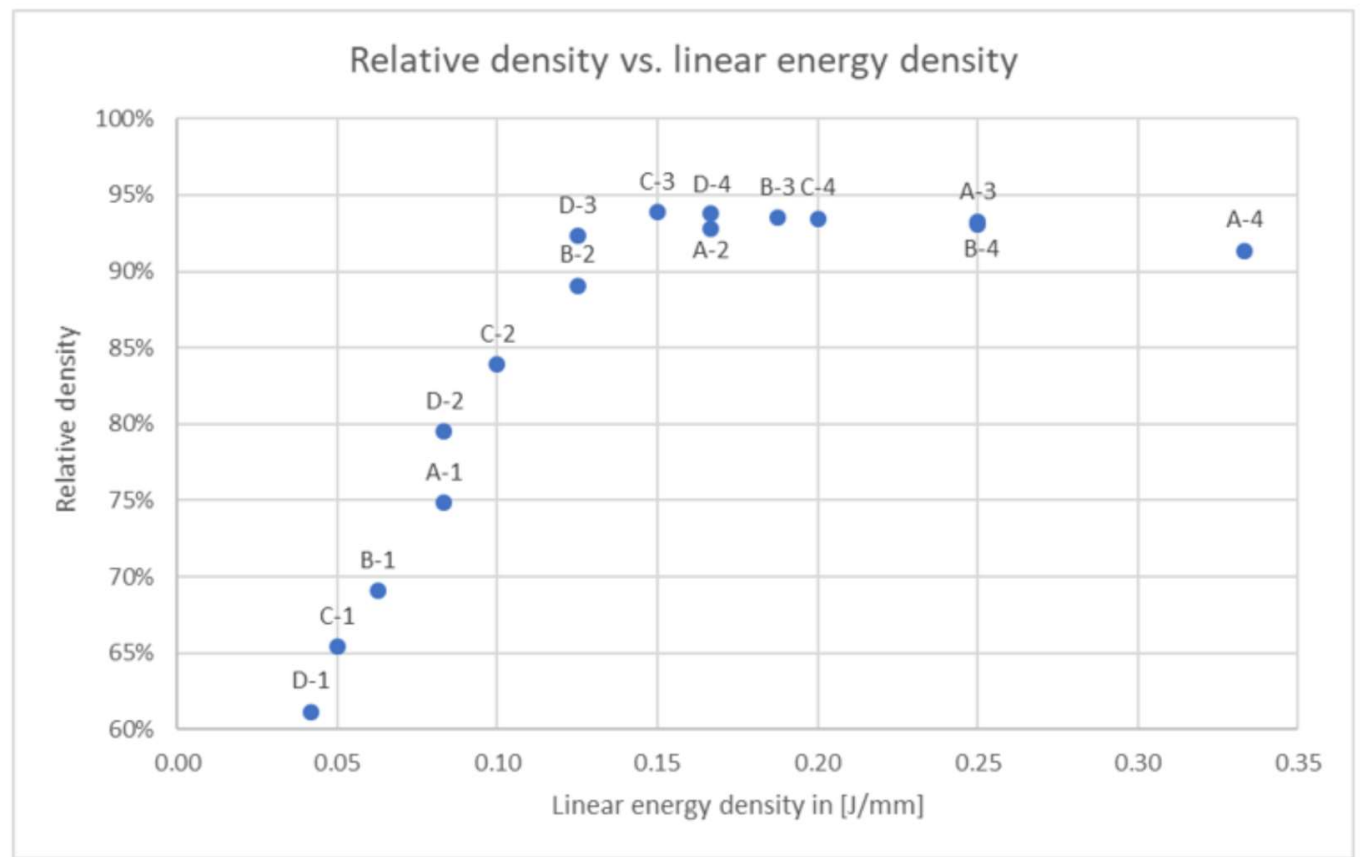

Figure 22. Relative Density vs Linear Energy Density Applied on the Powder Bed. The first portion of the curve shows linear relationship between the two. (Pohl)

\subsection{Sample Preparation}

With the optimized setting of energy input to the powder bed, the samples are built differently according to the treatment of the study. The threads of all samples are cleaned up by tapping process with M6x1.00 die because the as-built threads are rough enough not to fix the samples on Gleeble machine.

Since the cross section of rods in XY-direction is relative larger, the residual stress can warp the part. This is a problem because the warped samples cannot be loaded on Gleeble. In order to print XY-direction of rods straightly, the 3D model is needed to modified for compensation to obtain a straight rod so that samples can be loaded to the machine. To study the amount of warpage on the rod, a simple straight rod with the same geometry was printed first. As the sample was cut from the build plate by band saw, the warpage was seen. 
To evaluate the amount of warpage, the angle of warpage was inspected with a coordinate measurement machine (CMM). The Figure 23 shows two rods; one in $\mathrm{Z}$ direction print and the other one in $\mathrm{XY}$ direction. It is obvious to observe the curvature in the sample.

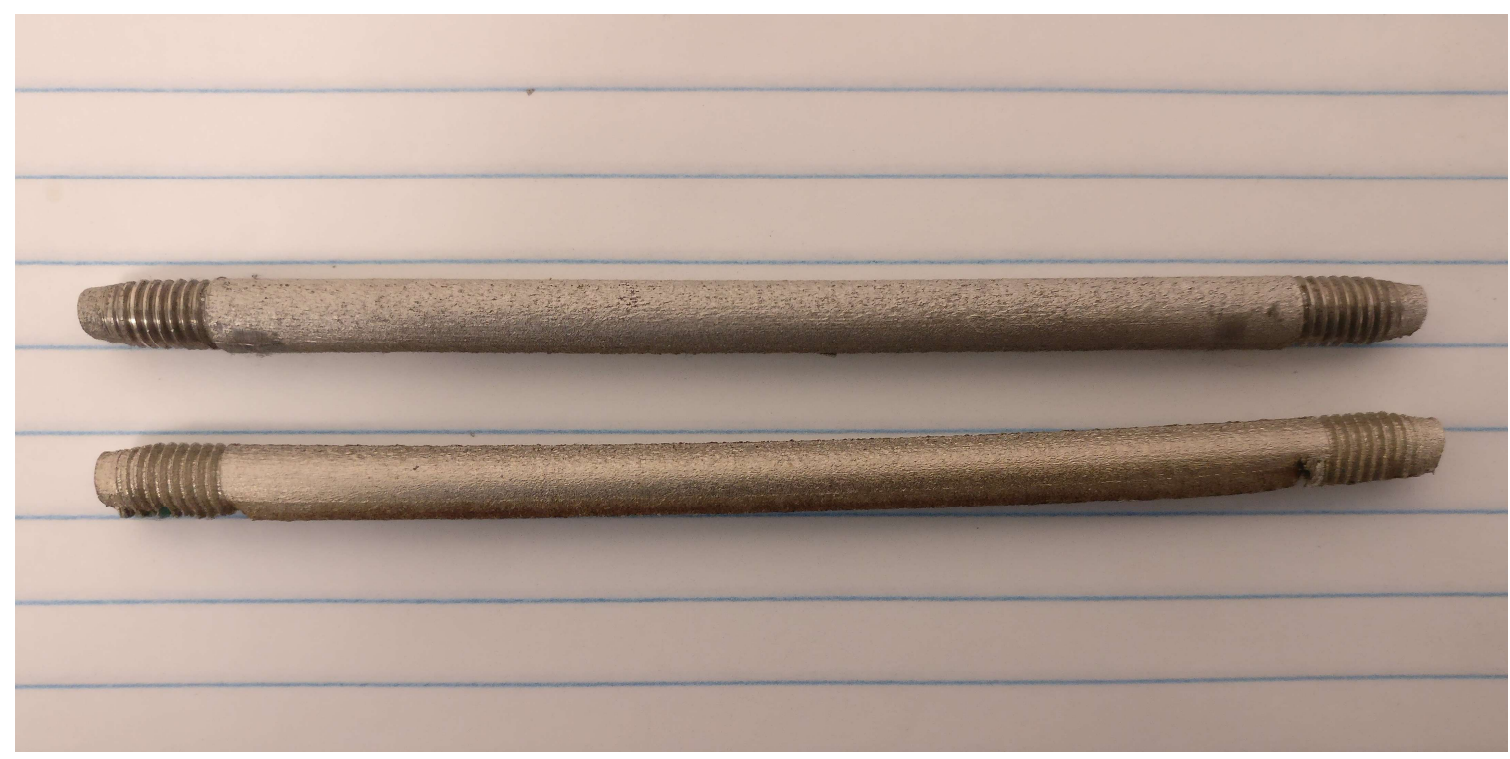

Figure 23. The Image Shows the Amount of Warpage from Different Orientation of Print. The top rod is built in Z-direction (along the rod) and the bottom rod is built in XY-direction (across the rod).

With CMM inspection, it is determined that the angle for the warpage is 3 degrees. This is simply calculated by taking the tangent of deviation from the bottom. For this calculation, it is assumed that the part gets warped from the center and the amount of deviation is linearly proportional to the distance from the center. This assumption will form a small triangle from the middle of the triangle shown in Figure 25. Therefore, the angle is simply calculated by the inverse tangent of deviation and the half length of the rod. 


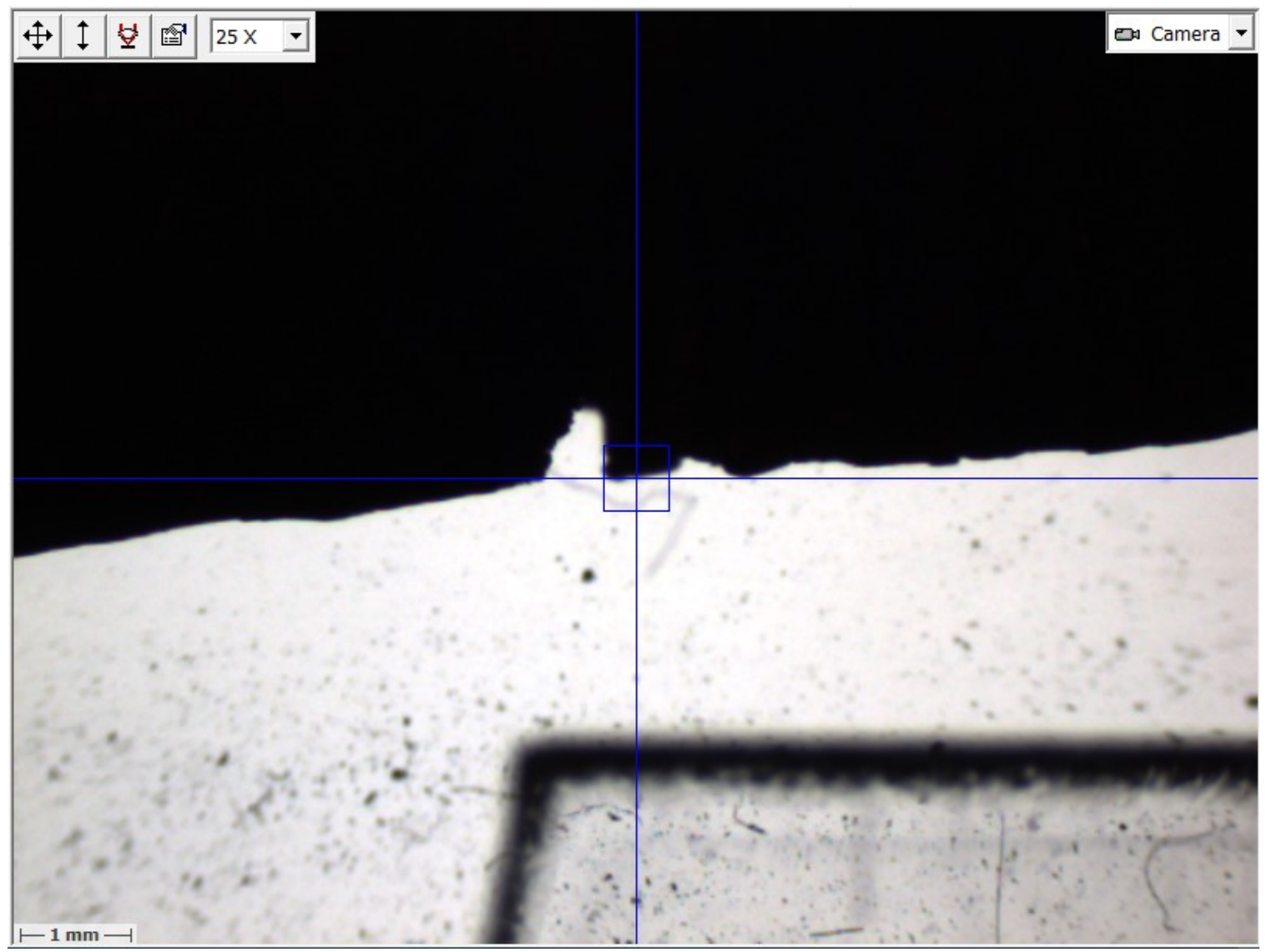

Figure 24. The Measurement Window for the Warpage Analysis. The cursor is focused on the warped point before the thread parts on the sample.

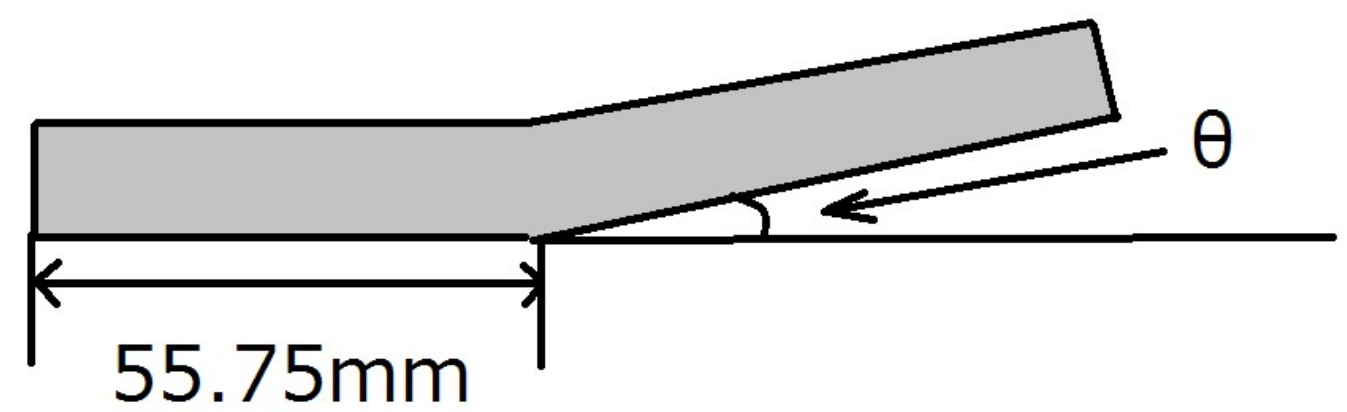

Figure 25. The Assumption in the Warpage Analysis. The warpage is small enough and the amount of warpage is assumed to be linear from the middle of the entire rod. The angle is calculated from the inverse tangent function.

The compensated 3D model from the angle analysis is generated and it is loaded on the build plate so that the direction of warpage is directed downward. The samples are printed with the same parameters as other samples. The XY-direction samples turned to be 
straight due to the residual stress when they are off the build plate. The Figure 26 shows the original geometry and compensated parts.

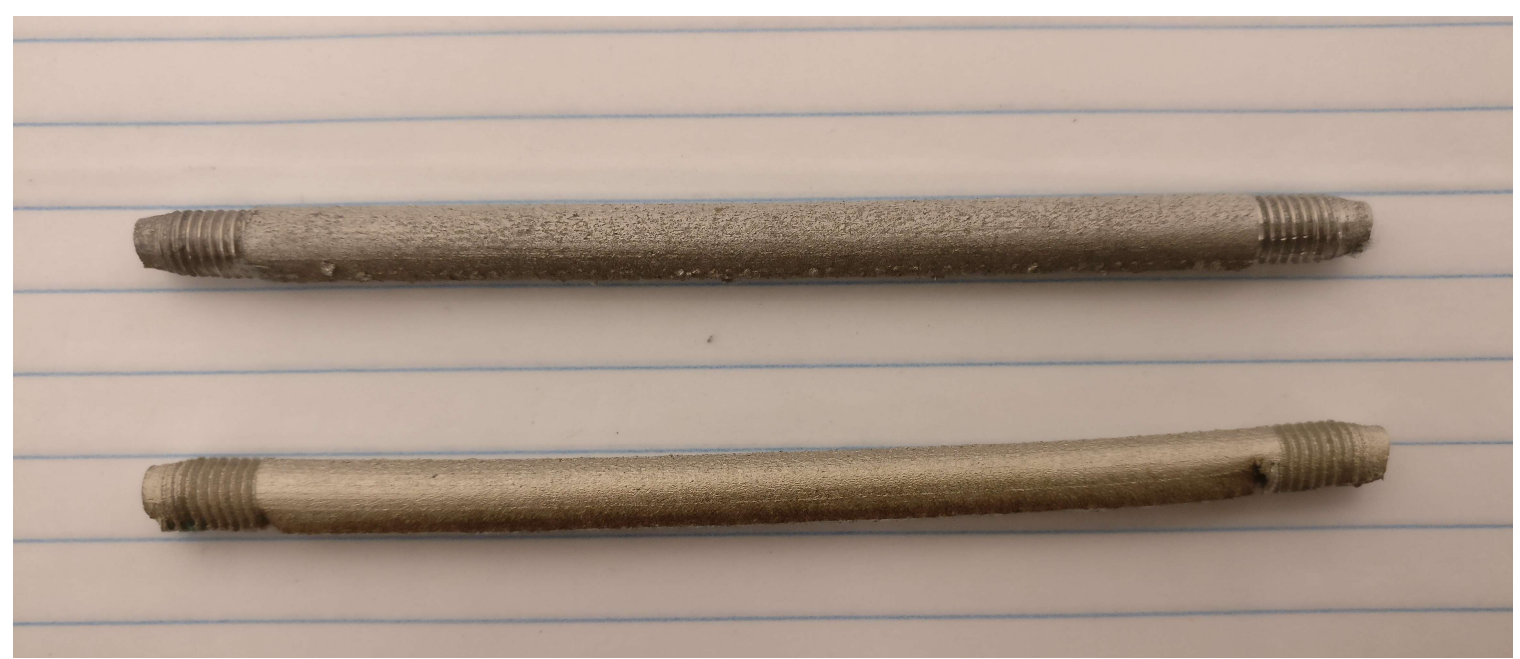

Figure 26. The Comparison of the Amount of Warpage in the Rod. The top rod shows sample printed with warp compensated geometry and the bottom shows sample without warp compensated.

\subsection{Test Profile}

The temperature profile for both On-Heating and On-Cooling test is shown in Figure 27. The On-Heating temperature profile is fairly simple. The sample is heated up to the target temperature with $100^{\circ} \mathrm{C}$ per second, and the sample is held at the target temperature for a second to stabilize the controlled temperature. Finally, the test sample is pulled with $5 \mathrm{~cm}$ per second to failure. The data is collected at a rate of $50 \mathrm{~Hz}$ during heating up the sample to the target temperature. When the temperature is held at the target and tensile testing is conducted, the data is collected at a rate of $1000 \mathrm{~Hz}$.

The test profile of On-Cooling is slightly different form the one of On-Heating. The sample is initially heated up to $1200^{\circ} \mathrm{C}$ with $100^{\circ} \mathrm{C}$ per second, and then, the sample is heated up to $1350^{\circ} \mathrm{C}$ with $37.5^{\circ} \mathrm{C}$ per second. The sample is heated up to the peak temperature from $1350^{\circ} \mathrm{C}$ with only 0.50 seconds and the sample is held there for 0.25 seconds. The peak temperature is determined from the nil strength temperature testing of 
samples. The frequency of data acquisition is the same as On-Heating; $50 \mathrm{~Hz}$ rate data collection upon heating and $1000 \mathrm{~Hz}$ data collection during the tensile testing. This temperature profile can simulate the heat cycle which is the similar with the welding thermal cycles. Finally, the temperature is brought down to the target temperature with $90^{\circ} \mathrm{C}$ per second and the mechanical testing is conducted after the temperature is held at the target temperature. One of the reasons why the duration of peak temperature is because the liquation happens at the temperature and small load can fracture the sample. However, the short time at the peak temperature is to physically simulate the thermal cycle that can be seen in the welding.

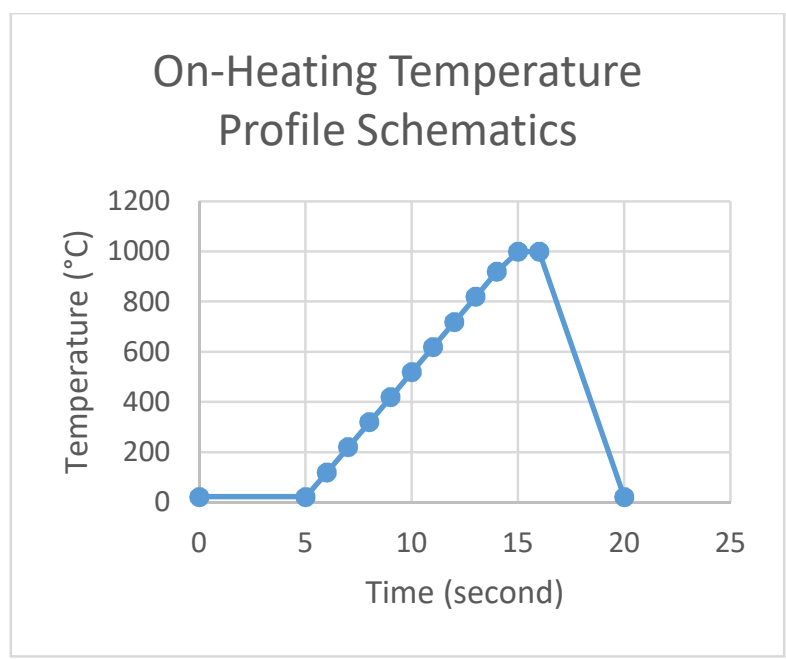

(a)

\section{On-Cooling Temperature Profile Schematics}

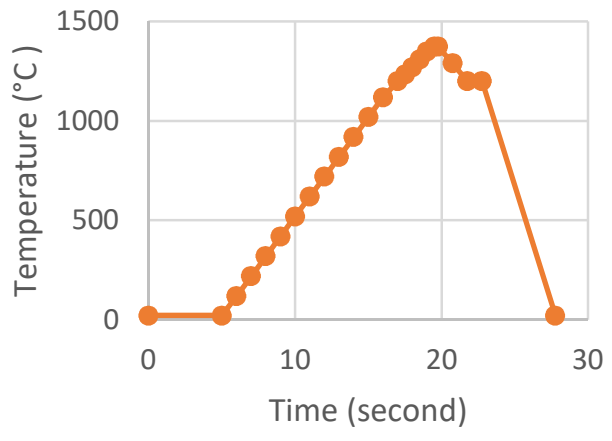

(b)

Figure 27. The Temperature Profile Used in (a) On-Heating Test at $1000^{\circ} \mathrm{C}$ and (b) On-Cooling Test at $1200^{\circ} \mathrm{C}$. The On-Cooling is designed so that the thermal cycle by welding process can be simulated physically.

After the test is done, the temperature of the sample is brought down to the room temperature with the cooling system in Gleeble. This takes about 5 seconds to achieve to the room temperature. 


\section{RESULT AND DISCISSION}

The data for each experiment is successfully collected. However, the data point in the hot ductility test is only one rather than two to increase the reliability of the response. This is due to the time conflict and the limitation in the access to the Gleeble machine. The data points in NST is done according to the design of experiment except for one of the treatments. The followings show the result and statistical analysis of those data and discuss the possible explanation of the results obtained from this study.

\subsection{Nil Strength Temperature (NST) Test}

Two data points of NST for each combination of orientation and laser pattern are planned to be collected for the statistical analysis, but due to machine error during experimentation, one of the samples needed to be aborted. Therefore, the data set in this experiment is not balanced.

\subsubsection{Statistical Analysis}

The multi-factor ANOVA test is conducted to see the effects on response from factors which are orientation of the print and the laser pattern (Figure 28).

$\begin{array}{lrrrrr}\text { Analysis of Variance } & & & & & \\ & \text { DF } & \text { Adj SS } & \text { Adj MS } & \text { F-Value } & \text { P-Value } \\ \text { Source } & 1 & 331.78 & 331.78 & 7.47 & 0.072 \\ \quad \text { orientation } & 1 & 51.98 & 51.98 & 1.17 & 0.359 \\ \quad \text { laser pattern } & 1 & 43.26 & 43.26 & 0.97 & 0.397 \\ \quad \text { orientation*laser pattern } & 3 & 133.30 & 44.43 & & \\ \text { Error } & 6 & 663.58 & & & \\ \text { Total } & & & \end{array}$

Figure 28. The ANOVA Table from the NST Test. The p-value shows some indication that the orientation has a statistical significance on the NST since the p-value is closer to 0.05 .

It is seen that the p-value from orientation is close to 0.05 which is the significant level used in this study. However, the p-value for laser pattern and the interaction terms are larger than 0.05 . This can tell that the effect from the orientation of build could be 
statistically significant on the nil strength temperature and the interaction and laser pattern are not statistically significant on the NST. Since the interaction and the laser pattern turned out to be insignificant and there is an indication where orientation of the build is significant, those insignificant terms are put into error terms and only orientation of the build is analyzed by the One-Way ANOVA. Figure 29 shows the ANOVA table of the result. As is expected, the p-value is less than 0.05 and therefore it can be concluded that the orientation is statistically significant. However, the data points should be collected more to verify the same result from the multi-factor ANOVA analysis.

$\begin{array}{lrrrrr}\text { Analysis of Variance } & & & \\ \text { Source } & \text { DF } & \text { Adj SS } & \text { Adj MS } & \text { F-Value } & \text { P-Value } \\ \text { orientation } & 1 & 450.8 & 450.82 & 10.59 & 0.023 \\ \text { Error } & 5 & 212.8 & 42.55 & & \\ \text { Total } & 6 & 663.6 & & & \end{array}$

Figure 29. The One-Way ANOVA Table from the NST Test. The p-value of orientation shows a statistical significance on the NST since the p-value is less to 0.05 .

The main effect plot of orientation is shown in Figure 30 (a), and the residual plots for this analysis is shown in Figure 30 (b) to show the validity of the analysis. Since the residual plots follows the normal distribution, equal variance, and randomness in order, this analysis should be valid. From the statistical analysis, it is found that the NST for XYdirection build is $1400.8^{\circ} \mathrm{C}$ and the NST for Z-direction build is $1384.6^{\circ} \mathrm{C}$. Therefore, NST in Z-direction is lower than that of XY-direction by $15^{\circ} \mathrm{C}$. 


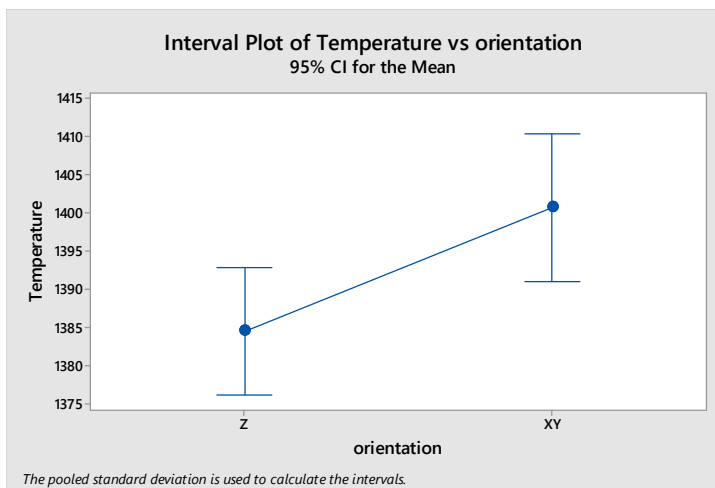

(a)

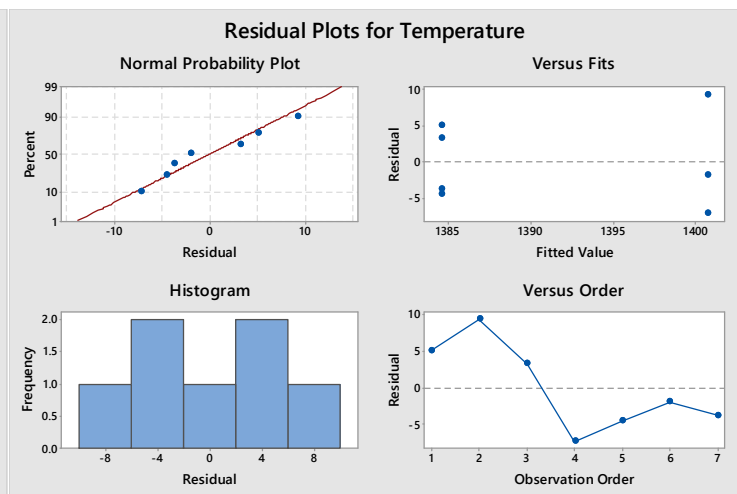

(b)

Figure 30. (a) The Interval Plot and (b) Residual Plots to Show the Validity of the Statistical Study. The XY-direction shows higher NST and the residuals plot show normality, equal variance, and randomness.

\subsubsection{Discussion}

By definition, the failure of sample in NST test is due to the liquation effect at the grain boundaries, where secondary phases can mostly form because of the austenitic solidification mode. The lower NST in Z-direction can be interpreted that Z-direction samples could contain more secondary phases in the samples than the XY-direction samples because the higher content secondary phases in the material has, the higher chance the liquation at the grain boundaries can form by the incipient melting of those secondary phases. The images in Figure 31 show the microstructure of sample from this test. The microstructure is taken so that the sample is pulled in horizontal direction of the Figure. In Figure 31(a), the cracks along grain boundaries are obviously shown in the image. These intergranular cracks should have occurred due to the liquation effect at those grain boundaries. Figure 31 (b) shows the higher magnification of the liquation cracks. 


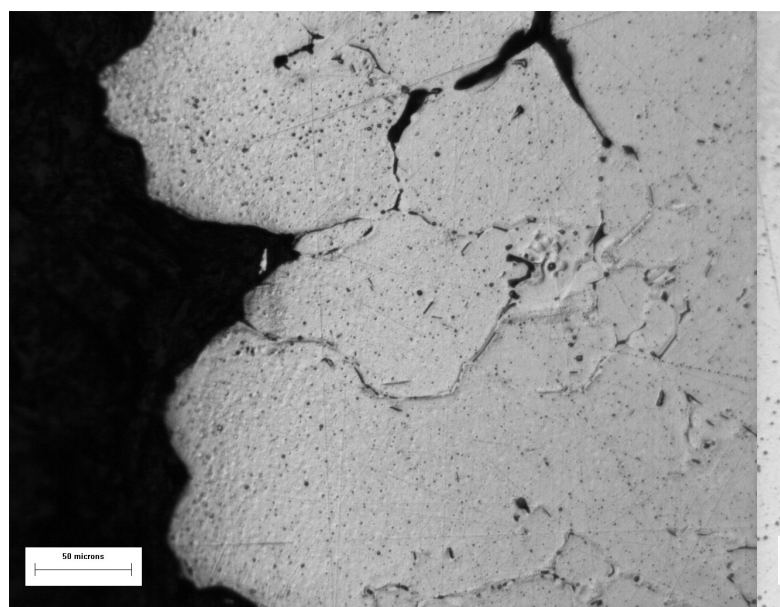

(a)

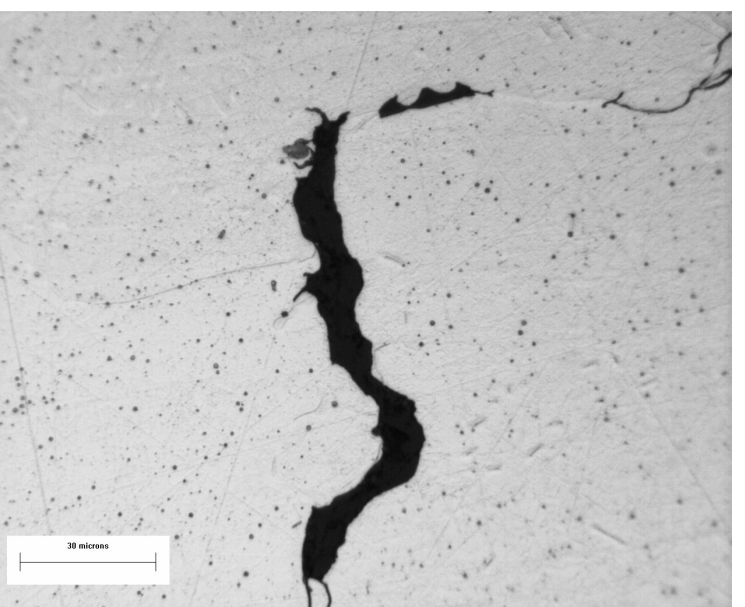

(b)

Figure 31. Cracks in NST Sample Captured by Light Microscopy at (a) 200x and (b) 500x Magnification. The circular grains could be the secondary phases such as sigma phase.

If the liquation of secondary phases at grain boundaries is the primary reason for making this difference in NST, the following argument could be made that there are different amounts of intermetallic phases based on the orientation of the sample. To understand the difference in the amount of secondary phase such as sigma phase based on the orientation of the print, the interlayer temperature should be understood well.

When the laser is applied on the cross section on the Z-direction and XY-direction upon printing the sample rods, the Z-direction samples have much smaller cross sectional area than that of XY-direction samples. Also, the time for the laser to complete scanning each layer will be greater in XY-direction than Z-direction. This longer time to complete scanning the top layer in XY-direction sample lets samples cooled down before recoating the new layer much greater than that of Z-direction sample, and therefore, the temperature of the top layer right before the powder is coated (interlayer temperature) is lower in XYdirection sample. On the other hand, Z-direction samples have smaller cross sectional area, and therefore the laser scanning is done faster and the interlayer temperature is higher in Z-direction. The cross section of both Z-direction and XY-direction samples are shown in 
Figure 32. Roughly the cross sectional area of XY-direction is 23 times greater than the cross section area of Z-direction samples.
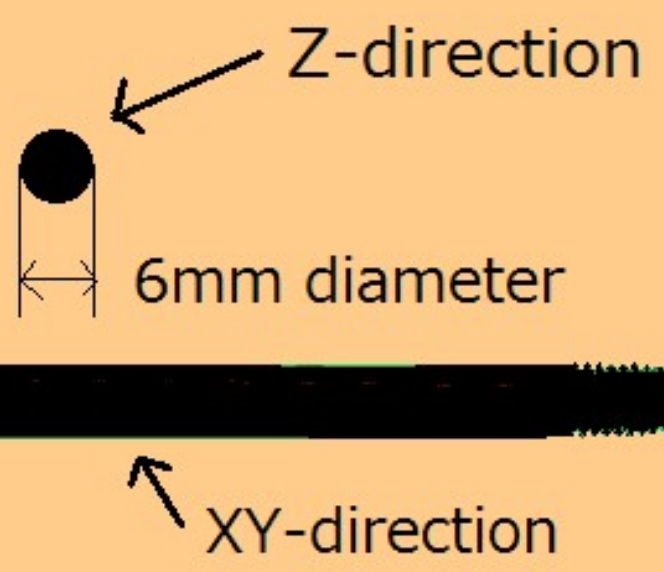

Figure 32. Comparison of Cross Section Between Z-Direction Sample and XY-Direction Sample. The cross sectional area for XY-direction sample is much larger.

When the interlayer temperature is higher, it can have a higher chance of forming the secondary phase in the material. Figure 33 shows the time-temperature-transformation diagram of sigma phase formation in $24 \mathrm{Cr}-14 \mathrm{Ni} \mathrm{L}$ austenitic stainless steel. It is seen that the nose of the $\mathrm{C}$-curve is around $850^{\circ} \mathrm{C}$ and the curve is close to $\mathrm{y}$-axis of the graph which represents 0.1 hour. Compared with the interlayer temperatures in XY- and Z-direction samples, the higher interlayer temperature should have narrower window to form sigma phase. Thus, the sample with higher interlayer temperature should have higher chance of forming the secondary phase at the grain boundaries, and therefore, it can lead to lower the NST in the Z-direction samples because of the liquation of those intermetallic phase. 


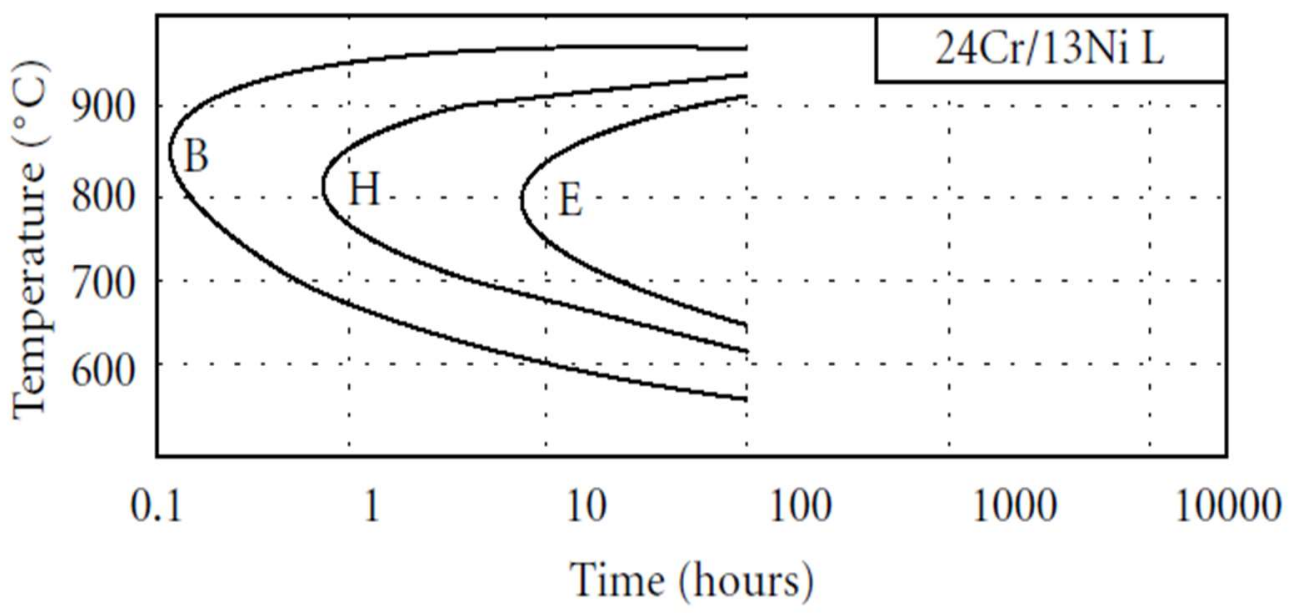

Figure 33. Time-Temperature Transition (TTT) Diagram for Sigma Phase in Austenitic Stainless Steel. $\mathrm{B}$ stands for the begging of formation, $\mathrm{H}$ stands for intermediate stage, and $\mathrm{E}$ stands for the end of precipitation formation. (Folkhard, and Rebensteiner)

\subsubsection{Magne-Gage Measurement}

As one of the approaches to understand the amount of phases present in the SLM samples, magne-gage (Figure 34) is utilized to measure the ferrite number in the sample. The mange-gage is a magnetic measurement equipment where a magnetic contact probe and an attached spring load can measure the resistivity of the separating the probe from the tested samples. Based on the resistivity, the ferrite number is derived from the calibration graph. 


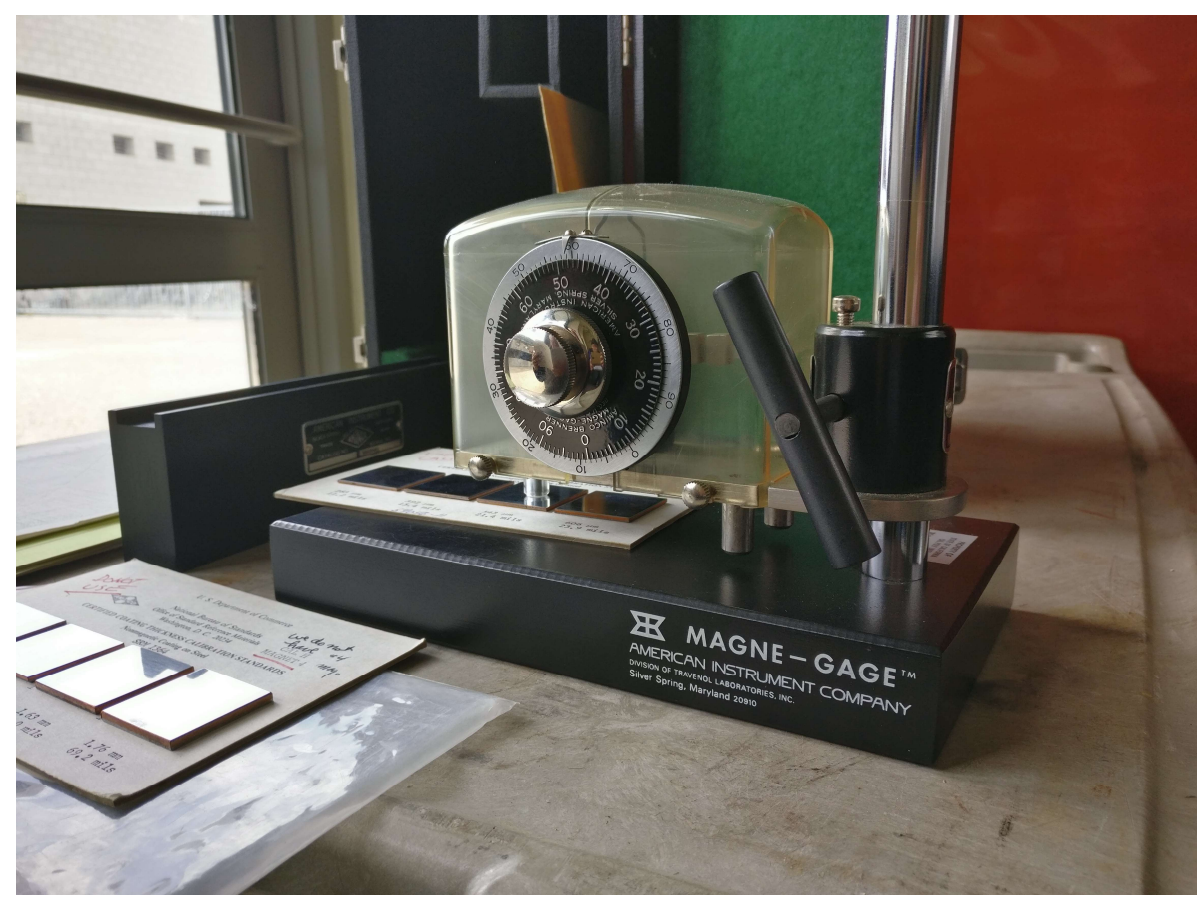

Figure 34. Magne-Gage Used to Find the Ferrite Number of the Test Samples. The balanced force of leaving the magnetic from the sample is used to determine the ferrite number of the material.

The dial number on the gage is the measurement of the amount of magnetic component in the stainless steel. There is a conversion graph to find the corresponding ferrite number. This magnetic measurement can tell the amount of delta ferrite in the stainless steel because delta ferrite has body center cubic (BCC) crystal structure and therefore it is ferromagnetic. Ferrite number $(\mathrm{FN})$ is the number to describe the amount of ferrite contained in the stainless steel. [Source: welding of ss] Ferrite number does not describe the direct percentage of the ferrite contained in the material, and it just describes the relationship between the magnetic attraction and the standard of the ferrite content. [source: predictive] Therefore, to know the ferrite number of the stainless steel, calibrated graph is needed to find out from the measurement (shown in Figure 35). 


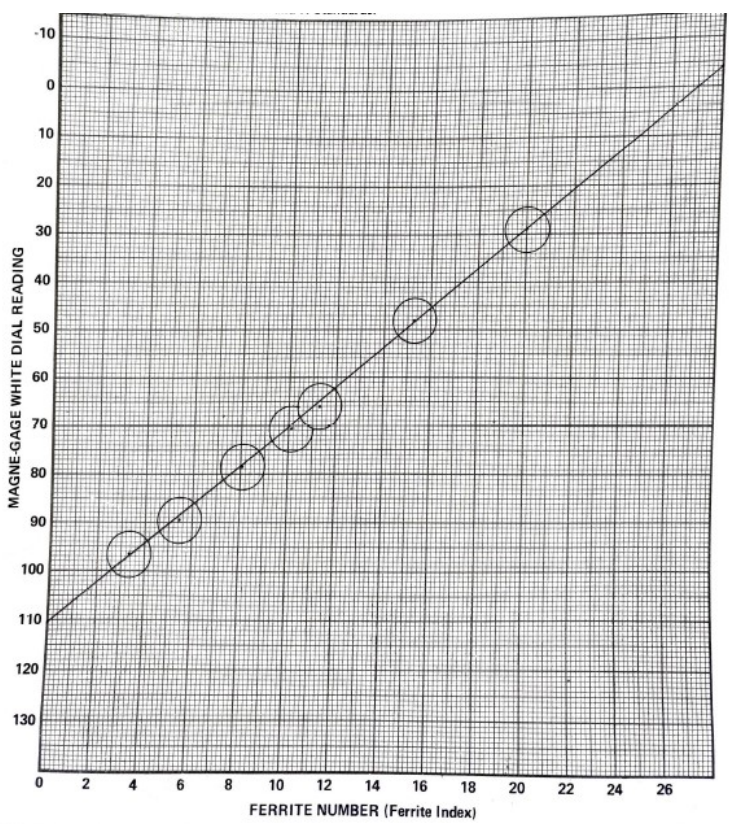

Figure 35. Ferrite Number Chart for the Magne-Gage System Used in This Study. The y-axis is the dial number on the magne-gage and $\mathrm{x}$-axis is the ferrite number.

The results of the magnetic measurement are shown in the following table (Table IV). This measurement is done on the Z-direction samples with stripe laser pattern. As it is seen, most of ferrite number is small and it is concluded that the ferrite numbers in the printed samples are zeros. From this result, there are two hypotheses that can be drawn about the phases present in the samples:

1) The ferrite phases contained in the sample are converted to sigma phase which is not magnetic during the solidification process. Because the magne-gage only detects the amount of magnetic component in the sample, and therefore, the amount of ferrite, it is not possible to tell the amount of sigma phase from the magne-gage measurement.

2) To begin with, almost no ferrite is formed in the process of solidification. This leads that the amount of sigma phase which is converted from the ferrite phase is also small. This hypothesis could be too simplistic. 
This theory could be verified if there is equipment to measure the sigma phase such as orientation imaging function in SEM or microprobe analysis equipment.

Table 4. Dial Reading on Magne-Gage and the Corresponding Ferrite Number

\begin{tabular}{|c|c|c|c|c|}
\hline Sample & $\mathrm{OH}-900^{\circ} \mathrm{C}$ & $\mathrm{OH}-1000^{\circ} \mathrm{C}$ & $\mathrm{OH}-1100^{\circ} \mathrm{C}$ & $\mathrm{OH}-1200^{\circ} \mathrm{C}$ \\
\hline Dial Reading & 109 & 110 & 110 & 115 \\
\hline Ferrite Number & 0.2 & 0 & 0 & 0 \\
\hline
\end{tabular}

\subsubsection{Scanning Electron Microscopy (SEM) Characterization}

Fracture surfaces of NST samples are taken by scanning electron microscopy (SEM). Figure 36 shows the SEM images of both Z-direction sample and XY-direction sample. For both images, "liquidy" surfaces are shown on the surfaces. This is due to the liquation of intermetallic secondary phases at the grain boundaries.

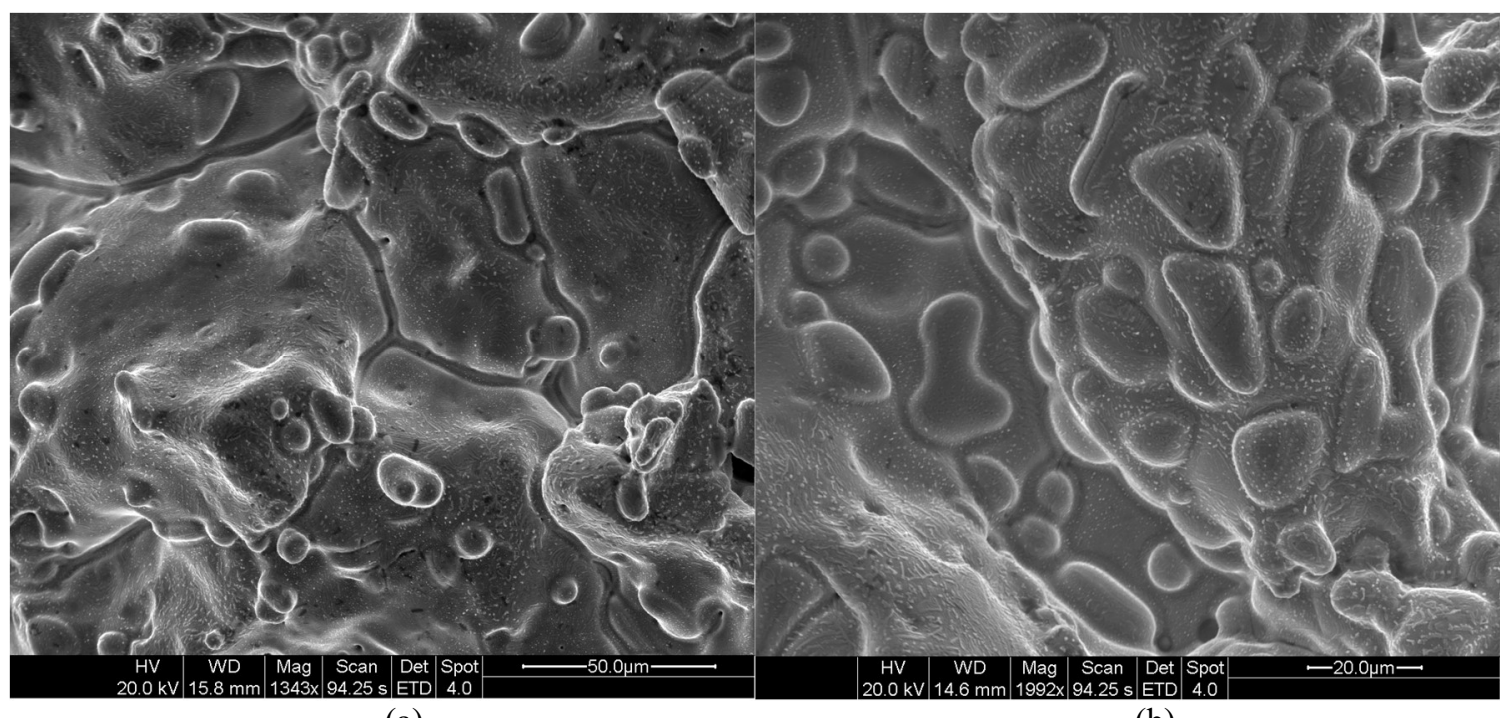

(a)

(b)

Figure 36. SEM Image of (a) Z-Direction at 1343x and (b) XY-Direction at 1992x. Both images show "liquidy" surface due to the liquation.

Because of lack in availability of equipment, it is not possible to find out the small precipitation grains are secondary phase such as sigma phase. However, considering the fully austenitic solidification mode of the $316 \mathrm{~L}$ stainless steel, it is not too far to say that 
those small blobs could be secondary phases because the austenitic solidification pushs the secondary phases to the grain boundaries by the phase segregation. Orientation imaging in SEM should be utilized to characterize those small grains because the preferred orientation of solidification will be found out from the orientation imaging function. This can differentiate the matrix phase or precipitation phase.

\subsection{Hot ductility Test}

The data from hot ductility test are the maximum load measured from the sample at the tensile testing at higher temperatures and the change in cross sectional area of the samples. From the hot ductility testing, two types of graphs could be built: ultimate tensile strength vs temperature, and reduction of area vs temperature. The ultimate tensile strength is calculated by dividing the maximum load in $\mathrm{kN}$ during the testing by the original cross section area. Since the stress calculated from the data is the stress where the material could hold before fracture, the stress should be ultimate tensile stress (UTS) rather than yield stress. The reduction of area is measured directly from the sample. Stereoscopic microscope is utilized to capture the cross section of the fracture surface, and the image processing software called ImageJ is used to measure the area of the fracture surface to find the reduction of area. The reduction of area in the sample can tell the ductility of the material at the tested temperatures. The more the reduction of area in the material, the more ductile the material should be at the tested temperature. The both ultimate tensile strength and reduction of area results are put into one graph, and the graphs for on-heating and oncooling are shown. Figure 37 and Figure 38 shows the graphs for each treatment in the experiment. 


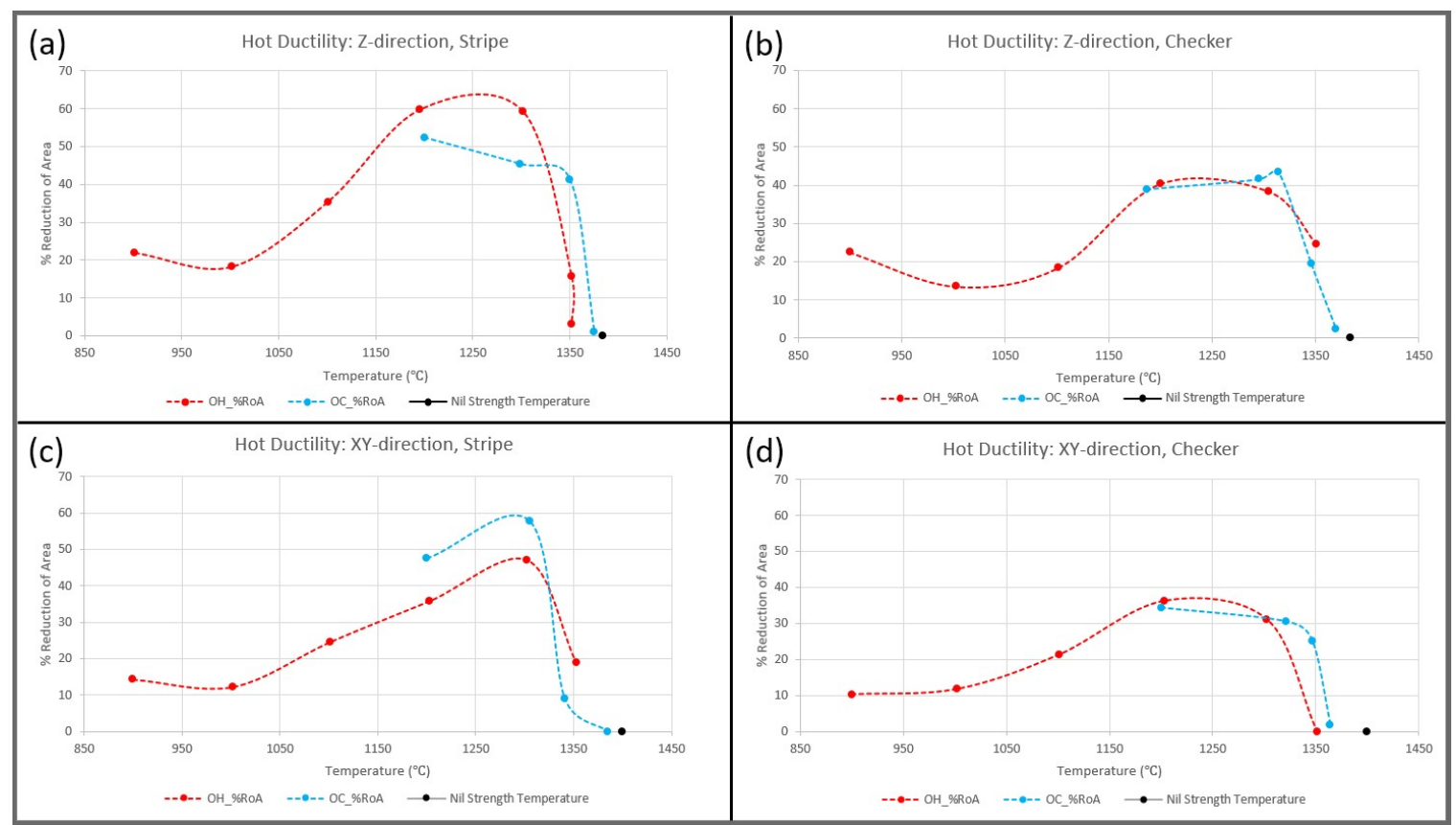

Figure 37. Result Graphs of Ductility from Hot Ductility Test with Different Treatment: (a) Z-direction build, Stripe, (b) Z-direction build, Checker board, (c) XY-direction build, Stripe, and (d) XY-direction build, Checker. Only reduction of area for On-Heating and On-Cooling test are included.

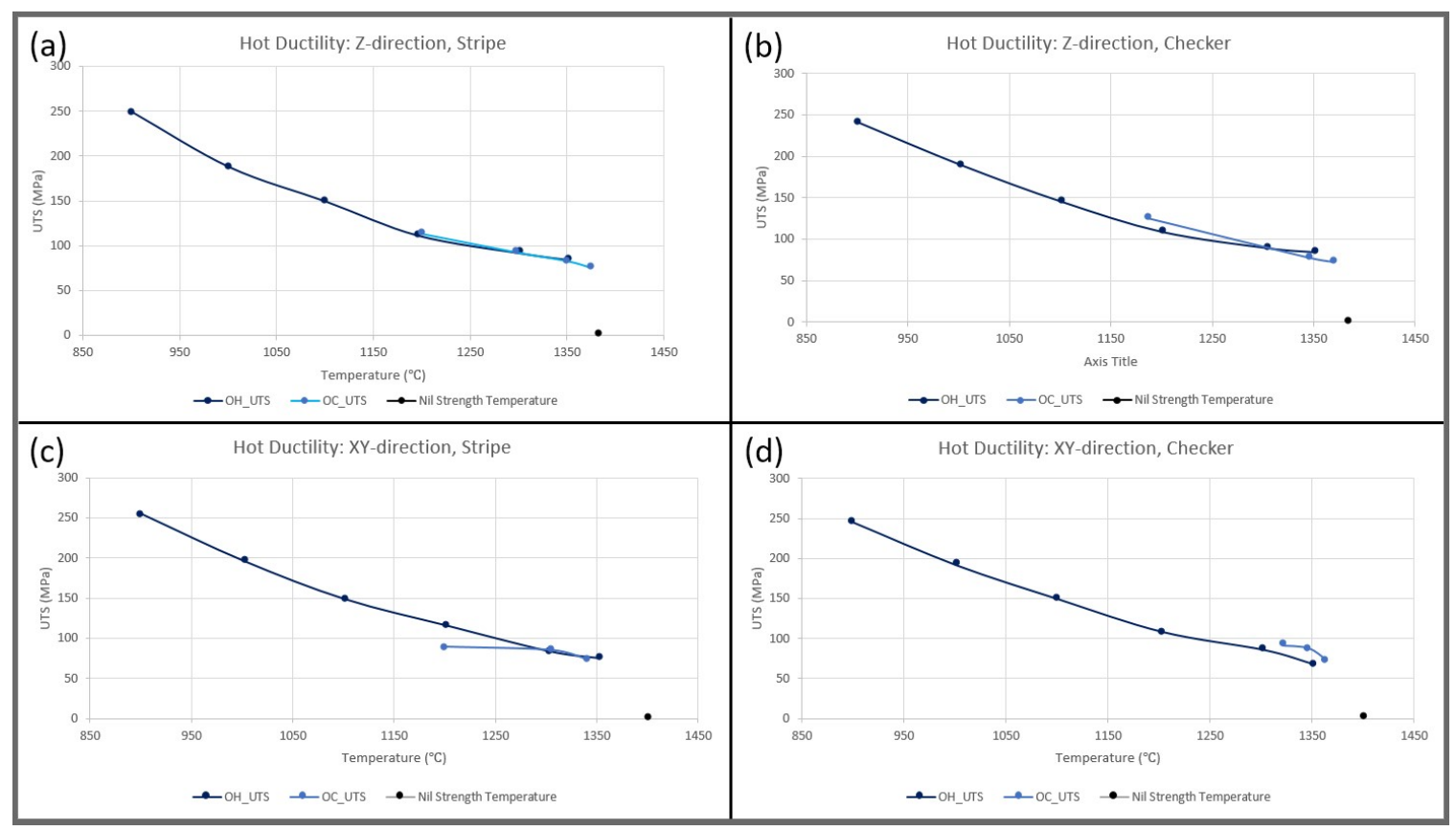

Figure 38. Result Graphs of Strength from Hot Ductility Test with Different Treatment: (a) Z-direction build, Stripe, (b) Z-direction build, Checker board, (c) XY-direction build, Stripe, and (d) XY-direction build, Checker. Only UTS for On-Heating and On-Cooling test are included.

\subsubsection{General Behavior and Discussion}

There are some similarities and differences in the Figure 37 and Figure 38. In general, the shape of reduction of area (RoA) curves and ultimate tensile strength (UTS) 
curves are similar for each treatment. For On-Heating $(\mathrm{OH})$ RoA, there is a decreasing ductility region at lower temperatures. However, the ductility increases as the temperature increases in the middle part. At around nil strength temperature (NST), the ductility suddenly drops to almost zero ductility. The On-Cooling (OC) follows the similar shape as OH RoA curves. It has higher ductility and an abrupt drop in ductility close to NST. The $\mathrm{OH}$ and OC UTS curves are also similar. The strength gradually decreases as the temperature increases. The fact that the $\mathrm{OH}$ and $\mathrm{OC}$ ductility curves are similar shapes is a good news because this shows that the hot cracking during the welding process should not be a major concern for the AM $316 \mathrm{~L}$ stainless steel.

As explained in the literature review, the behavior of ductility and strength in the material can be explained by the dislocation density and relaxation of the dislocation by recrystallization. As the material is pulled in the testing, dislocations are introduced and start to move throughout the material to deform permanently. The more material deforms, the more dislocations are introduced and move in the material, and therefore, the dislocation density in the material should increase exponentially as the material is pulled during tensile test. As the pulling is happening at the high temperature, the annealing can decrease the dislocation density because the tested temperature is high enough for material to go through recrystallization. Also, there is an effect from the dynamic recrystallization which is a recrystallization effect due to both strain and temperature. The competition of dislocation density and annealing should determine the amount of ductility. When the material is ductile, the strength of the material tends to get decreased. In all images in Figure 37 and Figure 38, the collected ductility graph data can also be divided into three regions: Region I, Region II, and Region III. In Region I, the hardening process should be 
the dominant mechanism in the material and the softening process should not be prevalent. Therefore, the ductility is not high before fracture. To associate the obtained graph with the physical evidence in material, microstructural analysis is investigated. Figure 39 shows the microstructure of the sample where the ductility dip is obvious in the graph. The micrograph shows the side view of the rods, and the direction of pulling is the horizontal direction of the image. In the low magnification microstructure (Figure 39 a), some micro cracks are seen. The directions of the cracks are all relatively vertical in the image, which is perpendicular to the direction of the pulling. The right micrograph (Figure $39 \mathrm{~b}$ ) is at the higher magnification. It is interesting to see that the crack in the middle occurs along the boundaries of solidification dendrite colonies. This matches with the theory because the microstructure shows the melt pool structure and cellular dendrites which can be seen in the as-print samples. This means that the material did not go through the annealing process to form new grains. The microstructure on the right in Figure 39 shows the cracks propagating along the cellular dendrite colonies. From the knowledge about solidification of the sample, it is expected to have the intermetallic phases on the edge of the grains. The microstructure may show the evidence. However, from the micrograph, it is not possible to tell which secondary phases they are, but the dark color in the microstructure indicate that they are some types of secondary phases such as sigma phase or $\delta$ ferrite. It was only this testing temperature where the cracks are continuous and visible. 


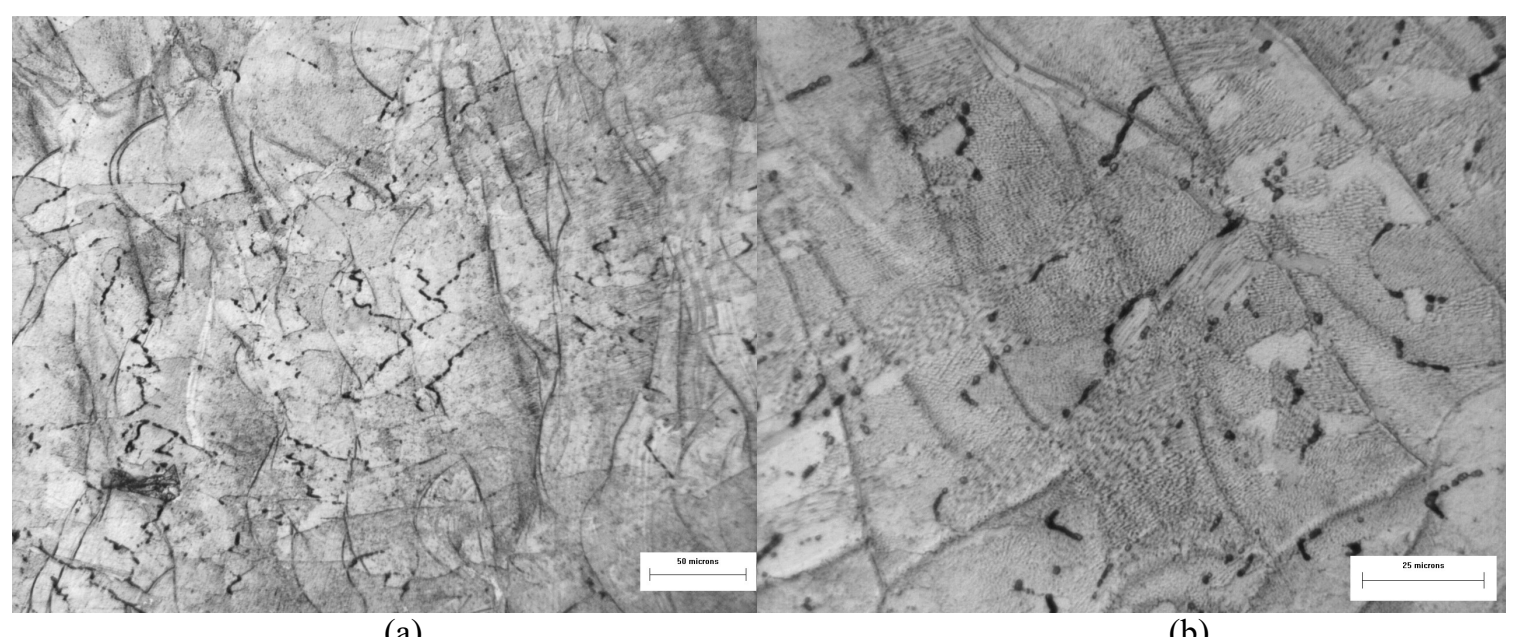

(a)

(b)

Figure 39. Micrograph of On-Heating Z-Direction and Stripe Laser Pattern Sample Tested at $1000^{\circ} \mathrm{C}$ with (a) 200x Magnification and (b) 500x Magnification. It is seen that the cracks happen along the colony of dendrite and they are continuous.

In Region II, the recrystallization should start to occur in the material and becomes to be dominant in the material as the temperature increases. Thus, the increase in ductility shows in the graph that the recrystallization process begins to overwhelm the competition of softening and hardening in the material. Not only annealing by high temperature, but there should be an effect in softening process by dynamic recrystallization, which is defined to be recrystallization process during plastic deformation. To show this recrystallization process, microstructural analysis is also investigated at these temperatures. The Figure 40 shows some result from the analysis. The weld path melt pool is no longer seen in the microstructure. Instead, there are small recrystallized grains at the crack tips. This change in microstructure is a good indicative of annealing process in the material. 


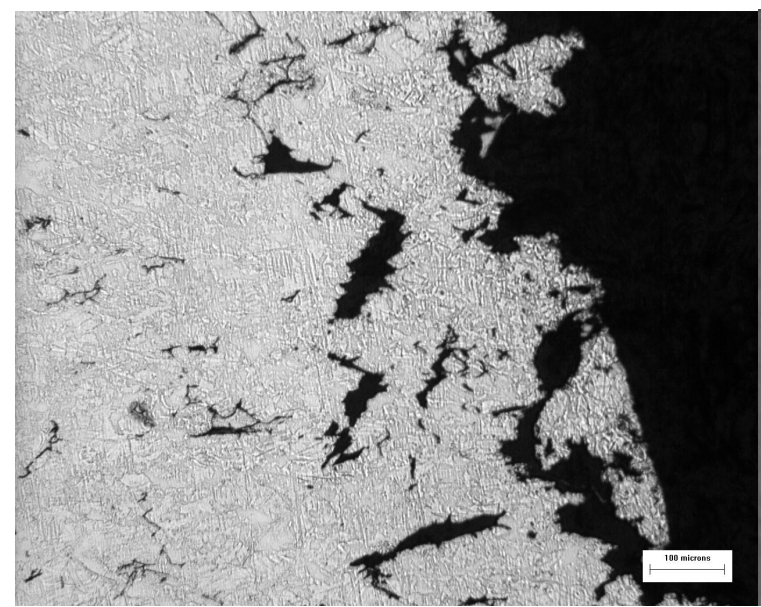

(a)

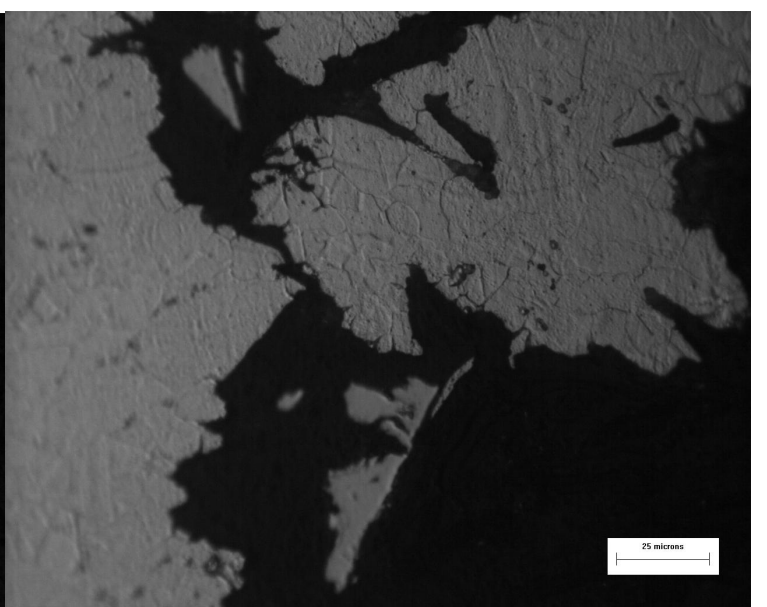

(b)

Figure 40. Micrographs of On-Heating XY-Direction and Stripe Laser Pattern Sample Tested at $1200^{\circ} \mathrm{C}$ with (a) 100x Magnification and (b) 500x Magnification. Recrystallization is obviously seen at higher magnification.

In Region III, the liquation around the grain boundaries happens and the ductility drops suddenly. The liquation is due to the secondary phase in the material since the secondary intermetallic phases have lower melting point than austenite phase in the material. Those secondary phases, usually formed at the grain boundary due to the solidification mode of the material, melt at the temperature and it leads to fracture of the material. Microstructure of this region is also investigated. Figure 41 shows the microstructure of NST samples. The orientation of the view is the same as micrographs above. The Figure 41 (a) shows the low magnification of the crack tip, and large grains and intergranular cracks are obviously seen, and the mechanism of material failure should be due to this cracking. In the higher magnification, there are number of black dots seen in the grains. The black dots in the grain should be the precipitation during the NST testing. 


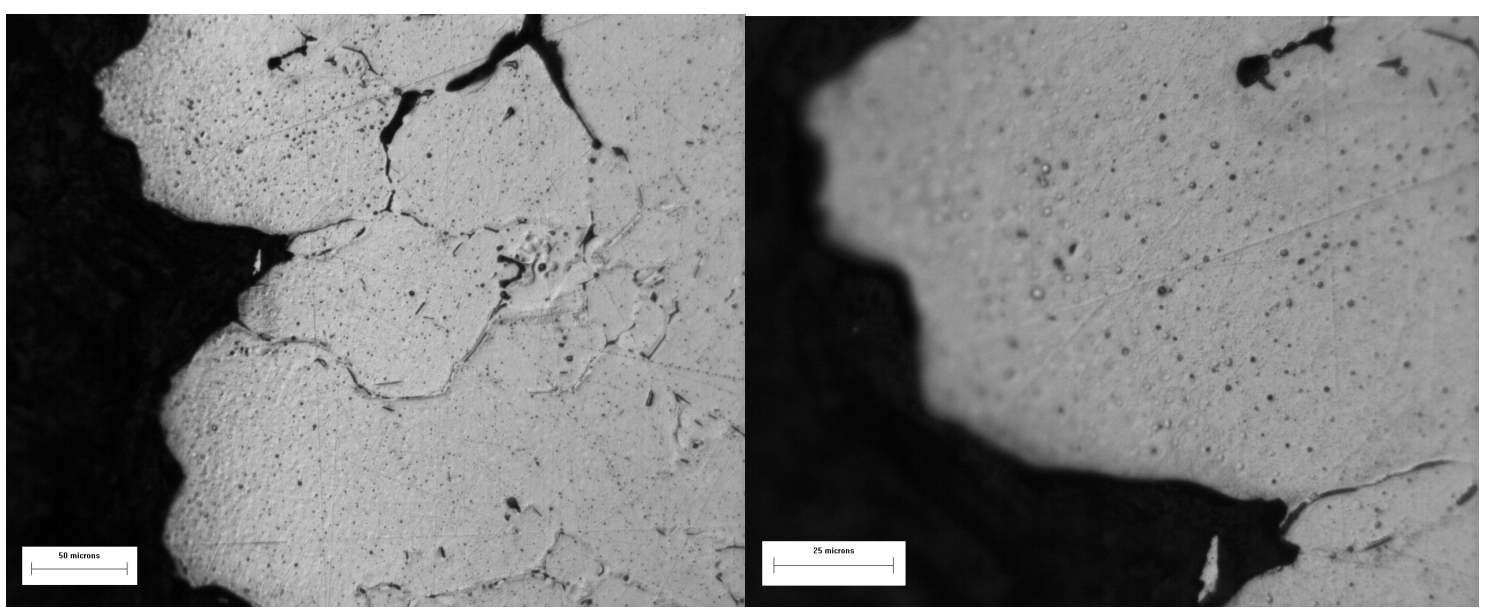

(a)

(b)

Figure 41. Micrograph of NST Z-Direction and Stripe Laser Pattern Sample with (a) 200x Magnification and (b) 500x Magnification. It is seen that the black precipitates form at the crack tips.

\subsubsection{Comparison with Wrought 316L Stainless Steel}

Even though the general shapes of curves for all cases are similar, the graphs show a number of differences. One of the general differences is that the hot ductility result of AM part shows worse result in ductility compared with wrought $316 \mathrm{~L}$ stainless steel. The Figure 42 shows the previously conducted test result of wrought $316 \mathrm{~L}$ stainless steel. The test was done by a different researcher, and therefore, the temperature settings are slightly different from what is studied here. However, it can obviously show the higher ductility in wrought $316 \mathrm{~L}$ stainless steel because both $\mathrm{OH}$ and OC have almost $100 \%$ RoA. Also, the curves follow almost in the same way compared with the result from AM parts. 


\section{AISI 316}

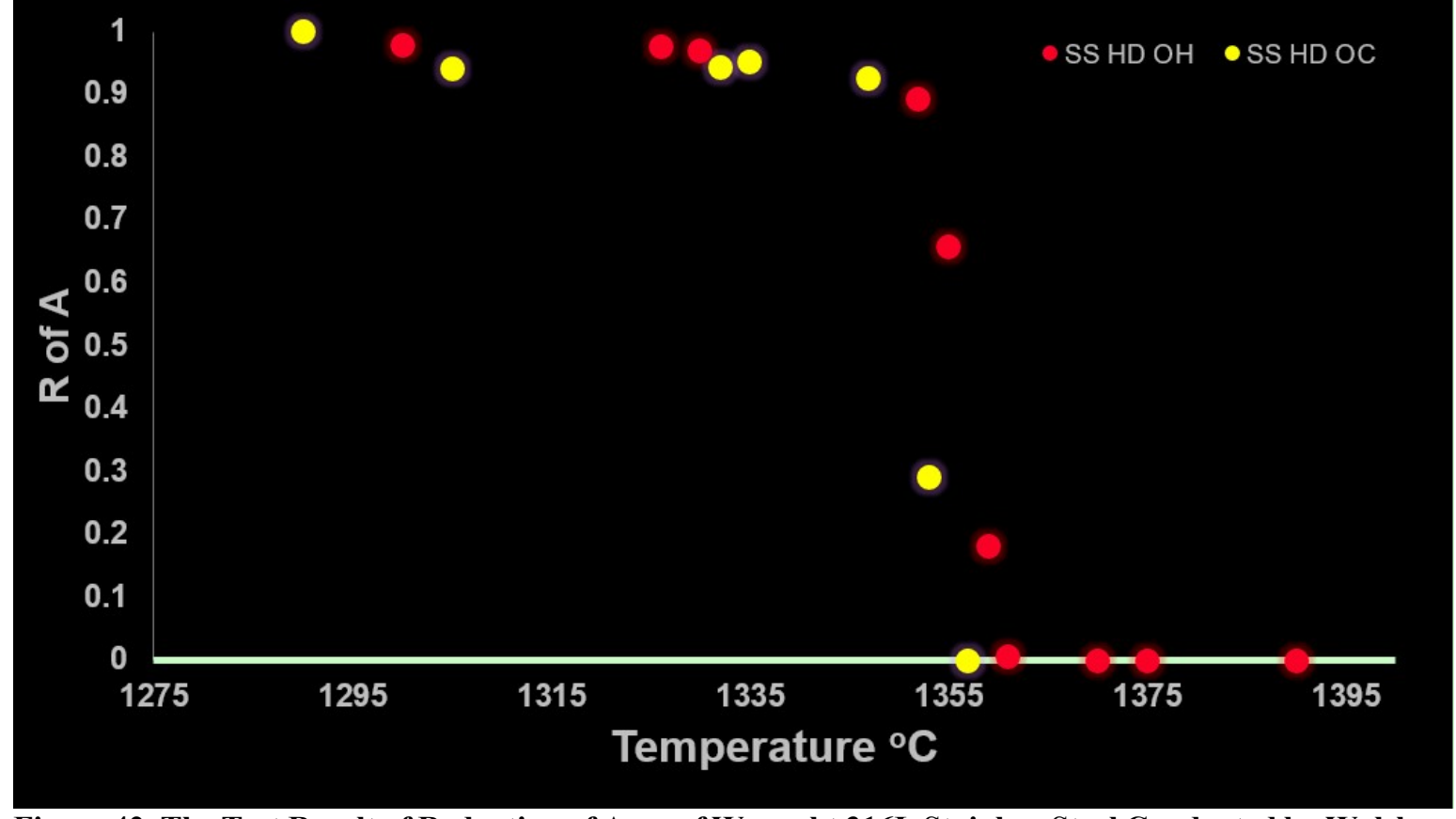

Figure 42. The Test Result of Reduction of Area of Wrought 316L Stainless Steel Conducted by Walsh. The RoA for $\mathrm{OH}$ and $\mathrm{OC}$ follows quite similarly and their ductility is close to $100 \%$. (Walsh)

One of the reasons why there is such difference in ductility could be explained by the precipitation formation in the samples. To capture the precipitation from the samples, they are gone through metallographic processes such as mounting, grinding/polishing, and etching. Figure 43 shows some metallography capturing the precipitation forming in the as-printed sample. Upon etching the sample to look at the microstructure, there are two kinds of etchants used to show different features. The first etchant is $10 \%$ by mass oxalic acid solution. (Petzow) This solution can be used for electrolytic etching, where sample is submerged into the solution while electric voltage is applied in the solution to promote the solution to attack at the grain boundary. As a result, the grain boundaries will be revealed under the optical microscope. The other etchant is 10 molar sodium hydroxide $(\mathrm{NaOH})$ solution. This solution is known to stain the sigma phase in the stainless steel into yellow to brown colors (Petzow). The solution is also used in electrolytic etching. For both etching methods, the samples are etched with $5 \mathrm{~V}$ for 45 seconds. Figure 43 (a) shows the 
metallography of as-print sample with only oxalic acid solution etch. The melt pool path is obviously seen in the image and the color of the image is generally yellow, which is caused by the light adjusted to see the metallography. Figure 43 (b) shows the result from $\mathrm{NaOH}$ solution etch. It can be seen that some portion in the microstructure turns out to be darker colors compared with only oxalic acid solution etch. These dark color portion could be a collection of tiny sigma phases. Since it is so tiny to recognize each sigma phase precipitation but it forms everywhere in the microstructure, the discolored portions could be captured. The small precipitations could be dangerous in terms of fracture. Since those precipitations are brittle compared with other phases and they can initiate the void under the load. The voids link up in the material under load and eventually let the material fail. Due to the ductile fracture, all of those precipitation sites could be the void initiator in the material, and that could be the reason why the ductility of AM parts is much lower than wrought materials. 


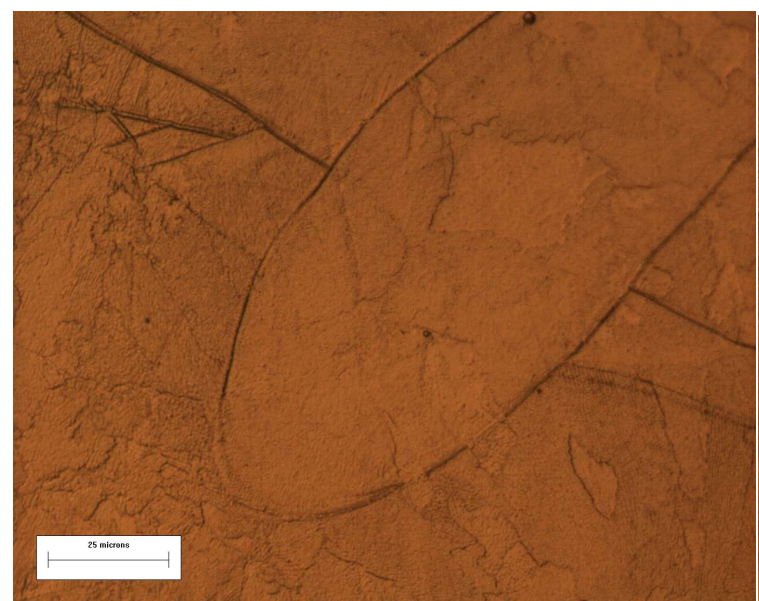

(a)

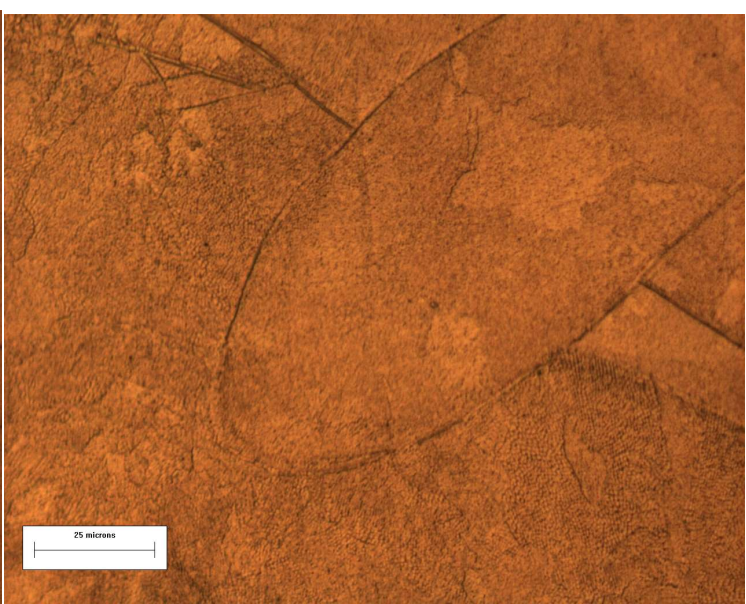

(b)

Figure 43. Microstructure of As-Printed Z-Direction Stripe Sample at 500x Magnification. The sample is etched with (a) only oxalic acid solution, and with (b) $\mathrm{NaOH}$ solution. The etching time and voltage are both same.

Another possible explanation of low ductility is the presence of oxide in the sample.

The Figure 44 shows some evidence of oxide in as-print sample. In any kind of processes during the printing and sieving, the stainless steel powder should not be exposed to the air and therefore oxygen, but this is not completely guaranteed. For example, when the part is taken out from the print chamber for cleaning, the entire chamber is exposed to the ambient air environment. However short exposure to the air, the powder can still react with the air to form oxide. The powder in general has higher chance of forming oxide on the surface because the surface to volume ratio of powder is much higher than the bulk form of the same material. ("What's So Special About The Nanoscale? | Nano") The availability to the surface to react to form the oxide is attributed to the higher chances of forming the oxide. Oxides formed on the powder surface do not melt during the printing process because the melting point of oxides is usually higher than that of the stainless steel. Therefore, the oxides are flown on the melt pool and get trapped in the material as the melt pool solidifies. The oxides stuck in the material are brittle because it is an ionic compound, and this can lead to become a crack initiator in the material. The existence of the oxide should be 
another reason to explain the low ductility compared to the ductility of wrought $316 \mathrm{~L}$ stainless steel at higher temperatures.

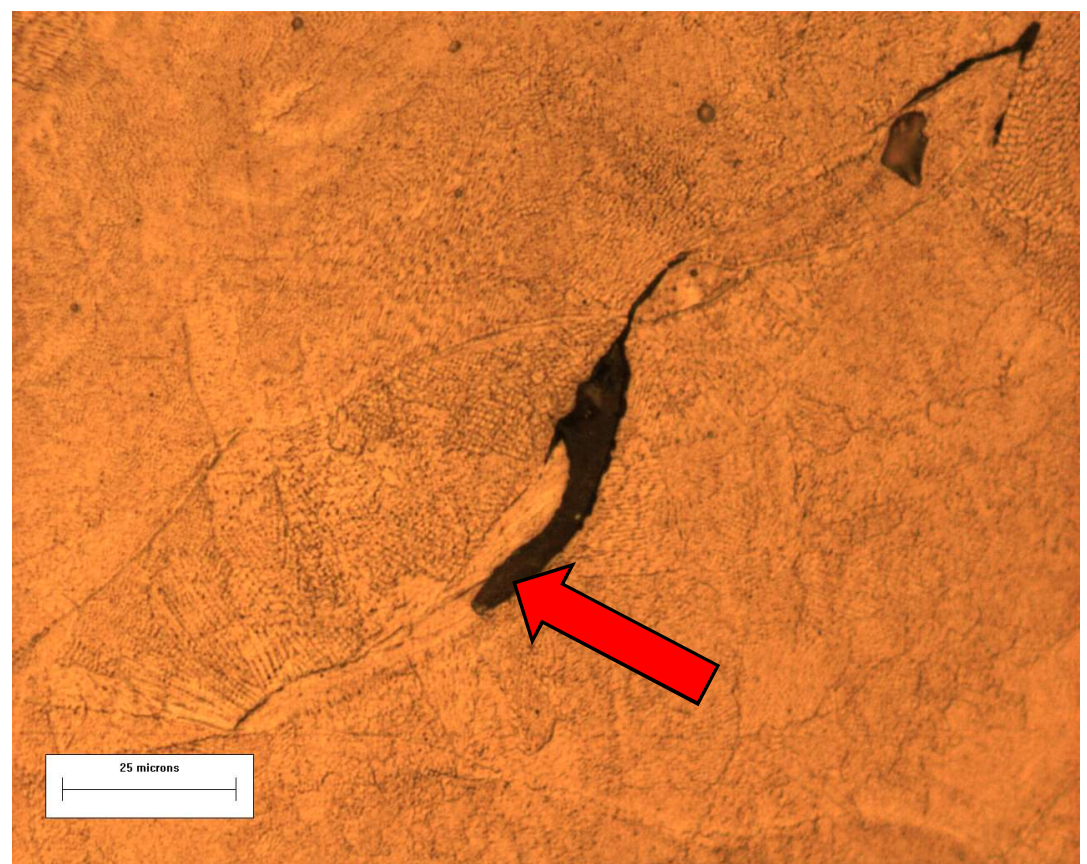

Figure 44. A Large Oxide Crack Seen on Z-Direction Stripe Sample at 500x. The gray color surface (indicated by the red arrow) in the crack is the indication of the oxide formation. The crack propagates along the melt pool boundaries.

\subsubsection{Comparison Between Laser Patterns}

Differences are not only between wrought 316L and AM 316L stainless steel, but the results between treatments show some differences in behaviors. When the RoA curves between laser patterns are compared, the stripe laser pattern has higher maximum ductility at around $1300^{\circ} \mathrm{C}$. However, the checker board laser pattern shows lower ductility $(<40 \%$ at around $\left.1300^{\circ} \mathrm{C}\right)$. This difference could be explained when the differences between the two laser scanning processes are considered with the solidification mode of the austenitic stainless steel and phase segregation. Figure 45 shows the schematics of one laser path and associated melt pool. The $316 \mathrm{~L}$ stainless steel is a fully austenitic stainless steel which shows austenitic solidification. Therefore, on the laser weld path, it makes sense that phase segregation will be seen at the edge of the path. If the brittle carbide phases can be seen on 
the edge of the laser weld path, it makes sense to reason that the more laser paths on a certain layer contains, the higher the chance of forming brittle carbide precipitation in the layer.

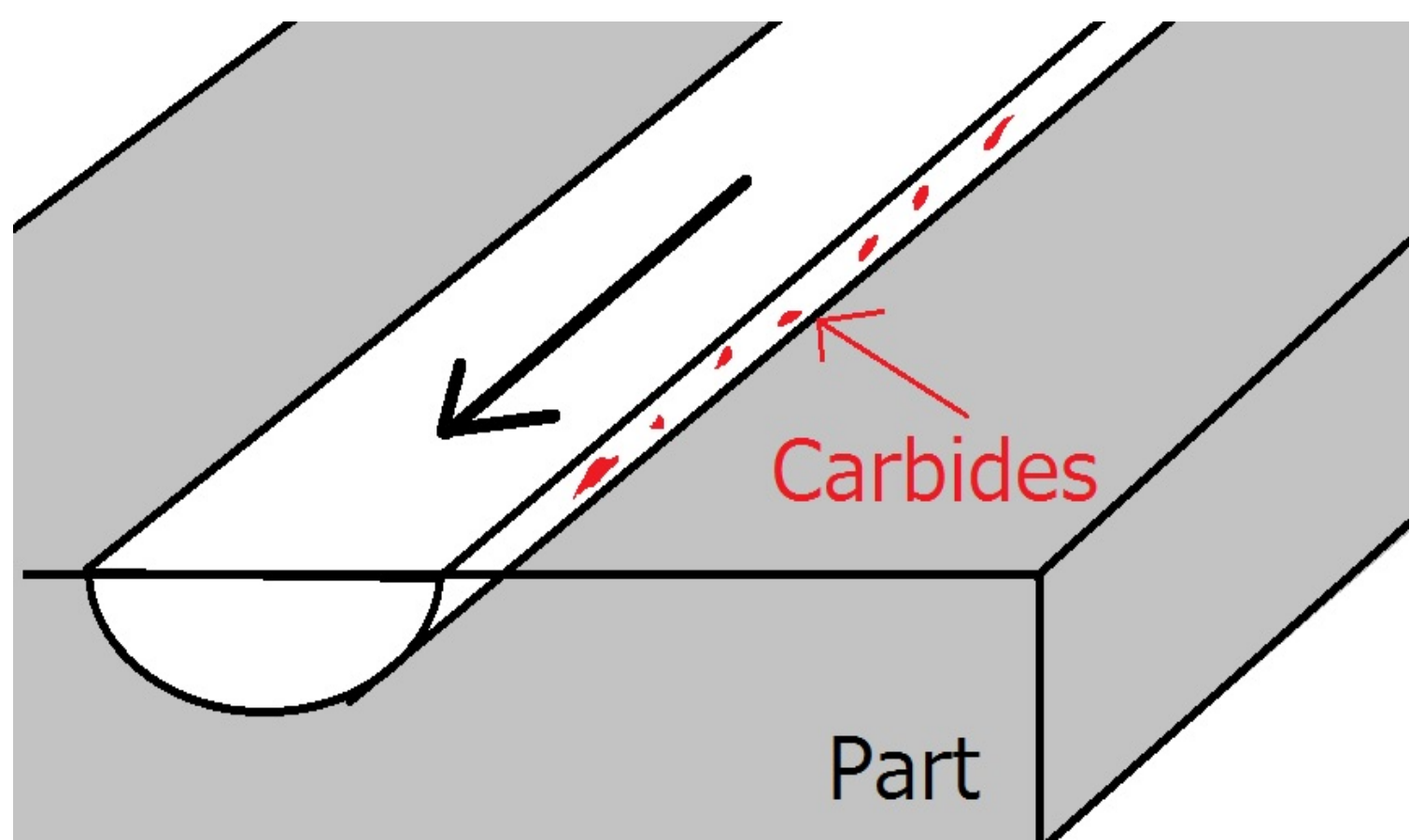

Figure 45. The Carbide Formation on the Edge of the Laser Weld Path Due to the Austenitic Solidification. The red carbides shown in the image are emphasized and they are not at right scale.

When the laser patterns of stripe and checker board are compared with each other, there is a large difference in the number of paths in one layer. In the stripe shape, the laser scans the layer from one end to the other end. The laser spot size is known from the previous study that it is $70 \mu \mathrm{m}$ and the melt pool size is also known to be $100 \mu \mathrm{m}$. This indicates that for the stripe laser pattern there are 60 paths simply calculated from the diameter of the sample $(6 \mathrm{~mm})$ by the melt pool path, assuming there is no overlap between melt pools. On the other hand, checker board laser pattern scans and fills the surface with $1 \mathrm{~mm}$ by $1 \mathrm{~mm}$ squares. To make the calculation simple, the incomplete $1 \mathrm{~mm}^{2}$ squares on the edge of cross sections are ignored, and there should be 4 by 4 matrix of complete squares. In each square, there are 10 melt pool paths. In total, the checker board laser 
pattern should have 160 paths on one layer of the sample. The amount of laser paths in checker board is almost triple amount of laser paths in stripe laser pattern. The schematic is shown in Figure 46. This difference in the number of paths between laser patterns could explain the difference in ductility for $\mathrm{OH}$ RoA. The checker board laser pattern has more paths in one layer and therefore it has higher chance of forming more carbides in one layer compared with the strip laser pattern. This can lead to have more precipitation in checker board laser pattern in the material and cause void coalescence when load is applied on the material. The result of the large amount of precipitation is the fracture before elongating a lot by plastically deforming the material. The checker board is said to be better in heat dissipation. However, in terms of ductility at high temperatures, stripe shape could behave better.

\section{Stripe Laser Pattern}

\section{Checker board}

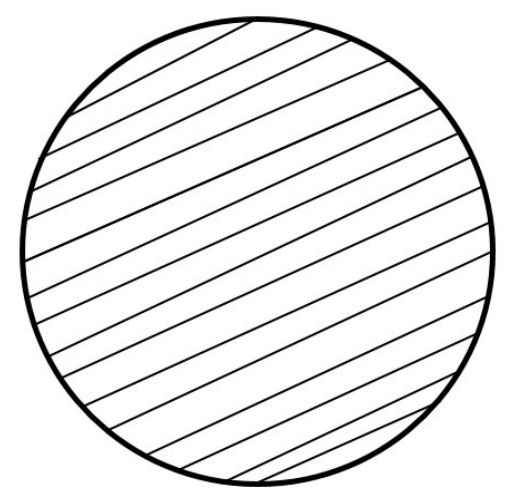

(a)

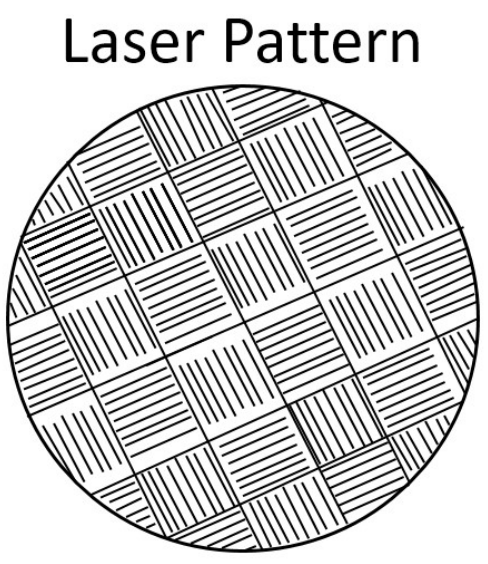

(b)

Figure 46. The Number of Laser Pattern of (a) Stripe and (b) Checker Board. The laser paths in checker board is much more than that of stripe laser pattern.

\subsubsection{Comparison Between On-Heating and On-Cooling Curves}

Another interesting difference in the graphs is the ductility difference between OnHeating $(\mathrm{OH})$ and On-Cooling $(\mathrm{OC})$ curves. For example, the ductility curves for Z- 
direction and stripe laser pattern shows that the OC ductility curve is slightly better than $\mathrm{OH}$ curve at $1300^{\circ} \mathrm{C}$. This result is, in general, an awkward behavior since usually $\mathrm{OH}$ behavior of material is usually higher than OC behavior of material (Savage). To investigate on this differences, metallography of $\mathrm{OH}$ sample and $\mathrm{OC}$ sample at $1300^{\circ} \mathrm{C}$ is compared. The Figure 47 shows images of the metallography. Both micrographs show liquation cracking along the grain boundaries. However, the OC metallography shows more distinct grain boundaries and larger grain sizes. Also, the OC grains looks elongated in the horizontal direction which is actually the direction of pull during the test. From the micrographs, it could be concluded that the elongated large grains in OC could be the result of liquation at grain boundaries and grain growth at the higher temperature. The grain growth occurred at the crack tip can be beneficial for the material because the large grains elongates and deforms before the fracture. This explanation could be attributed to the higher ductility in OC sample than $\mathrm{OH}$ sample.

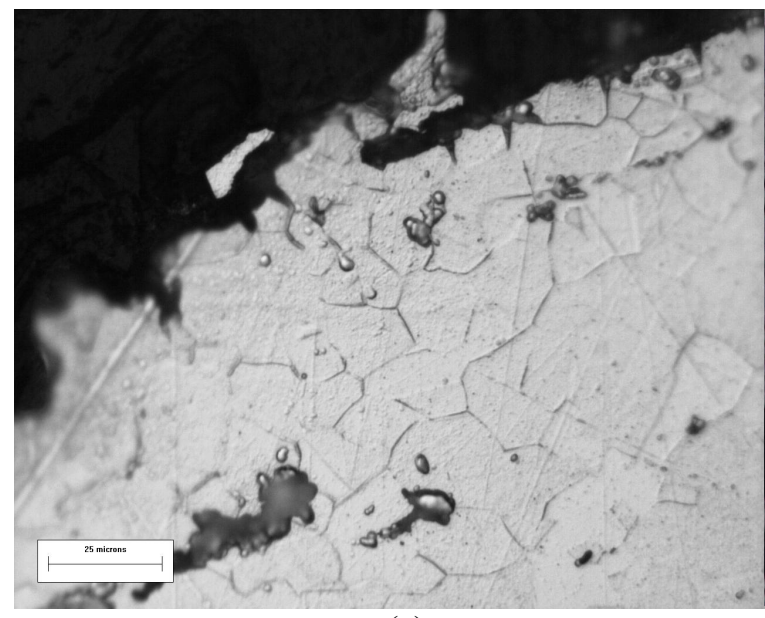

(a)

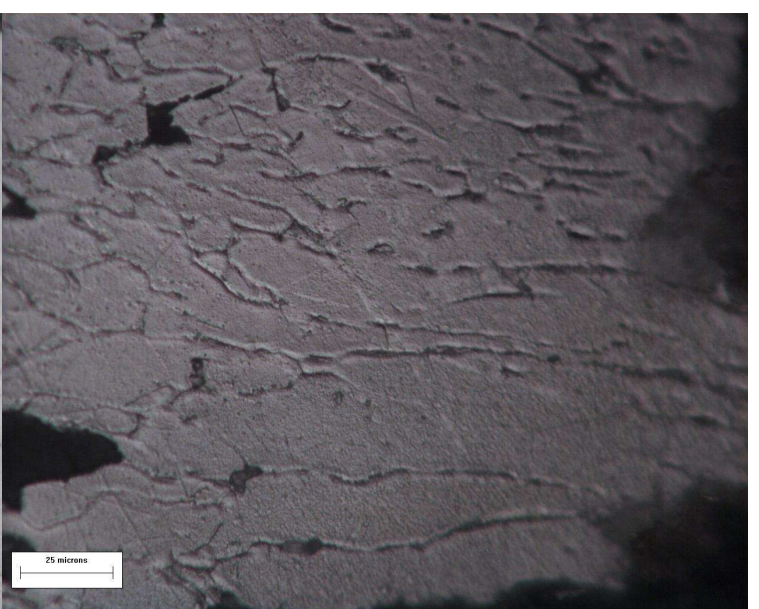

(b)

Figure 47. Metallography of (a) $\mathrm{OH}$ and (b) $\mathrm{OC}$ Sample at $1300^{\circ} \mathrm{C}$ at $500 x$ Magnification. Both are Zdirection and stripe laser pattern. Larger grains are seen in $\mathrm{OC}$ sample compared to $\mathrm{OH}$ sample. 


\subsubsection{Precipitation Density Changes Over Distance}

As the microstructure is investigated, there is an interesting finding. The Figure 48 shows the microstructure of NST at different locations from the crack tip. As is seen in the micrographs, the further away the grain gets from the crack tip, the less amount and smaller size of black dots are seen in the microstructure. This indicates that the precipitations will nucleate and increase in number and size as the material keeps increasing to higher temperature like NST. These precipitation forms at the grain boundaries and grow to eventually form cracks. The images show microstructures (a) 1mm, (b) $3 \mathrm{~mm}$, and (c) $6 \mathrm{~mm}$ away from the crack tip.

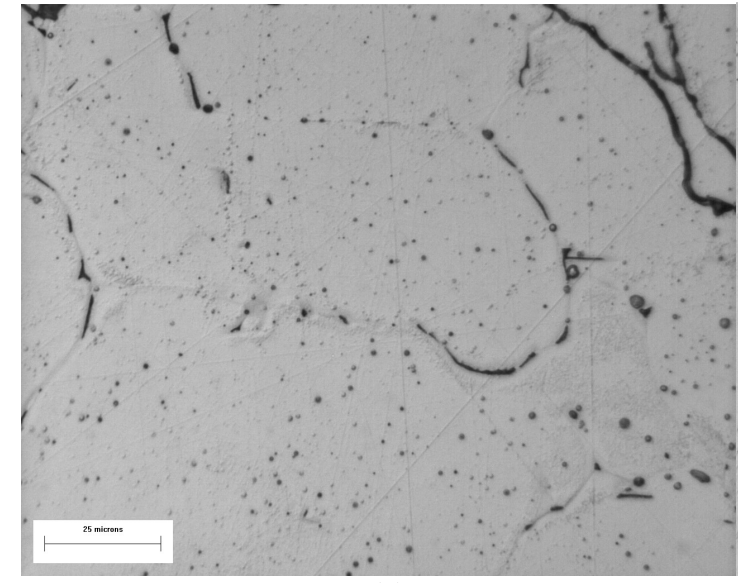

(a)

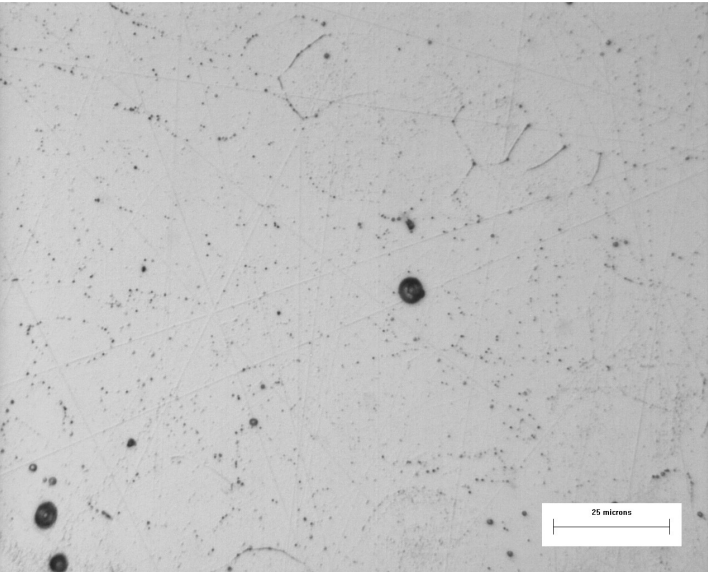

(b)

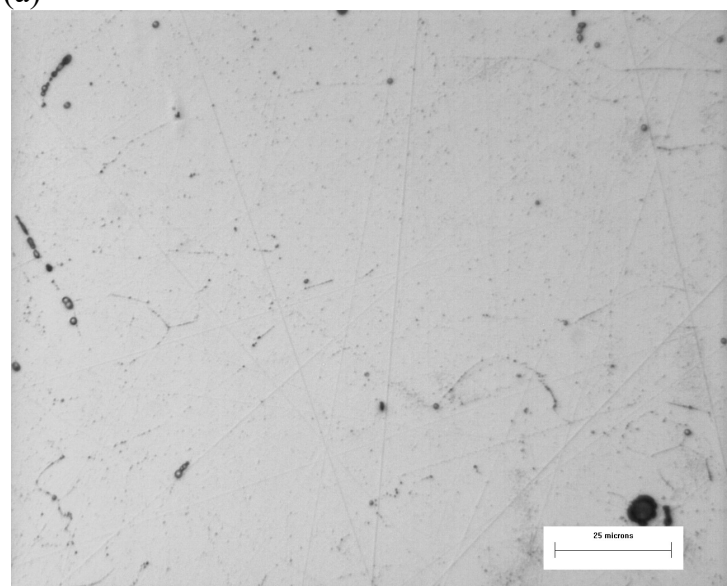

(c)

Figure 48. The Microstructure of NST Sample at Different Locations from the Crack Tip (a) $1 \mathrm{~mm}$ Away, (b) $3 \mathrm{~mm}$ Away, and (c) $6 \mathrm{~mm}$ Away. The amount and sizes of precipitation changes as the microstructure gets away from the tip. 


\subsubsection{Constitutional Liquation}

The indication of constitutional liquation is also captured by another micrograph taken in the same sample. The Figure 49 shows "liquidy" surface on the image. Constitutional liquation occurs when the material is heated up rapidly. When the material passes the eutectic temperature, there are some secondary phases that do not dissolve to the matrix even though the temperature is above the eutectic temperature. This lets the "soluterich" region to be liquid, and thus, the liquid thin film forms at the grain boundaries. The constitutional liquation is critically seen in welding process and this is one of the mechanisms that can lead to cracking in the material because the liquation of secondary phase can stop the grain growth. (Pepe, and Savage) In Figure 49, the microstructure shows liquid texture image around some black dots. This may indicate that the constitutional liquation occurs around these precipitates. This image also encourage that the black dots are secondary phase because constitutional liquation occurs with the secondary phases.

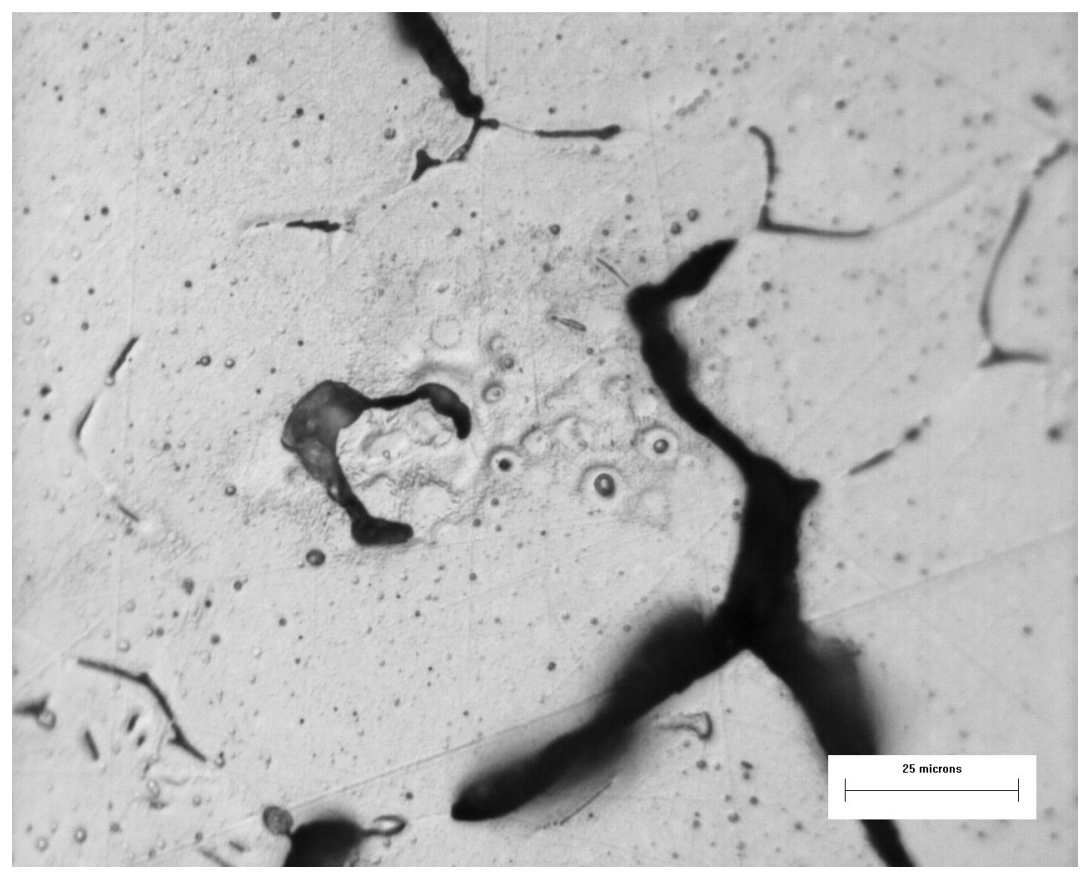

Figure 49. Constitutional Liquation Captured from NST Samples. The black dots should be the secondary phase and the organic shape around the dots is the result from the constitutional liquation. 


\section{CONCLUSIONS AND RECOMMENDATIONS}

In conclusion, the ductility and strength behaviors of additively manufactured $316 \mathrm{~L}$ stainless steel at higher temperatures are collected. Overall, the study is successful to show the similar behaviors of mechanical properties of the material and underlying mechanism with metallographic evidences. There are mainly three findings in this study.

1. The nil strength temperature (NST) differs based on the orientation of the build. It is found that the NST in XY-direction of build is higher than NST in Z-direction of build. This phenomenon could be explained by the interlayer temperature and the formation of intermetallic phases such as sigma phase associated with the interlayer temperature. However, there was a limitation in the availability in equipment.

2. The ductility behavior of AM 316L stainless steel is much worse than that of wrought $316 \mathrm{~L}$ stainless steel. This phenomenon could be explained by the existence of many crack initiators such as intermetallic phases and oxides. These intermetallic phases and oxides are shown with microstructure in this study.

3. The stripe laser pattern show the better ductility at higher temperatures than the checker board laser pattern. This phenomenon could be explained by the number of paths in the layer for stripe and checker board pattern. The checker board laser pattern has almost triple amount of laser paths in the layer can increase the chance of having the nucleation void phases forming at the edge of the grain boundaries due to the phase segregation during the solidification of the material.

4. On-Cooling $(\mathrm{OC})$ ductility curves are better than On-Heating $(\mathrm{OH})$ ductility curves in general. This is an unusual result, but the metallography images support this behavior by showing larger grain sizes in OC samples. The grain growth could have 
happened in the OC samples and this could contribute the higher ductility at higher temperatures.

With the results from hot ductility test, a practical recommendation could be suggested. For example, it is necessary to build a simple box where one of the faces will be welded into other parts. The result of this study recommends to build the box in Zdirection where the face that will be welded against is the top surface of the print and the laser pattern should be the stripe laser pattern. This is because the $\mathrm{OH}$ and $\mathrm{OC}$ ductility in Z-direction and stripe laser pattern shows the best ductility from the study, and therefore, it should have the least chance of experiencing cracks. The Figure 50 shows the direction of the build of this case study.

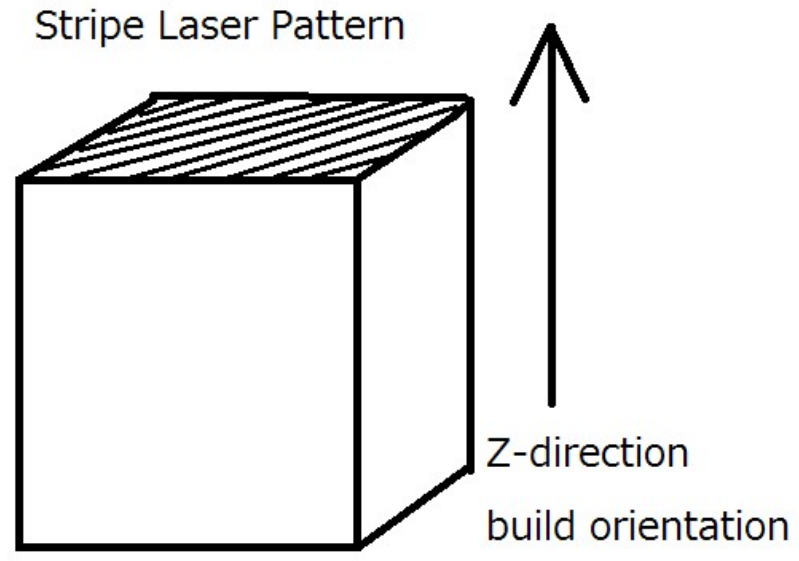

(a)
Weld to other parts

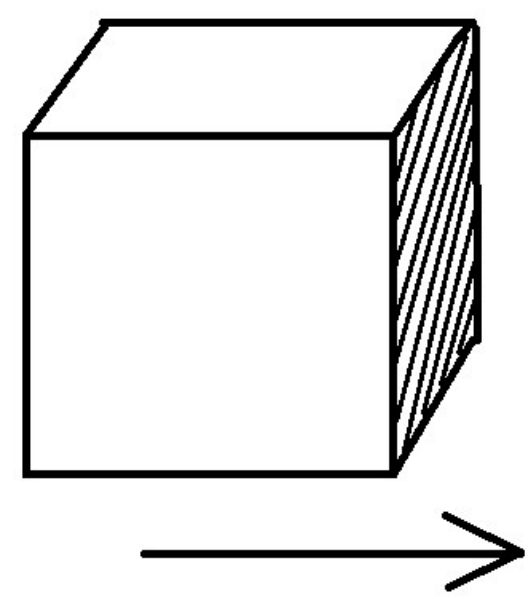

(b)

Figure 50. (a) The Recommended Orientation of the Build and Laser Setting for the Box and (b) the Direction of the Box That Will Be Welded to Other Parts. From the result in this study, the Z-direction build and stripe laser pattern shows the highest ductility in $\mathrm{OH}$ and $\mathrm{OC}$ 


\section{FUTURE SUGGESTIONS}

Even though this study finds a number of interesting behaviors of AM 316L stainless steel at higher temperatures, there are some future suggestions to investigate this study further.

1. Determine and confirm the sigma phase with appropriate equipment such as orientation imaging in Scanning Electron Microscopy (SEM) or microprobe analysis. This equipment should help to understand the position of the sigma phase formation in the grain and the distribution of it. Understanding of sigma phase in AM 316L stainless steel will help to prove the solidification mode of the material and the cause of the material fail in the testing.

2. Find out the interlayer temperature between a large cross sectional area and a small cross sectional area during the print. This could be found out by the thermal camera installed in the chamber of the printer so that the camera can capture the temperature during the printing process. This will help to prove the differences in NST based on different orientation of the build.

3. Investigate on getting more data points from Gleeble machine. Some of the graph show the ductility is better in $\mathrm{OC}$ than $\mathrm{OH}$. This might not make sense because the $\mathrm{OC}$ sample should have gone through the grain liquation process by thermal cycle so the ductility is not expected to be as good as ductility before going through the thermal cycle. To verify this, the more data points should be collected. 


\section{BIBLIOGRAPHY}

3D Metals. SLM Solutions Group AG, 2019, https:/www.slm-solutions.com/. Accessed 23 May 2019.

Asuncion Valiente Bermejo, M. "Predictive And Measurement Methods For Delta Ferrite Determination In Stainless Steel". Welding Journal, 2019, pp. 113-s - 121-s., Accessed 23 May 2019.

Bhadeshia, Harshad, and Robert Honeycombe. Steels. Elsevier Science And Technology Books, Inc., 2017.

Chan, Kai, and Sie Tjong. "Effect Of Secondary Phase Precipitation On The Corrosion Behavior Of Duplex Stainless Steels". Materials, vol 7, no. 7, 2014, pp. 5268-5304. MDPI $A G$, doi:10.3390/ma7075268.

Conejero, O. et al. "Premature Corrosion Failure Of A 316L Stainless Steel Plate Due To The Presence Of Sigma Phase". Engineering Failure Analysis, vol 16, no. 3, 2009, pp. 699-704. Elsevier BV, doi:10.1016/j.engfailanal.2008.06.022.

Davis, J. R. Stainless Steels. ASM International, 1996.

Easterling, K.E. "Solidification Microstructure Of Fusion Welds". Materials Science And Engineering, vol 65, no. 1, 1984, pp. 191-198. Elsevier BV, doi:10.1016/00255416(84)90212-x.

Folkhard, Erich, and Günther Rabensteiner. Welding Metallurgy Of Stainless Steels. Springer-Verlag, 1988.

Gleeble Applications Notes. Dynamic Systems Inc., 2017, Accessed 25 May 2019.

"Gleeble - Home". Gleeble.Com, 2019, https://www.gleeble.com/. Accessed 26 May 2019. 
Horvath, Joan. Mastering 3D Printing. Apress, 2014.

Hsieh, Chih-Chun, and Weite Wu. "Overview Of Intermetallic Sigma ( $\sigma)$ Phase

Precipitation In Stainless Steels". ISRN Metallurgy, vol 2012, 2012, pp. 1-16.

Hindawi Limited, doi:10.5402/2012/732471.

Jiang, Chao, and Zi-Kui Liu. "Computational Investigation Of Constitutional Liquation In Al-Cu Alloys". Acta Materialia, vol 51, no. 15, 2003, pp. 4447-4459. Elsevier $B V$, doi:10.1016/s1359-6454(03)00280-5.

Korzhyk, V. et al. "Welding Technology In Additive Manufacturing Processes Of 3D Objects". Materials Science Forum, vol 906, 2017, pp. 121-130. Trans Tech Publications, doi:10.4028/www.scientific.net/msf.906.121.

Kou, Sindo. Welding Metallurgy. Wiley-Interscience, 2010.

Kruth, J-P. et al. "Binding Mechanisms In Selective Laser Sintering And Selective Laser Melting". Rapid Prototyping Journal, vol 11, no. 1, 2005, pp. 26-36. Emerald, doi:10.1108/13552540510573365.

Kubík, Petr et al. "Comparative Investigation Of Ductile Fracture With 316L Austenitic Stainless Steel In Small Punch Tests: Experiments And Simulations". Theoretical And Applied Fracture Mechanics, vol 98, 2018, pp. 186-198. Elsevier BV, doi:10.1016/j.tafmec.2018.10.005.

Kumar, Subodh et al. "A Comparison Of Additive Manufacturing Technologies". International Journal For Innovative Research In Science \& Technology, vol 3, no. 01, 2016, pp. 147 - 152., Accessed 23 May 2019.

Kurz, Willy, and David J Fisher. Fundamentals Of Solidification. Trans Tech Publ., 1992. 
Kurzynowski, Tomasz et al. "Correlation Between Process Parameters, Microstructure And Properties Of 316 L Stainless Steel Processed By Selective Laser Melting". Materials Science And Engineering: A, vol 718, 2018, pp. 64-73. Elsevier BV, doi:10.1016/j.msea.2018.01.103.

Lin, Wang-En. "A Methodology For Quantifying Heat-Affected Zone Liquation Cracking Susceptibility". Master Thesis at Ohio State University, 1991, Accessed 23 May 2019.

Lin, W. et al. "An Evaluation Of Heat-Affected Zone Liquation Cracking Susceptibility, Part I: Development Of A Method For Quantification". Welding Journal, 1993, pp. 135-s - 153-s., Accessed 23 May 2019.

Lippold, J.C. et al. "Heat-Affected Zone Liquation Cracking In Austenitic And Duplex Stainless Steel". Welding Journal, 1988, pp. 1 - 14., Accessed 23 May 2019.

Lippold, John C, and Damian J Kotecki. Welding Metallurgy And Weldability Of Stainless Steels. John Wiley, 2005.

Lippold, J.C., and W.F. Savage. "Solidification Of Austenitic Stainless Steel Weldments: Part I—A Proposed Mechanism". Welding Journal, 1979, pp. 362 - 374. , Accessed 23 May 2019.

Liverani, E. et al. "Effect Of Selective Laser Melting (SLM) Process Parameters On Microstructure And Mechanical Properties Of 316L Austenitic Stainless Steel". Journal Of Materials Processing Technology, vol 249, 2017, pp. 255-263. Elsevier BV, doi:10.1016/j.jmatprotec.2017.05.042. 
Matilainen, Ville-Pekka et al. "Weldability Of Additive Manufactured Stainless Steel". Physics Procedia, vol 83, 2016, pp. 808-817. Elsevier BV, doi:10.1016/j.phpro.2016.08.083.

McEvily, A. J. Metal Failures. John Wiley \& Sons, Inc., 2013.

Nippes, E.F. et al. "An Investigation Of The Hot Ductility Of High Temperature Alloys". Welding Journal, 1955, pp. 183s - 196s., Accessed 23 May 2019.

Nippes, Ernests F. et al. "Further Studies Of The Hot Ductility Of High-Temperature Alloys". Welding Research Council Bulletin, 1957, pp. 1 - 32., Accessed 23 May 2019.

Pepe, J.J., and W.F. Savage. "The Weld Heat-Affected Zone Of The 18Ni Maraging Steels". Welding Journal, 1970, pp. 545 - 553., Accessed 23 May 2019.

Petzow, Günter. Metallographic Etching. ASM Internat., 2001.

Pohl, Sebastian. "Improving Printing Quality By Optimizing Linear Energy Density In Selective Laser Melting And Demonstrating Its Inherent Constraints". 2019, Accessed 25 May 2019.

Rajamäki, Pekka. Fusion Weld Metal Solidification. Lappeenrannan Teknillinen Yliopisto, 2008.

Ruggieri, C. "Numerical Investigation Of Constraint Effects On Ductile Fracture In Tensile Specimens". Journal Of The Brazilian Society Of Mechanical Sciences And Engineering, vol 26, no. 2, 2004, pp. 190-199. Fapunifesp (Scielo), doi:10.1590/s1678-58782004000200011.

Savage, Warren F. "Apparatus For Studying The Effects Of Rapid Thermal Cycles And High Strain Rates On The Elevated Temperature Behavior Of Materials". Journal 
Of Applied Polymer Science, vol 6, no. 21, 1962, pp. 303-315. Wiley, doi:10.1002/app.1962.070062108.

Siewert, T.A. et al. "Ferrite Number Prediction For Stainless Steel Welds". Key Engineering Materials, vol 69-70, 1992, pp. 149-166. Trans Tech Publications, doi:10.4028/www.scientific.net/kem.69-70.149.

Silva, R.J. et al. "Additive Manufacturing Of Metal Parts By Welding". IFACPapersonline, vol 48, no. 3, 2015, pp. 2318-2322. Elsevier BV, doi:10.1016/j.ifacol.2015.06.433.

Simson, Thomas et al. "Residual Stress Measurements On AISI 316L Samples Manufactured By Selective Laser Melting". Additive Manufacturing, vol 17, 2017, pp. 183-189. Elsevier BV, doi:10.1016/j.addma.2017.07.007.

SLM 125 Selective Laser Melting Machine. SLM Solutions Group AG, 2019, https://www.slm-solutions.com/. Accessed 23 May 2019.

"SLM Solutions Group AG: Home". Slm-Solutions.Com, 2019, https://www.slmsolutions.com/. Accessed 26 May 2019.

Smith, Ryan. "MATE 450: Fracture And Failure Analysis". 2018.

Suryawanshi, Jyoti et al. "Mechanical Behavior Of Selective Laser Melted 316L Stainless Steel". Materials Science And Engineering: A, vol 696, 2017, pp. 113-121. Elsevier BV, doi:10.1016/j.msea.2017.04.058.

Tamura, Hiroshi, and Takehiko Watanabe. "Study On The Behaviour Of Grain-Boundary At Heat-Affected Zone Of Austenitic Stainless Steel (Report 1)". 1972, pp. 1094 1108., Accessed 23 May 2019. 
"Thermocouple-Thermocouples-What Is A Thermocouple-Types Of Thermocouples". Thermocoupleinfo.Com, 2019, https://www.thermocoupleinfo.com/. Accessed 26 May 2019.

Tucho, Wakshum M. et al. "Investigation Of Effects Of Process Parameters On Microstructure And Hardness Of SLM Manufactured SS316L". Journal Of Alloys And Compounds, vol 740, 2018, pp. 910-925. Elsevier BV, doi:10.1016/j.jallcom.2018.01.098.

Villanueva, D. M. E. et al. "Comparative Study On Sigma Phase Precipitation Of Three Types Of Stainless Steels: Austenitic, Superferritic And Duplex". Materials Science And Technology, vol 22, no. 9, 2006, pp. 1098-1104. Informa UK Limited, doi:10.1179/174328406x109230.

Walsh, Dan. "Constitutional Liquation - Class 12". 2018.

Walsh, Dan. "Fundamentals Of Solidification". 2018.

Walsh, Dan. "Physical Simulation In Welding: Moving Welding From Art To Science". 2018.

Wang, Xuan. Understanding The Process Characterization Of Selective Laser Melting To Build Quality Parts. 2019, Accessed 10 June 2019.

Weiss, B. et al. "Physical Metallurgy Of Hot Ductility Testing". Welding Research Supplement, 1970, pp. 471 - 487., Accessed 23 May 2019.

"What's So Special About The Nanoscale? | Nano". Nano.Gov, 2019, https://www.nano.gov/nanotech-101/special. Accessed 26 May 2019. 
Yang, Jingjing et al. "Weldability, Microstructure And Mechanical Properties Of LaserWelded Selective Laser Melted 304 Stainless Steel Joints". Journal Of Materials Science \& Technology, 2019. Elsevier BV, doi:10.1016/j.jmst.2019.04.017. 


\section{Appendix A: Test Coupon Drawings}

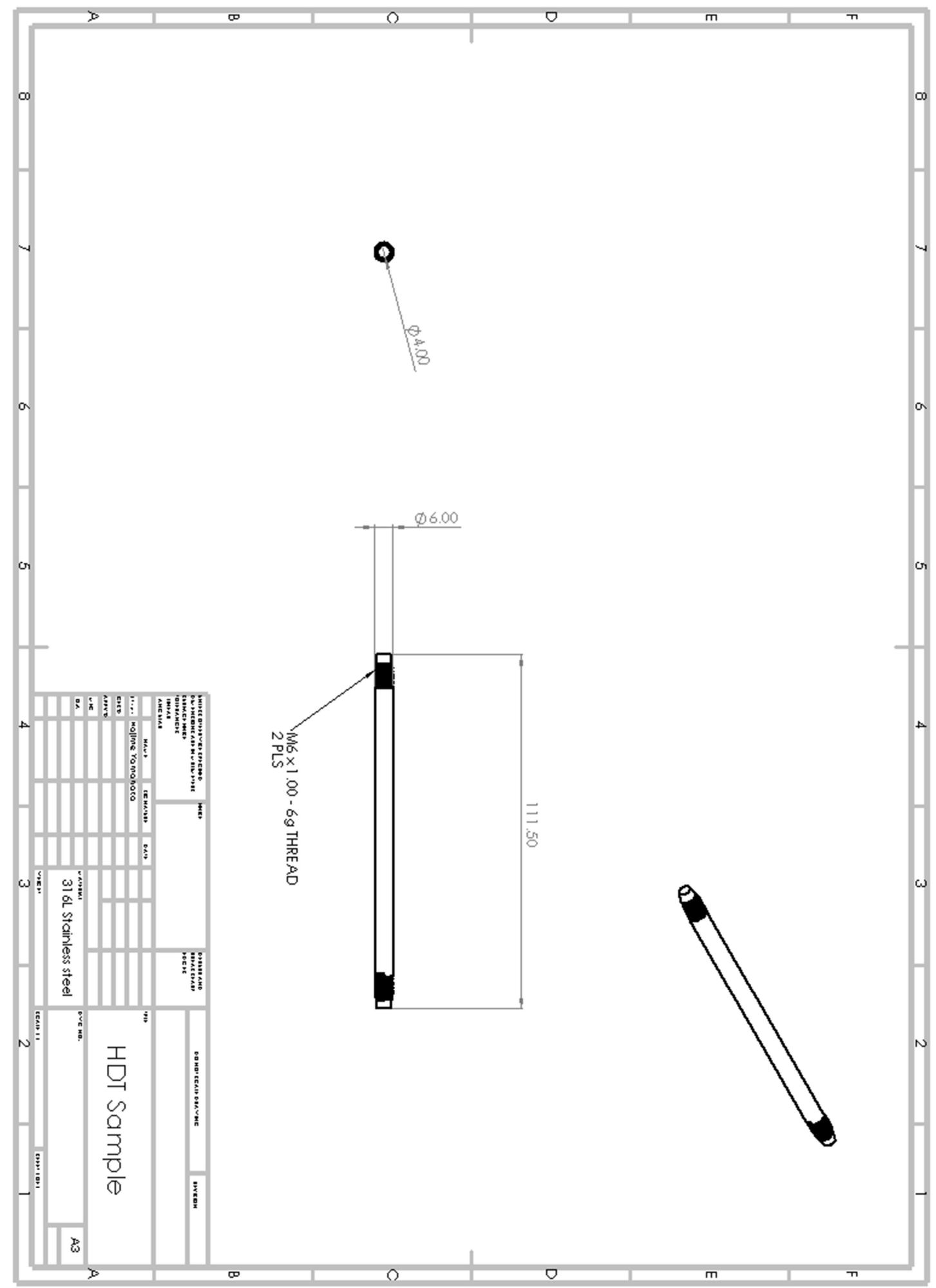

Figure 1. Engineering Drawing of Hot Ductility Test Sample in Z-Direction. 


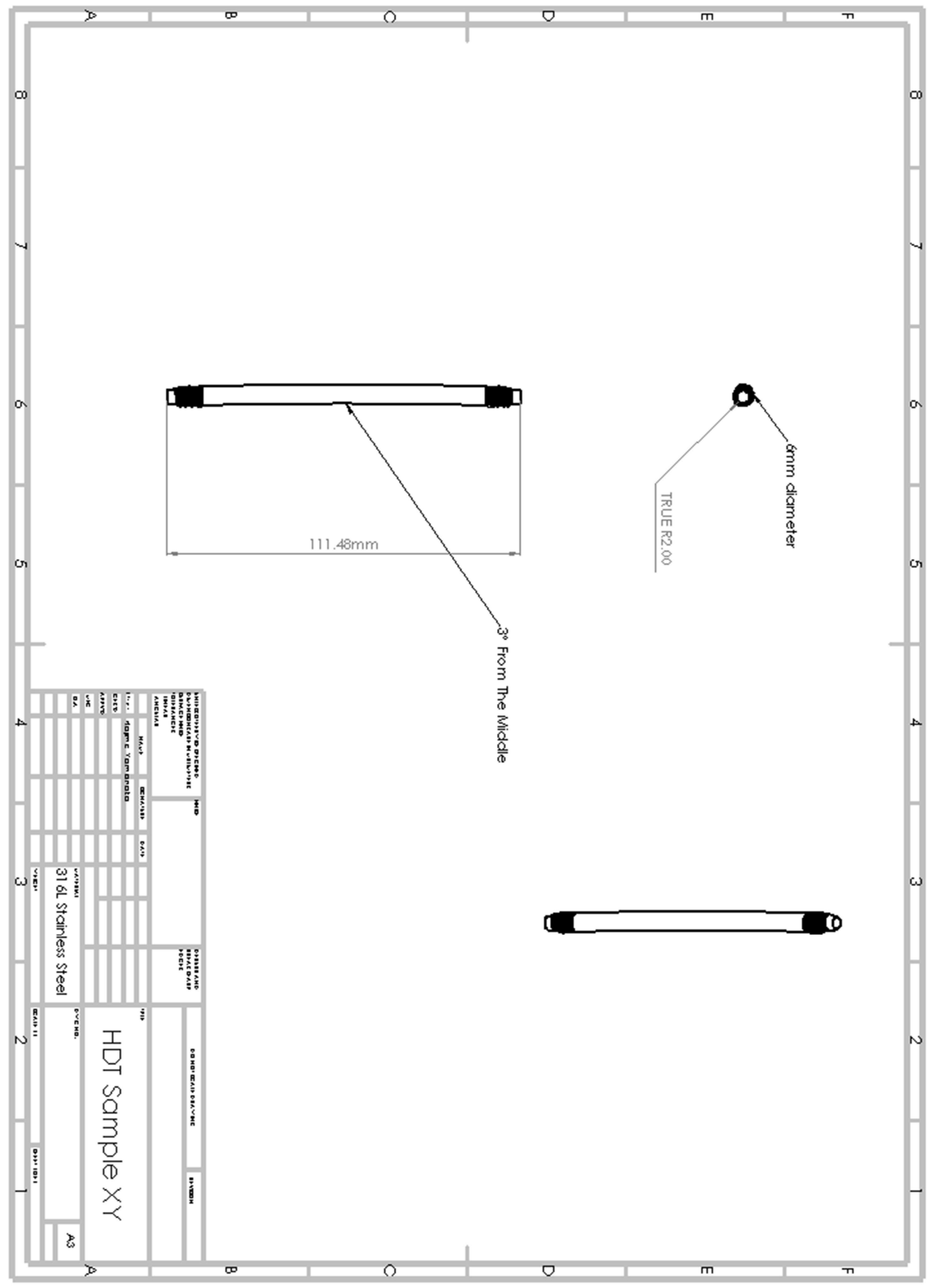

Figure 2. Engineering Drawing of Hot Ductility Test Sample in XY-Direction. 


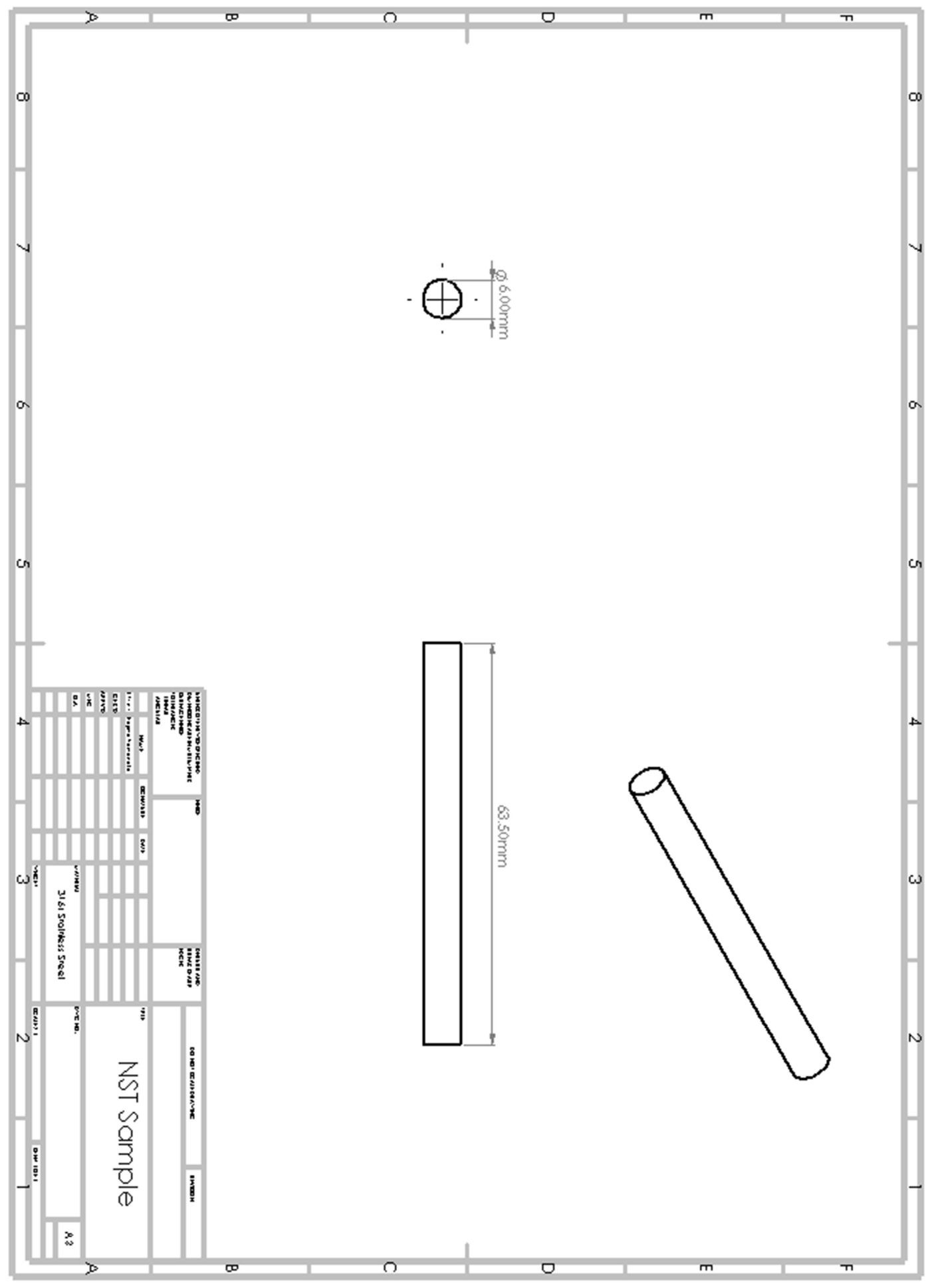

Figure 3. Engineering Drawing of Nil Strength Temperature Test Sample 


\section{Appendix B: Study on Sigma Formation}

In the discussion section of the study, sigma phase in 316L stainless steel could be one of the explanations of the obtained results. To prove this point and to show the effect of sigma phase on the mechanical properties of samples, an additional study is briefly conducted to understand the nature of this phase. In this experiment, samples are held at $850^{\circ} \mathrm{C}$ in the Gleeble chamber for different amounts of times to encourage the material to form sigma phase. The temperature is determined from the time temperature transition diagram of austenitic stainless steel. The samples used in this study are all consistent: Zdirection and stripe laser pattern rods. The tested times are 1 second, 20 minutes, and 70 minutes. At the end of the exposure to the temperature for those times, the samples are pulled to fracture. The figure below shows the ductility and strength over the time from this experiment.

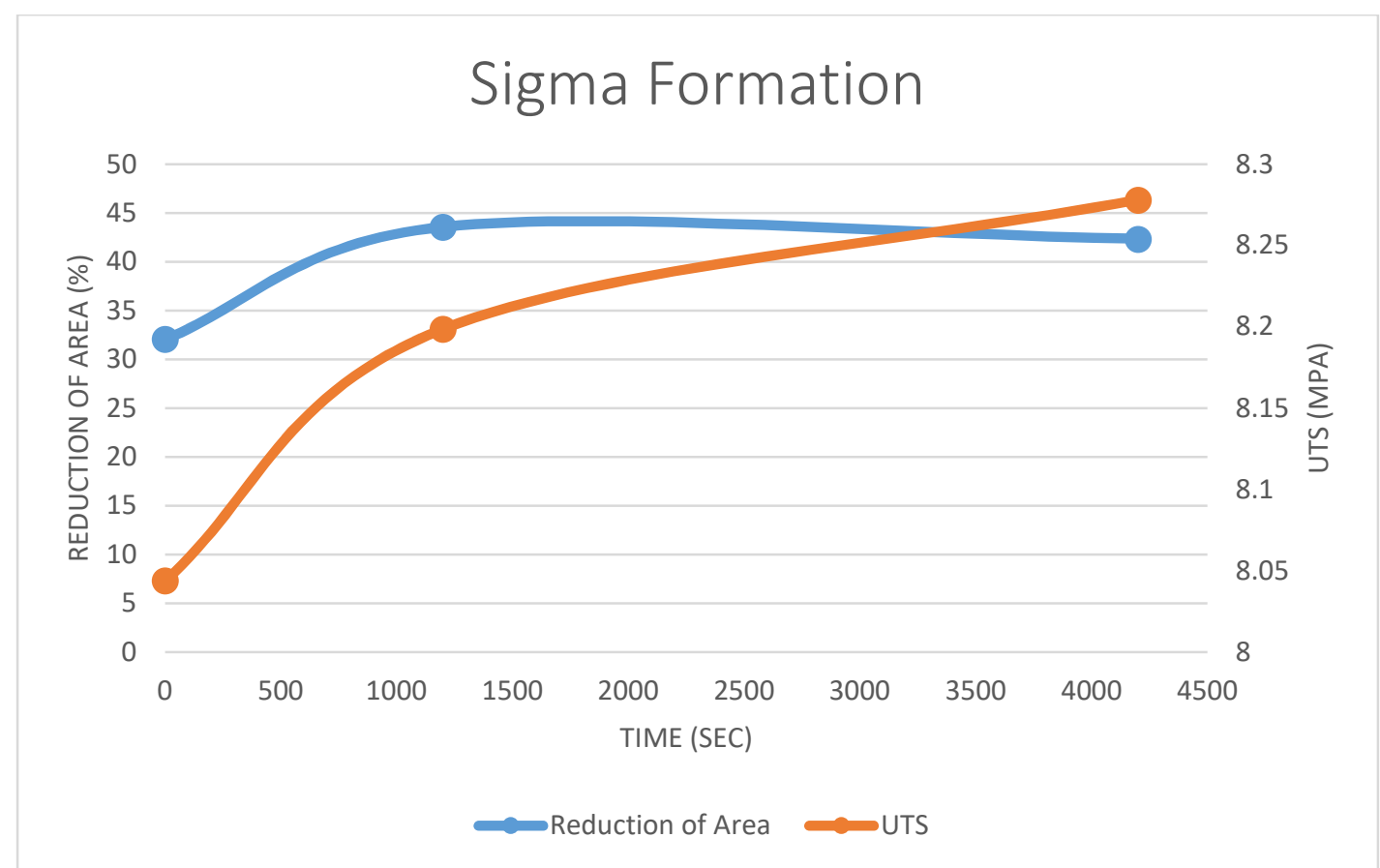

Figure 1. Reduction of Area and Ultimate Tensile Strength of the Z-Direction, Stripe Sample Over A Period of Times. 
The graph shows that an increase in both strength and ductility from 1 second to 20 minutes. This is an interesting result because it is expected such that a large number of sigma phases are formed at the temperature, and therefore, the ductility decreases and the strength increases as the exposure time gets longer. However, at least the first portion of the graph shows the opposite effect from the expectation. From this experiment, it is not possible to draw a conclusion. However, this indicates that there is a large room to investigate on the sigma phase formation in additively manufactured austenitic stainless steel. One of the equipment that can help this research could be microprobe or Transmission Electron Microscope (TEM). 